Portland State University

PDXScholar

Summer 11-2-2018

\title{
Measuring and Modeling Evolution of Cryoconite Holes in the McMurdo Dry Valleys, Antarctica
}

Felix Jacob Zamora

Portland State University

Follow this and additional works at: https://pdxscholar.library.pdx.edu/open_access_etds

Part of the Geology Commons

Let us know how access to this document benefits you.

\section{Recommended Citation}

Zamora, Felix Jacob, "Measuring and Modeling Evolution of Cryoconite Holes in the McMurdo Dry Valleys, Antarctica" (2018). Dissertations and Theses. Paper 4706.

https://doi.org/10.15760/etd. 6590

This Thesis is brought to you for free and open access. It has been accepted for inclusion in Dissertations and Theses by an authorized administrator of PDXScholar. Please contact us if we can make this document more accessible: pdxscholar@pdx.edu. 
Measuring and Modeling Evolution of Cryoconite Holes

in the McMurdo Dry Valleys, Antarctica

\section{by}

Felix Jacob Zamora

A thesis submitted in partial fulfillment of the requirements for the degree of

\section{Master of Science}

in Geology

Thesis Committee:

Andrew G. Fountain, Chair

Adam Booth

Matthew J. Brunengo

Portland State University 2018 


\begin{abstract}
Cryoconite holes are vertical columns of meltwater within the shallow subsurface of glaciers. In the McMurdo Dry Valleys (MDV) of Antarctica cryoconite holes are a source of meltwater and harbor microbial communities in an otherwise arid environment with low biologic activity. The holes form as sediments on the ice surface, which are darker than the surrounding ice, are preferentially heated by solar radiation. The warm sediments melt the underlying ice and migrate downwards. An ice lid forms, isolating them from the below-freezing atmosphere enabling them to remain thawed. In this study, field observations, laboratory experiments, and numerical modeling are used to characterize the fundamental variables controlling cryoconite hole development.
\end{abstract}

Field and laboratory results show that solar radiation drives cryoconite hole melting by controlling the energy available to the cryoconite and to warm the surrounding ice. Holes deepen further in warmer ice. Laboratory results show that at temperatures of $-10^{\circ} \mathrm{C}$ at least $405\left(\mathrm{~W} \mathrm{~m}^{-2}\right)$ are needed to warm the cryoconite sufficiently to melt surrounding ice. Numerical modeling shows that increased radiation flux into the subsurface and warmer air temperatures cause cryoconite to descend deeper and the meltwater-filled holes to enlarge, while increased surface ablation decreases their average depth. Cryoconite holes thaw sooner and refreeze later when the optical properties of the ice facilitate greater radiation transmission. Cryoconite warms the ice significantly more than ice without cryoconite. Within the melt-filled hole, the heat capacity of the water keeps the surrounding ice warm for several weeks after the cryoconite-free ice has cooled. The cryoconite itself is last to completely freeze. 


\section{Acknowledgments}

This research was funded by the National Science Foundation (ANT - 1443578). I would like to thank my advisor, Andrew G. Fountain, for his guidance and insights. Pacifica Sommers, Dorota Porazinska, Jack Darcy, Steven Schmidt, Adam Solon, and Lara Vimercati of the University of Colorado at Boulder provided assistance in the field. Thomas Nylen of UNAVCO provided assistance with field instrumentation. Anne Nolan of Oregon State University lent the spectrometer to measure the radiation in the laboratory. Matthew Hoffman provided invaluable insights into the adapting the model to the cryoconite hole environment. Anna Bergstrom, Krista Meyers, and James McClure of the McMurdo Long Term Ecologic Research project provided meteorologic data to operate the model. 


\section{Table of Contents}

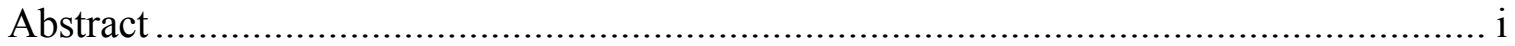

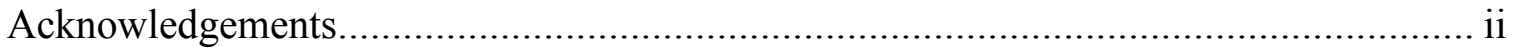

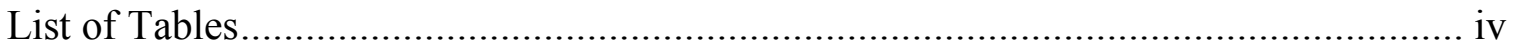

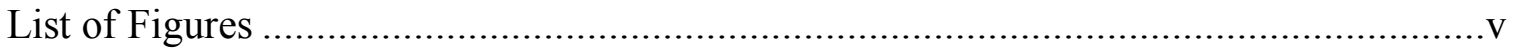

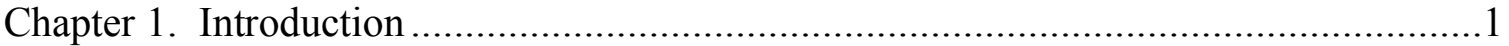

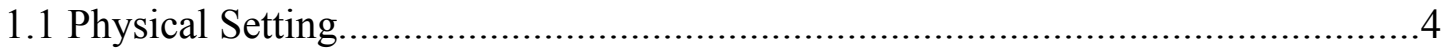

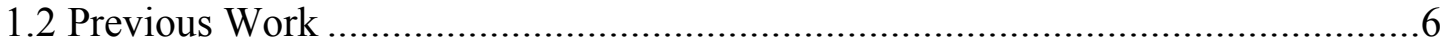

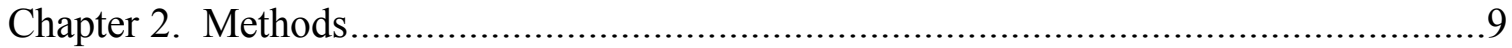

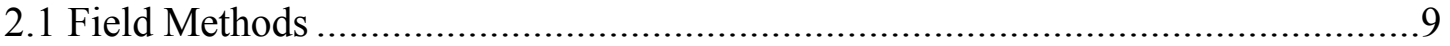

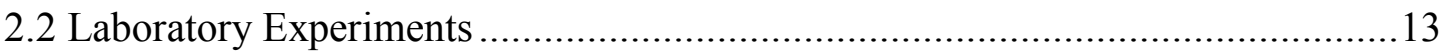

2.3 Modeling Cryoconite Holes......................................................................... 15

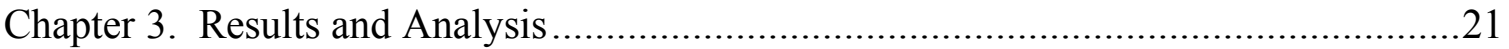

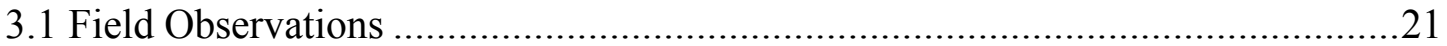

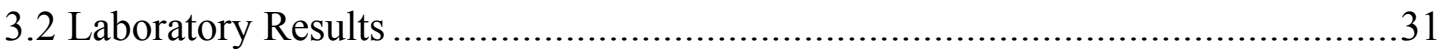

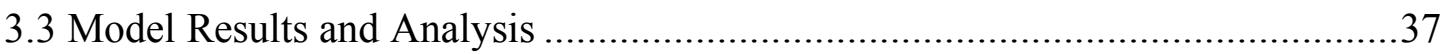

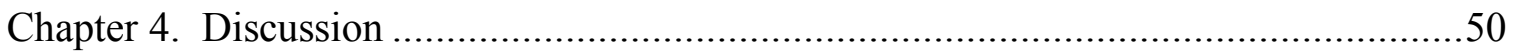

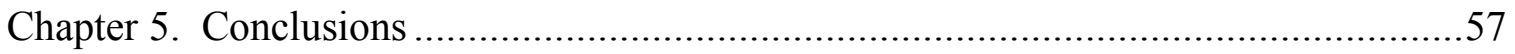

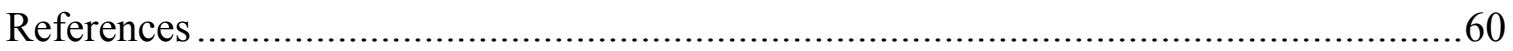

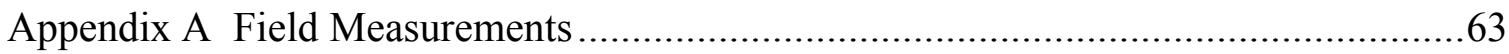

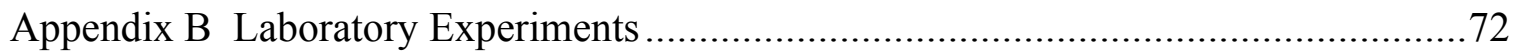

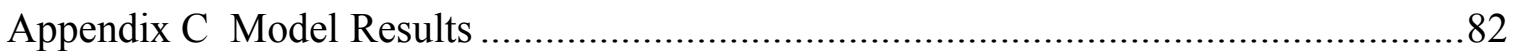




\section{List of Tables}

Table 3.1 Local meteorology of Canada Glacier.................................................24

Table 3.2 Comparison of adjustable model parameters........................................37

Table 3.3 Sensitivity analysis of $2005-06$ cryoconite model ....................................48 


\section{List of Figures}

Figure 1.1. Image and cross-section of cryoconite hole on Canada Glacier.....................2

Figure 1.2 Map of Taylor Valley, Antarctica...................................................

Figure 2.1 Profile of experimental arrangements deployed on Canada Glacier ..............10

Figure 3.1 Conditions in a natural cryoconite hole during the $2016-17$ summer............23

Figure 3.2 Conditions in a natural cryoconite hole during the $2017-18$ summer............27

Figure 3.3 Conditions in an artificial hole during the $2017-18$ summer........................28

Figure 3.4 Radiation attenuation on Canada Glacier and in laboratory ice ....................32

Figure 3.5 Radiation scattering along a laboratory ice block...................................33

Figure 3.6 Artificial hole conditions and sediment deepening when ambient air temperatures equal $-3^{\circ} \mathrm{C}$

Figure 3.7 Equilibrium depth of sediment versus the incident shortwave radiation and ambient air temperature

Figure 3.8 Modeled subsurface conditions over the 2005-06 austral summer .38

Figure 3.9 Measured and modeled cryoconite depth and surface ablation over the 20052006 austral summer.

Figure 3.10 Surface energy balance over the 2005-2006 austral summer

Figure 3.11 Difference in modeled subsurface conditions over the 2005-06 austral summer calculated by the cryoconite model versus model of Hoffman et al. (2014) 


\section{Chapter 1 Introduction}

Cryoconite holes are vertical cylinders of meltwater that form in the surface of glaciers, lake ice, and sea ice (Gribbon et al., 1979; Ishikawa and Kobayashi, 1985; Podgorny \& Grenfell, 1996; Takeuchi et al., 2000; Fountain et al., 2004; Jepsen et al., 2010; Anesio and Laybourn-Parry, 2012). The term "cryoconite" is derived from the Greek word "cryo," meaning ice, and "conite", meaning dust and were first described by A.E. Nordenskjold during his 1870 traverse of the Greenland Ice Cap (Leslie, 1879). They form from patches of sediment that preferentially absorb solar radiation due to their lower albedo compared to the surrounding ice (Figure 1.1). The sediment on the ice surface comes from the non-glacier covered landscape surrounding the glacier, commonly by eolian transport (Wharton et al. 1985). Biologic material entrained with the sediment inoculates the cryoconite hole and establishes microbial communities within (McIntyre et al. 1984; Porazinska et al. 2004). The meltwater produced by cryoconite holes may be a large portion of the subsurface component of glacier runoff in Antarctica (Hoffman et al. 2014).

Cryoconite holes are found in the ablation zone of glaciers globally, including British Columbia (McIntyre 1984), the Himalaya (Takeuchi et al. 2000), Europe, the Arctic (Anesio et al. 2009), and Antarctica (Wharton et al., 1985). On temperate glaciers, the holes are open water-filled pools that freely exchange water and gases with the surrounding air and supraglacial meltwater. In the McMurdo Dry Valleys (MDV), Antarctica, the holes are constantly sealed by an ice lid that isolates the water and 
sediments within during the summer. The cylindrical shape of cryoconite holes have typical vertical and horizontal dimensions of $\sim 20 \mathrm{~cm}$, and maximum dimensions of $<1 \mathrm{~m}$ (Fountain et al. 2004). Their unique structure has led researchers to use them as a gauge of hydrologic, biologic, and geochemical processes across the glacial surfaces (Porazinska et al. 2004; Fountain et al. 2004; Tranter et al. 2005; Cook et al. 2015).

In the MDV, during the austral summer, the energy balance favors the solid-state greenhouse effect whereby the cold winds keep the ice surface frozen but the solar
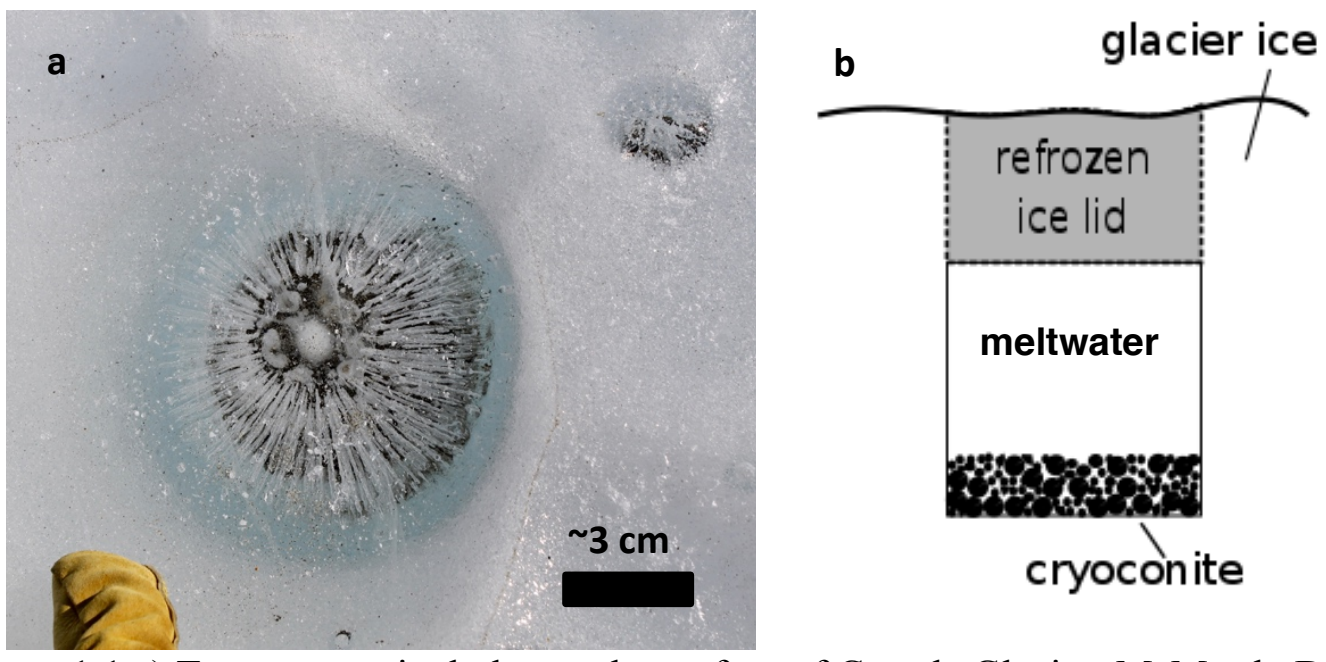

Figure 1.1 a) Two cryoconite holes on the surface of Canada Glacier, McMurdo Dry Valleys, Antarctica. Sediments have a significantly lower albedo than surrounding glacier ice. b) Cross-section of typical cryoconite hole in the MDV in mid-summer.

radiation transmitted through the ice preferentially heats the sediment compared to the ice (Wharton et al., 1985; Brandt and Warren, 1993; Liston et al., 1999). When the heat gain from radiation is greater than the head conduction from the sediment its temperature warms above $0^{\circ} \mathrm{C}$ and the surrounding ice melts. Holes generally harbor communities of cyanobacteria, tardigrades, among other microbial organisms (Wharton et al., 1985; Christner et al., 2003; Porazinka et al., 2004). These communities have been considered 
as models of microbial colonization in more extreme cold environments, such as "snowball earth" (Hoffman et al., 1998) or ice-covered planets (Vincent and HowardWilliams, 2000; Nibset and Sleep, 2001). Individual cryoconite holes can exist on the glaciers for decades before the sediments are flushed away or the hole migrates to the edge of the glacier (Fountain et al., 2004). In the MDV the holes may be important sources and reservoirs of meltwater. Surface fractures may connect some holes constituting a shallow hydrologic system (Fountain et al., 2004). Glacial meltwater is severely limited in the MDV, making cryoconite holes one of the few consistent sources of meltwater (Fountain et al. 2004). Although broad surveys of cryoconite holes have attempted to quantify their contribution to runoff, their connectivity to the glacier hydrologic system is poorly understood (Fountain et al., 2004; MacDonell and Fitzsimmons, 2008).

The evolution of cryoconite holes has been studied empirically (McIntyre, 1984; Takeuchi et al., 2000; Fountain et al., 2008; MacDonell and Fitzsimmons, 2008). However, a detailed understanding of the mechanisms driving melting and freezing within the holes that control their evolution has not been extensively examined. To more accurately characterize the physical processes controlling cryoconite evolution my thesis uses field observations, laboratory experiments, and numerical modeling. Changes in cryoconite hole attributes in response to changes in different physical parameters and meteorologic variables will elucidate which among them exert the most control. By understanding the environmental conditions controlling cryoconite hole evolution, this research supports a broader project which aims to elucidate the processes controlling 
assemblage dynamics of the microbial communities in cryoconite holes, lending a better understanding of biodiversity and ecosystem processes in the MDV.

\subsection{Physical Setting}

Taylor Valley, one of the McMurdo Dry Valleys, lies along the western coast of the Ross Sea, within the Central Transantarctic Mountains (Figure 1.2). The valley is bounded to

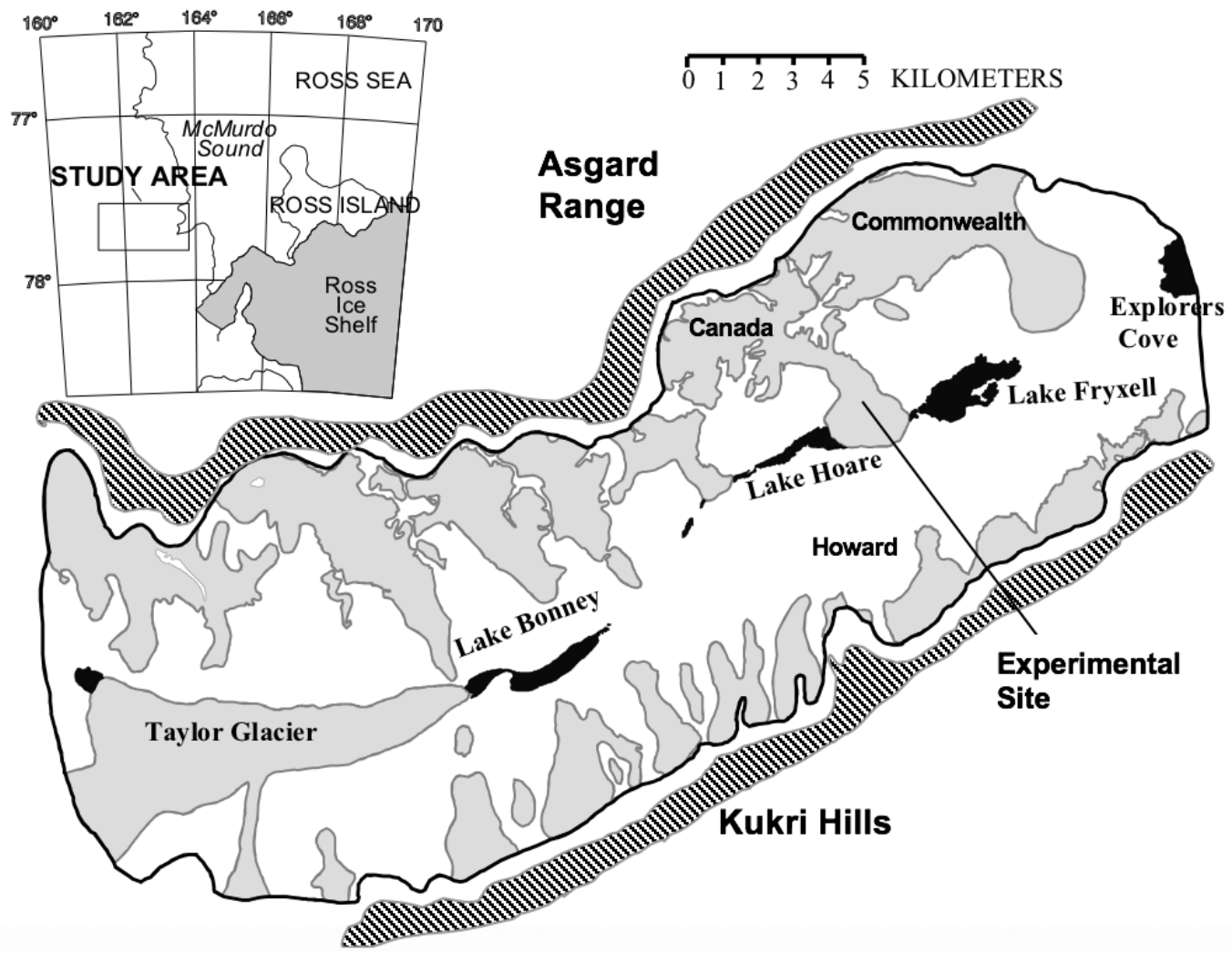

Figure 1.2 Map of Taylor Valley. The black shapes are the perennially ice-covered lakes. The grey figures are the glaciers. The crests of the Kukri Hills and Asgard Range are cross-hatched. From Fountain et al. 2008.

the north and the south by mountain ranges that rise to $1500-2000 \mathrm{~m}$. To the west and east the valley is bounded by the Taylor Glacier, an outlet glacier of the East Antarctic Ice Sheet (EAIS), and the Ross Sea, respectively. The study site is located at $77^{\circ} 36^{\prime}$ S, 
$162^{\circ} 56^{\prime}$, in the ablation zone of Canada Glacier, $15 \mathrm{~km}$ inland from the coast, at an elevation of $\sim 400 \mathrm{~m}$ above sea level. The mean annual air temperature is about $-20^{\circ} \mathrm{C}$ on the valley floors with a mean summer temperature of about $-3^{\circ} \mathrm{C}$ with daily temperatures reaching as high as $1.4^{\circ} \mathrm{C}$ (Doran et al., 2002). Air temperature increases with distance from the coast, and decreases with elevation (Doran et al., 2002; Fountain et al., 2015). Average annual wind speed measured at the Lake Hoare meteorological station, adjacent to Canada Glacier, is $2.8 \mathrm{~m} \mathrm{~s}^{-1}$. The highest wind speeds, sometimes as high as $36.3 \mathrm{~m} \mathrm{~s}^{-1}$, come from the west. Slower easterly winds from the Ross Sea dominate in summer. Summer solar radiation persists 24 hours a day and its intensity fluctuates diurnally over the summer. In winter sunlight is absent. From November to January, average solar irradiance at noon is $471 \mathrm{~W} \mathrm{~m}^{-2}$ and $<50 \mathrm{~W} \mathrm{~m}^{-2}$ at midnight (Dana et al. 1998). Relative humidity averages $66 \%$ annually (Doran et al., 2002). Annual precipitation, which occurs entirely as snow, averages $6 \mathrm{~cm}$ water equivalent along the valley floors, with the majority sublimating before making a hydrologic contribution to streams or lakes (Fountain et al., 2010).

Glaciers in the MDV are in equilibrium, unlike glaciers in low-latitude regions elsewhere, based on mass balance reconstruction over the past 50 years (Fountain et al., 2006; 2016). The average annual ablation rate is $\sim 10 \mathrm{~cm} \mathrm{yr}^{-1}$, which is small compared to temperate glaciers (Chinn et al. 1998; Fountain et al., 2006). Winter ablation is entirely via sublimation and summer ablation consists of melting and sublimation, but is typically dominated by sublimation (Chinn et al., 1998; Hoffman et al. 2014). Melting in the subsurface, like in cryoconite holes, may account for $10-50 \%$ of total ablation (Hoffman 
et al., 2014). The ablation zones are generally snow free and lose mass in both summer and winter. Snow events dramatically increase the albedo of glacier surfaces and greatly reduce if not terminate melt and stream flow during the summer (Fountain et al., 1999). The scarcity of liquid water and the dramatic response of glacial runoff to relatively small shifts in weather (Hoffman et al., 2008) underpin the importance of understanding the evolution of cryoconite holes in MDV.

\subsection{Previous Work}

Cryoconite holes in the MDV evolve over the year (Wharton et al., 1985; Fountain et al., 2004). At the start of the austral spring (September - October) ice-temperatures are subfreezing, and the formerly water-filled holes are entirely frozen. As air temperatures and sunlight increase the glacier ice warms. Around early November the cryoconite warms to temperatures greater than the air temperature and by mid- to late-December the sediment warms to temperatures above freezing, melting the surrounding ice. As the underlying ice melts the cryoconite moves downward into the layer occupied by the meltwater and the hole develops with an increasingly thick layer of meltwater on top of a descending layer of cryoconite. The rate of cryoconite deepening slows as it gets deeper in the ice and absorbs less solar radiation. It reaches its maximum depth when the rate of deepening equals the ablation rate of the glacier surface. Temperatures within the meltwater remain at the melting point for days to weeks, often while air temperatures are several degrees cooler (Fountain et al. 2008). After solstice in late-December solar intensity decreases, and air and ice temperatures begin cooling, slowly freezing the 
cryoconite holes, which by mid-February, is complete (Fountain et al., 2008). The glacier surface continues to ablate over the winter, decreasing depth to frozen cryoconite until the cycle begins again the following spring.

On Canada Glacier, about half of the cryoconite holes appear to be hydrologically connected via subsurface cracks while the rest are hydrologically isolated, some for as long as 13 years (Fountain et al., 2004; Tranter et al. 2005). Although cryoconite holes only cover $4-6 \%$ of the glacier surface, they may contribute upwards of $13 \%$ of the meltwater runoff. The hole water is altered geochemically due to the elution of ions as ice melts, the dissolution of the cryoconite sediment, and photosynthesis of the cyanobacteria (Tranter et al., 2005; Bagshaw et al., 2007). Concentrations of $\mathrm{Ca}^{2+}$ and $\mathrm{HCO}_{3}{ }^{-}$within cryoconite holes can be 2 to 3 orders of magnitude higher than that found in glacier ice (Tranter et al., 2004; Fountain et al., 2008).

Throughout the MDV, hole diameter ranges between 5 to $145 \mathrm{~cm}$ and depth ranges between 4 to $56 \mathrm{~cm}$. Hole depth generally increases with diameter, although this relationship is weak (Fountain et al. 2004). However, average hole depth and diameter tend to cluster based on glacier, except for Taylor Glacier, with Canada Glacier having the deepest (Fountain et al. 2004). This relationship is likely the result of multiple variables including sediment availability, aspect, air temperature, wind speed, precipitation, and the optical properties of the ice, which change from glacier to glacier (Hoffman et al., 2014). Cryoconites on Canada Glacier are typically $19-24 \mathrm{~cm}$ beneath the surface by the start of summer in November and deepen to $33-37 \mathrm{~cm}$ by the end of 
January (Porazinska et al. 2004; Fountain et al 2008). There also appears to be a critical value of sediment thickness, where melting accelerates as sediment thickness increases but beyond a few tens of $\mathrm{mm}$, the sediment insulates the underlying ice and retards melting (Fountain et al., 2004; MacDonnell and Fitzgerald, 2008). No relationship exists between equilibrium depth and elevation because the entire ablation zone is generally snow-free all year long making all holes subject to roughly the same amount of radiation.

Several models have been developed to simulate ice melting for conditions in the MDV, though none focus on melting induced by cryoconite on the glacial surfaces. Jepsen et al. (2010) modeled sediment induced melt on lake ice though the results do not reflect cryoconite evolution on glaciers because of different environmental conditions. Wharton (1985) outlined an equilibrium model to calculate the energy balance at the level of cryoconite in water-filled holes to demonstrate that the rate of cryoconite melting is highest at the surface and decreases with depth as energy transferred downward diminishes. However, the model was not tested against field observations. While there are several models of solar heating and subsurface melt on Antarctic glaciers (Liston et al. 1999; Hoffman et al., 2008, 2014) they are limited to ice without cryoconite. 


\section{Chapter 2 Methods}

Cryoconite holes were examined in the field, the laboratory, and using numerical modelling to understand the processes of evolution. Natural holes as well as artificially created holes were monitored in the field. A series of laboratory experiments were conducted to elucidate the influence of solar radiation and ice temperature on hole development in a controlled environment. Finally, a physically-based model of surface energy balance and radiation transmission into the ice was adapted to investigate the detailed processes controlling cryoconite hole evolution, which was solved numerically. Physically-based models offer a means to better understand the processes that govern the evolution of cryoconite holes. The energy balance of the ice surface can be easily changed for a variety of conditions and multiple years of cryoconite evolution can be investigated. Hole attributes can be modeled using meteorologic data collected in the MDV. The veracity of the model can be assessed by comparing results to empirical observations from the MDV.

\subsection{Field Methods}

Natural holes were monitored as a baseline and used to compare against conditions within the artificial holes, which were created as part of a separate experiment to investigate microbial community dynamics. Artificial holes were created by using a 10 $\mathrm{cm}$ diameter hole saw to excavate a $2 \mathrm{~cm}$ deep depression into the glacier surface and filling it with $20 \mathrm{~g}$ of sediment collected from the surrounding surface. This mass filled the depression with a $2 \mathrm{~mm}$ thick layer of sediment. Platinum Resistance Thermistor 
(PRT) temperature probes $\left( \pm 0.1^{\circ} \mathrm{C}\right.$, Thermometrics Corp. $)$ were installed in the natural and artificial holes to measure the temperature of ice and water. Electrical conductivity (EC) probes were also used to confirm the presence of meltwater and provide a coarse measure of water chemistry, where higher EC indicates more solutes in the water, compared to the zero values of entirely frozen ice. Two different probe arrangements were used: Eulerian and Lagrangian (Figures 2.1, A.3). In the Eulerian arrangement, probes were fixed in the ice prior to melt, so as the cryoconite and water deepen as the holes develop, they intersect the probes. The probes were frozen into the ice diagonally with the sensors at fixed positions at the top of the cryoconite-ice boundary and $5 \mathrm{~cm}$ below the cryoconite. In the Lagrangian arrangement, probes were attached to

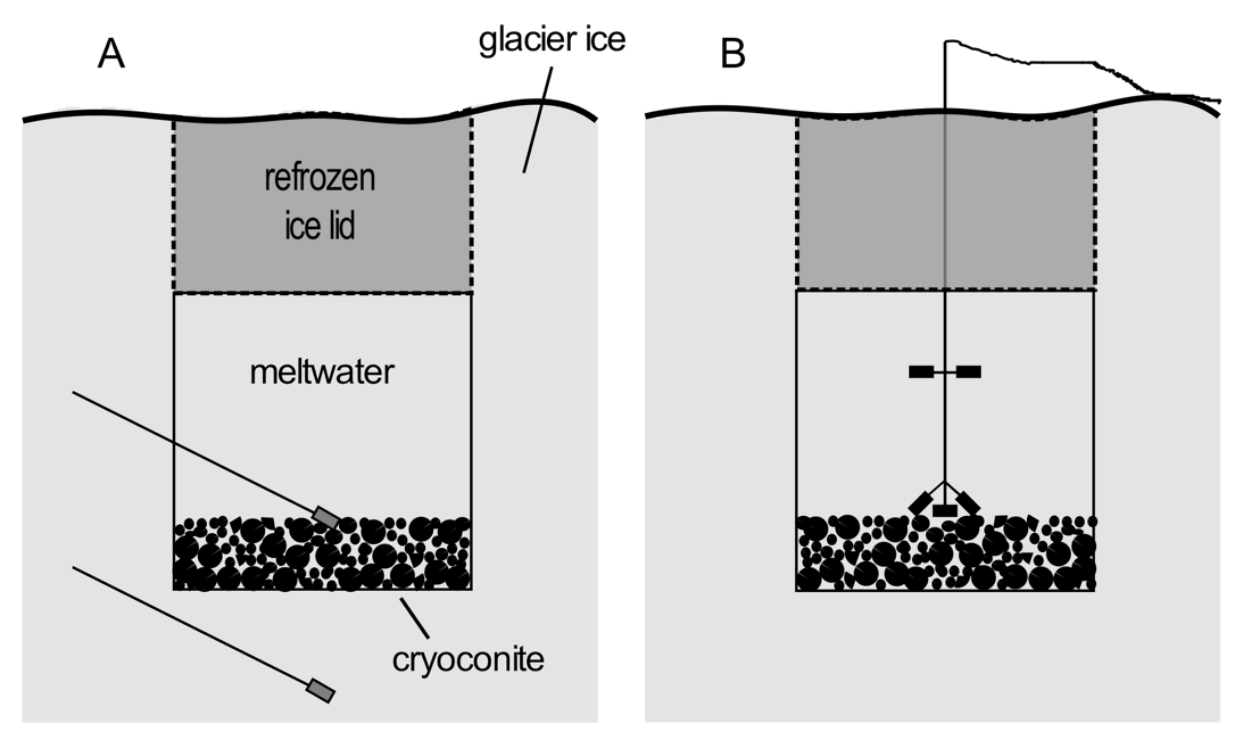

Figure 2.1 Cryoconite holes in the McMurdo Dry Valleys with the two experimental arrangements. A) temperature and electrical conductivity probes inserted diagonally into the ice hole in the Eulerian arrangement. B) probed mounted to a mast that plunges with the sediment in the Lagrangian arrangement. The probes are represented by the black rectangles at the end of the wires coming off the mast. The diagram is not to scale, but the distance between the lower and upper probes in both arrangements is $5 \mathrm{~cm}$. 
a stainless-steel post that rested on top of the cryoconite. A thin puck of sediment was glued to the bottom of the post to prevent preferential melting of the post into the ice. The intent was to allow the probes to descend with the cryoconite as it deepened into the ice and remain fixed relative to the cryoconite. Temperature and EC probes were attached to the bottom of the post to rest directly at the cryoconite-water boundary and 5 $\mathrm{cm}$ above the cryoconite. In both arrangements, the probes, wires, and post were wrapped in white Teflon tape to increase their reflectivity and minimize radiative heating. Laboratory tests of Teflon and mylar wrappings showed Teflon to be most effective at this (Appendix B). Data were recorded using a CR10X (Campbell Scientific, Inc.) solid state data logger.

When the site was revisited on December $13^{\text {th }}, 2017$, inspection of the instrumented cryoconite holes revealed that the Lagrangian arrangements did not deepen with the sediment as anticipated and were not properly seated and did not provide reliable measurements over the previous winter. Most likely the top of the post was frozen in place by the ice lid above the hole. The probes in the Eularian arrangement were securely fixed and provided reliable measurements. All probes were removed because the cryoconite deepened since initial installation, the surface had ablated, and the probes were too shallow and no longer near the cryoconite. Two pristine natural holes were instrumented within one meter of the holes monitored the previous season. Only one (16NE01) of the three natural holes was re-instrumented (renamed 17-NE01). New probes were installed in the Eularian arrangement. In a change from the previous season, holes were drilled vertically rather than diagonally to increase precision of probe placement. 
When the probes were installed for the season December $17^{\text {th }}, 2017$ initial depths to cryoconite varied from 20 to $22 \mathrm{~cm}$. The upper sets of probes were positioned $1 \mathrm{~cm}$ beneath the sediment ( $\sim 21$ to $23 \mathrm{~cm}$ beneath the surface) and the lower sets were $6 \mathrm{~cm}$ beneath the sediment ( $\sim 27$ to $29 \mathrm{~cm}$ beneath the surface). The probes were frozen into place using crushed ice and chilled meltwater while the cryoconite hole was still frozen.

Ten new artificial holes were created using the same procedure described earlier with 20 grams of sediment, collected from the glacier surface. For the biology experiments, sediments were inoculated with algal material collected from streams adjacent to the glacier. Sets of temperature and electrical conductivity probes were installed $5 \mathrm{~cm}$ and $10 \mathrm{~cm}$ beneath the sediment of five of the artificial holes. The probes were further from the sediment than those in the natural holes because the sediment in the artificial holes was expected to deepen further over the melt season. EC probes alone were installed in the five remaining holes because of lack of temperature probes. The automatic weather station continued to record meteorologic conditions at the study site.

Meteorological conditions were measured using a standard automatic weather station that included air and ice temperature, incoming shortwave radiation, and distance to the glacier surface (as a measurement of snowfall and ablation). Model 107 thermistor probes $\left( \pm 0.1^{\circ} \mathrm{C}\right.$, Campbell Scientific, Inc. $\left.)\right)$ measured the air temperature $1 \mathrm{~m}$ above the ice surface and the ice temperature $1 \mathrm{~m}$ below the surface. Incoming shortwave solar radiation was measured using a PSP pyranometer $\left( \pm 0.8 \mathrm{~W} \mathrm{~m}^{-2}\right.$, Eppley Laboratory, Inc.). Distance to the ice surface was measured using a SR50 sonic ranger $( \pm 1 \mathrm{~cm}$, Campbell 
Scientific, Inc.). The study site is $100 \mathrm{~m}$ up-glacier (north) of the permanent Canada Glacier meteorological station maintained by the McMurdo Long-Term Ecological Research project (McMLTER; Doran et al. 2002), which served as a backup meteorologic station, and included all of the variables measured at the cryoconite site, plus albedo, wind speed, and relative humidity.

\subsection{Laboratory Experiments}

To provide further insight into cryoconite hole initiation and evolution and to minimize the variability of field conditions, cryoconite holes were created in the laboratory. Based on observations from previous studies (e.g., McIntrye 1984, Fountain et al. 2008) experiments focused on the variables of shortwave radiation and air temperature, which control ice temperature. Experiments were conducted in a chest freezer $1.5 \mathrm{~m}$ long, 0.6 $\mathrm{m}$ wide, $0.7 \mathrm{~m}$ tall. A $5 \mathrm{~cm}$ thick insulated lid was fitted to the top with a $15 \mathrm{~cm} \mathrm{x} 24 \mathrm{~cm}$ window cut in the center to accommodate incoming light. Temperatures were controlled using a A421 digital temperature controller (Johnson Controls). Ice blocks were made with tap water. The water was frozen in a PVC cylinder, $14 \mathrm{~cm}$ in diameter and $20 \mathrm{~cm}$ tall. The cylindrical shape was chosen so that lateral heat conduction would be equal in all directions.

Light was provided by a high intensity LED lamp (Larson Electronics LLC) that produced $448 \mathrm{~W} \mathrm{~m}^{-2}$ at $20 \mathrm{~cm}$. The lamp emits light with a bimodal energy distribution that peaks in the blue $(\sim 450 \mathrm{~nm})$ and yellow $(\sim 550 \mathrm{~nm})$ portions of the visible spectrum (Appendix B, Figure B.1). The lamp did not replicate natural diurnal fluctuations of solar 
intensity. To determine radiation intensity with distance from the lamp a Field Spec Pro spectrometer (Analytical Spectral Devices, Inc.) was used. With the lamp directed toward a high-albedo Spectralon panel, $(\alpha=\sim 0.99)$ the radiation intensity of the panel was measured at distances of $30,40,60$, and $70 \mathrm{~cm}$. A regression curve was fitted to the measurements (Appendix B, Figure B.2) allowing the radiation intensity at any distance from the lamp to be calculated.

To measure radiation attenuation through ice, individual ice blocks were placed $30 \mathrm{~cm}$ away from the lamp and shortened from 20 to $5 \mathrm{~cm}$, in $5 \mathrm{~cm}$ increments (Appendix B). For each thickness, direct radiation intensity was measured at the end of the block and the percentage of incident radiation was calculated. Volume scattering of light and radiation attenuation within the block were limited compared to a glacier surface. To enhance scattering mylar was applied to the outside of the block. To determine how mylar augments attenuation compared to glacier ice, this was repeated with mylar applied to $1 / 4$, $1 / 2$, and the full circumference of the block.

To characterize internal scattering the forward, back, and normal components of scattering were measured along the length of the block (Figure B.3). Measurements were made at $10 \mathrm{~cm}$ along the side of a $20 \mathrm{~cm}$ ice block. Measurements were made with the sensor oriented 45 degrees from normal for back- and forward-scatter. The percentage of the scattered radiation relative to incident was calculated. Again, this was repeated with mylar applied to $1 / 4,1 / 2$, and the full circumference of the block. 
Temperature thermistors were placed at the center of the ice block on the surface, 5 , and $10 \mathrm{~cm}$ deep, with a fourth thermistor $5 \mathrm{~cm}$ deep but $3.5 \mathrm{~cm}$ from center. Temperatures were recorded continuously using a CR10x data logger. The ice block was initially located $40 \mathrm{~cm}$ from the lamp, which provided the minimum radiation intensity $\left(365 \mathrm{~W} \mathrm{~m}^{-}\right.$

$\left.{ }^{2}\right)$ to the ice surface. Once the ice block temperature reached equilibrium $20 \mathrm{~g}$ of sediment, pre-cooled to the freezer temperature, was spread on the block in a layer $\sim 2$ $\mathrm{mm}$ thick and $10 \mathrm{~cm}$ in diameter (matching field experiments) marking the start of the experiment. As the sediments warmed they melted the underlying ice and descended. When the sediments ceased to deepen and the ice temperatures no longer changed with time, the block was raised $5 \mathrm{~cm}$, increasing the radiation intensity, and the sediments deepened again until reaching a new equilibrium depth. This process was repeated until the surface of the ice block was $20 \mathrm{~cm}$ from the lamp $\left(448 \mathrm{~W} \mathrm{~m}^{-2}\right)$. At closer distances the lamp heat would melt the ice surface. These experiments were conducted at air temperatures of $-10,-5,-4$, and $-3^{\circ} \mathrm{C}$. Measurements of sediment depth beneath the surface, height of the water-filled hole above the sediment, and ice lid thickness were recorded manually.

\subsection{Modeling Cryoconite Holes.}

To model cryoconite holes I adapted the one-dimensional model of Hoffman et al. (2008) which was originally used to predict ice ablation in the MDV. This model was derived from Liston et al. (1999) which uses a one-dimensional heat transfer equation that calculates the radiative transfer, heat conduction, and temperature in a column of ice, 


$$
\rho_{\mathrm{i}} \mathrm{C}_{\mathrm{p}} \frac{\delta \mathrm{T}_{\mathrm{i}}}{\delta \mathrm{t}}=\frac{\delta}{\delta \mathrm{z}}\left[\mathrm{k} \frac{\delta \mathrm{T}_{\mathrm{i}}}{\delta \mathrm{z}}\right]-\frac{\delta \mathrm{q}}{\delta \mathrm{z}}
$$

where $T_{i}$ is the ice temperature, $z(\mathrm{~m})$ is the vertical coordinate, $t(\mathrm{~s})$ is time, $C_{p}$ is the specific heat of ice $\left(2106 \mathrm{~J} \mathrm{~kg}^{-1} \mathrm{~K}^{-1}\right)$, and $q\left(\mathrm{~W} \mathrm{~m}^{-2}\right)$ is the solar radiative flux. The density of ice, $\rho_{i}$, on Canada Glacier is $870 \mathrm{~kg} \mathrm{~m}^{-3}$ (Hoffman et al. 2008). Because water has different thermal properties than ice, the thermal conductivity $(k)$ changes as the ice melts and water content increases. Hoffman et al. (2008) accounted for the effect of water fraction on the thermal conductivity based on the following equation,

$$
k=\frac{2 k_{p} \rho_{i}}{3 \rho_{p}-\rho_{i}}
$$

where $k_{p}$ and $\rho_{p}$ are the thermal conductivity and density of pure ice $\left(917 \mathrm{~kg} \mathrm{~m}^{-3}\right)$. The solar radiation term is spectrally dependent, which produces a subsurface temperature profile more accurate than broadband models (Brandt \& Warren, 1993). Shorter wavelengths attenuate within ice slowly, penetrating deeper into the subsurface. Conversely, longer wavelengths attenuate more quickly and penetrate less deep.

Two boundary conditions define the modeling domain, the bottom and the surface. The bottom is a constant temperature the depth of which $(15 \mathrm{~m})$ is where seasonal temperature variations attenuate and are equal to the mean annual temperature (Liston et al., 1999). The surface is defined by the energy balance between the ice surface and atmosphere. The initial temperature at the surface is calculated using the surface energy balance (Hoffman et al. 2008), 


$$
\chi(1-\alpha) \mathrm{Q}_{\mathrm{si}}+\mathrm{Q}_{\mathrm{li}}+\mathrm{Q}_{\mathrm{le}}+\mathrm{Q}_{\mathrm{h}}+\mathrm{Q}_{\mathrm{e}}+\mathrm{Q}_{\mathrm{c}}-\mathrm{Q}_{\mathrm{m}}=0
$$

where $\chi$ is the fraction of solar radiation absorbed in the surface layer, $\alpha$ is surface albedo, $\mathrm{Q}_{\mathrm{si}}$ is incoming shortwave radiation, $\mathrm{Q}_{\mathrm{li}}$ is incoming longwave radiation, $\mathrm{Q}_{\mathrm{le}}$ is emitted longwave radiation, $\mathrm{Q}_{\mathrm{h}}$ is sensible heat flux, $\mathrm{Q}_{\mathrm{e}}$ is latent heat flux, $\mathrm{Q}_{\mathrm{c}}$ is heat conduction in the ice, and $Q_{m}$ is the energy available for surface melt. Ice albedo is 0.56 , from direct measurements (Hoffman et al. 2008). All energy flux terms are in units of $\mathrm{W} \mathrm{m}^{-2}$, and positive values indicates flux toward the surface. The turbulent terms $\mathrm{Q}_{\mathrm{h}}$ and $\mathrm{Q}_{\mathrm{e}}$ are calculated using a bulk energy method with a Monin-Obukhov correction for atmospheric stability (Brutsaert, 1982). Those terms that cannot be directly measured are cast in a form that leaves surface temperature as the only unknown, which is solved for iteratively using the Newton-Raphson method (Liston et al. 1999). The entire column of ice is represented by a vertical grid of cells with the temperature of each calculated using eq. 1 . When the ice temperature rises above freezing $T_{i}$ is reset to $0^{\circ} \mathrm{C}$ and the excess energy is used to calculate melt in that cell, which is expressed as the water fraction.

The adjustable parameters of the model are $\chi$, defined above, surface roughness $\left(z_{0}\right)$, and effective grain radius $\left(r_{\text {eff }}\right)$. Surface roughness affects turbulent heat exchange where rougher surfaces increase turbulent exchange of heat and mass with the atmosphere and increases surface ablation, generally. The effective ice grain radius is a proxy for internal scattering of solar radiation that captures the effects of grain size, bubbles and impurities (Hoffman et al. 2008). Scattering and the attenuation rate of radiation increases with decreased ice grain radius. Radiation flux through the underlying ice is calculated based 
on a two-stream approximation (Schlatter 1972). In this formulation, downwelling radiation passing through layer $\delta z$ is reduced by absorption and upward reflection but enhanced by downward reflection of the upward flux. Similarly, upwelling radiation is reduced by absorption and downward reflection, but enhanced by upward reflection of the downward flux. Radiation attenuates with depth as it is absorbed and scattered.

Model input includes air temperature, relative humidity, wind speed, incoming shortwave radiation, and incoming long-wave radiation. All were measured at the study site except for incoming longwave radiation, measured on Commonwealth Glacier, $9 \mathrm{~km}$ to the east. An hourly, rather than daily, time step was used because in this energy-limited environment brief excursions strongly influence melt (Hoffman et al. 2008) and presumably on the evolution of cryoconite holes. For example, brief subsurface warming events, where temperatures rise above $0^{\circ} \mathrm{C}$ are known to occur during the warmest hours of the day, and are sufficient for cryoconite to briefly melt underlying ice and deepen further. The model starts in mid-winter when no sunlight occurs.

\section{Adapting the model for cryoconite hole evolution}

Cryoconite holes represent an incongruity in an otherwise uniform column of ice as assumed by the original model. The optical and thermal properties of the cryoconite differ from the surrounding ice and affect the upward and downward flux of solar radiation and heat. The model domain is represented by a vertical grid with $1 \mathrm{~cm}$ spacing in the upper $50 \mathrm{~cm}$ and then exponentially increasing grid spacing to $15 \mathrm{~m}$ depth, for a total of 90 layers. The thickest layer at the base is $1.8 \mathrm{~m}$. To account for the cryoconite, 
a single cell $(1 \mathrm{~cm})$ was attributed with the physical characteristics of cryoconite according to its source of valley soils (Fountain et al., 2004; Porazinska et al., 2004). The physical properties include thermal conductivity of $2.5 \mathrm{~W} \mathrm{~m}^{-1} \mathrm{~K}^{-1}$ (higher than glacier ice), specific heat of $1480 \mathrm{~J} \mathrm{~kg}^{-1} \mathrm{~K}^{-1}$ (McKay 2009; Levy and Schmidt, 2016) and an albedo of 0.15 for wet soil. To account for the pore space of sediment, the water (ice) fraction is limited to 0.25 , which corresponds to coarse sand (Das, 2008). Because sediments do not change phase, temperatures in the sediment cell were allowed to rise above $0^{\circ} \mathrm{C}$, but, meltwater in the hole is not allowed to rise above $0^{\circ} \mathrm{C}$. At the start of the model run in mid-winter, the cryoconite was positioned $25 \mathrm{~cm}$ beneath the surface, which is the approximate depth of cryoconite sediments on Canada Glacier in mid-winter, accounting for surface ablation (Porazinska et al. 2004; Fountain et al. 2008).

The cryoconite absorbs the downwelling and upwelling radiation calculated at that depth, minus that reflected due to its albedo, which proved essential to amplify total energy flux to the cryoconite and warm temperatures above the melting point. Although the cryoconite is opaque, the up- and downwelling radiation is allowed to pass, violating energy conservation. This violation is permitted for two reasons. First, if the cryoconite is opaque, then it would shadow all deeper cells, analogous to an infinitely wide layer of cryoconite. Second, cryoconite only cover about $4 \%$ of the glacier surface (Fountain et al. 2004), essentially eliminating any cryoconite-induced shadowing leaving volume scattering in the ice largely intact. 
Modeled cryoconite descends into the glacier when the water fraction of the cell beneath the cryoconite sediment reaches 1 . The cryoconite cell is shifted down and the water fraction of the former cryoconite cell is set to 1 . The cryoconite and the hole ascend closer to the surface by one cell $(1 \mathrm{~cm})$ when surface ablation equals the dimension of the top cell $(1 \mathrm{~cm})$. Therefore, the model accounts for shallowing of the sediments over the winter, deepening of the sediment in summer, and changes in the vertical dimension of the cryoconite hole over the season. 


\section{Chapter 3 Results and Analysis}

\subsection{Field Observations}

Summer 2016-2017

In early-November the surface of Canada Glacier was snow free. Snow covered the ice in mid-November with about $8 \mathrm{~cm}$ of snow. The study plot was swept of snow, natural holes were selected for monitoring, and the artificial holes were installed on November $27^{\text {th }}, 2016$. The cryoconite in the natural holes were $19-20 \mathrm{~cm}$ deep and no melting had occurred. Despite sweeping, some snow remained lodged within small depressions across the ice surface increasing the albedo compared to snow-free ice. The surrounding ice was still snow covered which significantly limited solar heating of the ice surrounding the test area, which is critical to its warming (Hoffman et al. 2008). From November $15^{\text {th }}$, 2016 through February $15^{\text {th }}, 2017$, the climate was typical of the MDV (Table 3.1; Doran et al. 2002) with average air temperatures a few degrees below freezing and generally sunny. The ice surface ablated $6 \mathrm{~cm}$ via sublimation and no surface melt occurred.

Hole 16-NL01 is used as an example for the natural holes over the summer, prior to the mast being damaged over winter. Initially, temperature of the cryoconite and in the ice 5 $\mathrm{cm}$ above were well below freezing $\left(-8^{\circ} \mathrm{C}\right)$ and fluctuated diurnally, (Appendix Figure A.4). Air and ice temperatures warmed through mid-December. By late-December, the cryoconite and ice temperatures had warmed to near air temperatures, but the ice remained frozen around the probes. By January $15^{\text {th }}$, temperatures in the holes reached $0^{\circ} \mathrm{C}$ on a near daily basis and were commonly warmer than the air temperature by $1-2^{\circ} \mathrm{C}$ 
(Figure 3.1). The difference between daily cryoconite and ice temperatures show that warming and melting was focused around the cryoconite, while the surrounding ice warmed more slowly. Air temperature during daily melt episodes was about $-2^{\circ} \mathrm{C}$ illustrating the ice is warmer than the air due to solar heating of the cryoconite (Figure 3.1). Temperatures at the cryoconite and in the ice above continued to fluctuate diurnally, dipping below $0^{\circ} \mathrm{C}$ for several hours and $\mathrm{EC}$ dropped to zero. This suggests that melting only occurred locally around the cryoconite and probes, while the ice in between remained frozen. Such little melting is supported by energy balance calculations and by late season observations confirmed the cryoconite holes had not developed, although late-summer measurements were not made to confirm if any cryoconite deepening had occurred. The limited melting observed contrasts with previous, snowfree summers in the MDV (Fountain et al., 2004, 2008).

Some differences in ice and cryoconite temperatures response to diurnal fluctuations of solar radiation was observed. Ice and cryoconite warmed simultaneously during the morning, lagging several hours behind solar radiation. During evening the ice cooled first followed by the cryoconite several hours later. Daily minimum ice temperatures were typically colder than the cryoconite by -0.5 to $-1.0^{\circ} \mathrm{C}$. EC first increased in the cryoconite and several hours later within the ice above; the magnitudes were roughly equal, $400 \mu \mathrm{S}$ on January $21^{\text {st }}, 2017$ and gradually decreased to $200 \mu \mathrm{S}$ by January $30^{\text {th }}$, 2017. The drop in EC during the latter half of January may indicate seepage of meltwater from the adjacent ice into the hole or meltwater from the ice beneath the cryoconitet mixing with the water above (Fountain et al. 2008). By late-January decreasing solar 
radiation and cooler air temperatures caused cryoconite and ice to cool and meltwater to refreeze (EC dropped to $0 \mu \mathrm{S}$ ). In early-February, when the holes are entirely frozen diurnal variations in temperature continued as before, and $\mathrm{EC}$ was $0 \mu \mathrm{S}$.
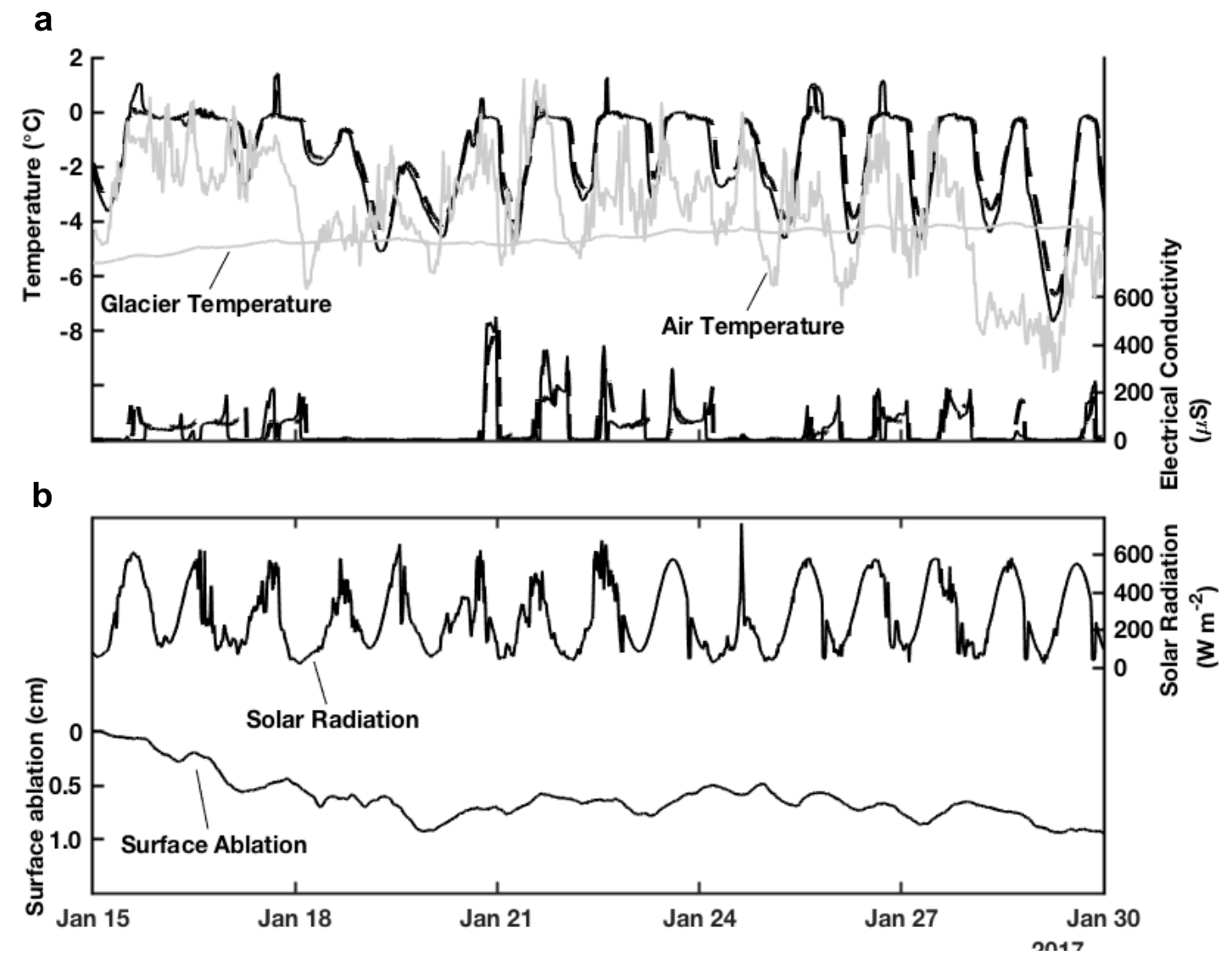

Figure 3.1. Results from a natural cryoconite hole (16-NL01) monitored on Canada Glacier during the 2016-2017 austral summer. Prior to melting, the sediment was $20 \mathrm{~cm}$ beneath the surface. a) Temperature and electrical conductivity of sediment (solid) and in the region $5 \mathrm{~cm}$ above (dashed) are shown in the top panels. The gray lines are air temperature and the ice temperature $1 \mathrm{~m}$ beneath the surface. b) Air temperature and solar radiation measured at the site.

The artificial holes were created on November 26th with sediments on the ice surface, 5 $\mathrm{cm}$ above the upper set of probes. The sediments immediately melted the underlying ice and migrating downward, despite below freezing air temperatures of $-7^{\circ} \mathrm{C}$. By December $19^{\text {th }}, 23$ days later, the sediment had descended $5 \mathrm{~cm}$ into the ice. Like the natural holes, 
temperature and EC measurements indicated that melting and refreezing occurred daily, although the sediment of the artificial holes was closer to the surface.

Table 3.1 Meteorology at the study site on Canada Glacier. Summer is from November $15^{\text {th }}$ through February $15^{\text {th }}$; winter is from February $16^{\text {th }}$ through November $14^{\text {th }}$. The ice temperature in 2016-17 was measured $1 \mathrm{~m}$ deep in the ice and by the summer 2017-18 it was $\sim 0.9 \mathrm{~m}$, accounting for ablation. Solar radiation is the daily average and the maximum at noon in mid-summer. For temperature and relative humidity the pattern is minimum / mean / maximum. For wind speed the pattern is average / maximum.

\begin{tabular}{lccc}
\hline \hline & Summer 2016-17 & Winter 2017 & $\underline{\text { Summer 2017-18 }}$ \\
Air Temp. $\left({ }^{\circ} \mathrm{C}\right)$ & $-15.9 /-4.7 / 5.8$ & $-37.4 /-20.4 /-4.5$ & $-14.0 /-5.3 / 5.1$ \\
Ice Temp. $1 \mathrm{~m}\left({ }^{\circ} \mathrm{C}\right)$ & $-12.8 /-7.5 /-4.1$ & $-33.1 /-23.1 /-7.3$ & $-15.6 /-6.2 /-2.6$ \\
Solar Radiation & $275 / 610$ & 40 (mean) & $256 / 603$ \\
$\left(\mathrm{~W} \mathrm{~m}{ }^{-2}\right)$ & $18.5 / 64.1 / 99.5$ & $10.4 / 50.7 / 94.3$ & $14.4 / 62.6 / 97.7$ \\
Relative Humidity $(\%)$ & $2.4 / 15.5$ & $3.7 / 27.1$ & $2.8 / 16.1$ \\
Wind Speed $\left(\mathrm{m} \mathrm{s}^{-1}\right)$ & 5.2 & 4.3 & 3.0 \\
Surface Ablation $(\mathrm{cm})$ & & &
\end{tabular}

Over winter (February $16^{\text {th }}$ through November $\left.14^{\text {th }}, 2017\right)$ the average air temperature was $-20.4^{\circ} \mathrm{C}$ (Table 3.1), but within the cryoconite holes the average was $-25.1^{\circ} \mathrm{C}$. Solar radiation was essentially zero from mid-March through mid-September. The surface ablated $4.3 \mathrm{~cm}$ over the winter entirely due to sublimation. By November $15^{\text {th }}, 2017$ the surface had ablated a total of $9.5 \mathrm{~cm}$ since the instruments were installed.

\section{Summer 2017-2018}

The summer climate was similar to that of 2016-17 but with less ablation (Table 3.1). On November $15^{\text {th }}$ a minor snow occurred, covering the surface with $1 \mathrm{~cm}$ of snow which ablated several days later. On December $9^{\text {th }}, 2017$, an additional $8 \mathrm{~cm}$ of snow fell. The study site was cleared on December $15^{\text {th }}$ but the surrounding ice remained covered 
through the summer. On January $9^{\text {th }}, 2018$, an additional $2 \mathrm{~cm}$ of snow fell and covered the study site for 2 days before it was swept away.

Hole 16-NE01 serves as an example of typical conditions at the start of summer. From November $1^{\text {st }}-15^{\text {th }}, 2017$, temperatures in the ice above the sediment averaged $-14^{\circ} \mathrm{C}$, following the trend of air temperature like the previous year. On November $15^{\text {th }}$, the Eularian probes in the natural hole were about $6 \mathrm{~cm}$ and $11 \mathrm{~cm}$ deep and the cryoconite was about $21 \mathrm{~cm}$ deep. On November $16^{\text {th }}$, air temperatures and subsurface temperatures began steadily warming, similar to the previous season. Ice temperatures reached $0^{\circ} \mathrm{C}$ and EC values spiked on November $25^{\text {th }}$ indicating the presence of meltwater. The temperatures at $11 \mathrm{~cm}$ deep fluctuated diurnally between $-2^{\circ} \mathrm{C}$ and $0^{\circ} \mathrm{C}$, and in the ice above $-4^{\circ} \mathrm{C}$ and $0^{\circ} \mathrm{C}$. Again, the daily pattern of warming shows that both the regions of ice deeper, closer to the sediment and those shallower warmed simultaneously, but the shallow ice began cooling several hours sooner. EC also fluctuated diurnally between zero and about $300 \mu \mathrm{S}$, exhibiting a daily pattern of melting and refreezing similar to the previous season. EC in the shallow ice began decreasing before the deeper ice closer to the cryoconite, as the relatively cooler temperatures refroze the meltwater sooner. The diurnal fluctuations were dampened on December $9^{\text {th }}$, when the snow event covered the ice and subsurface melting ceased. When the site was revisited on December $13^{\text {th }}, 2017$ the cryoconite was $19 \mathrm{~cm}$ deep and the probes were $4 \mathrm{~cm}$ and $9 \mathrm{~cm}$ beneath the surface. Given the surface ablated at least $9.5 \mathrm{~cm}$ since the time experiments were installed the previous summer, the sediments had to have deepened $\sim 9 \mathrm{~cm}$. So although a significant water column did not form above the sediment as in previous years (e.g. Fountain et al. 
2004, 2008), the minor melting observed at the sediment must have been sufficient for them to deepen.

When the natural holes were instrumented in mid-December, cryoconite were $20-22 \mathrm{~cm}$ beneath the surface. In the three natural holes, mid-summer temperatures fluctuated diurnally between $-3^{\circ} \mathrm{C}$ and $-0.5^{\circ} \mathrm{C}$, with temperatures closer to the sediments being as much as $1{ }^{\circ} \mathrm{C}$ warmer around noon. Above freezing temperatures were first recorded immediately beneath the sediment in all holes by December $30^{\text {th }}$ with EC rising above zero (indicating melt) several days later, marking the beginning of a prolonged period of melt (Figure 3.2). Cryoconite temperatures, as it deepened past the probe, rose as high as $+0.6^{\circ} \mathrm{C}$. Melting at the deeper probes occurred in early-January, with simultaneous sharp increases in EC from 0 . Temperatures at both probes were $0^{\circ} \mathrm{C}$ and showed slight diurnal fluctuations compared to earlier in the season or the previous season, when melting was less intense. Consistent $0^{\circ} \mathrm{C}$ temperatures and elevated $\mathrm{EC}$ measurements spanning about 2 weeks at both sets of probes suggest that the holes fully developed this season with a column of meltwater at least $5 \mathrm{~cm}$ in height. Further, that hole temperatures remained above freezing and EC remained elevated despite the snow event on January $9^{\text {th }}$, that lasted 2 days, underscores the stability of cryoconite holes once developed. Cooler air temperature and decreasing solar radiation in mid-January were cooling the ice such that by January $12^{\text {th }}$ meltwater at the lower probes froze. Several days later, the water around the upper probes froze. As the water froze, the EC abruptly increased before sharply dropping to $0 \mu \mathrm{S}$, simultaneous with temperatures dropping below freezing. By lateJanuary, temperatures around the upper and lower probes were $-6^{\circ} \mathrm{C}$. 
a

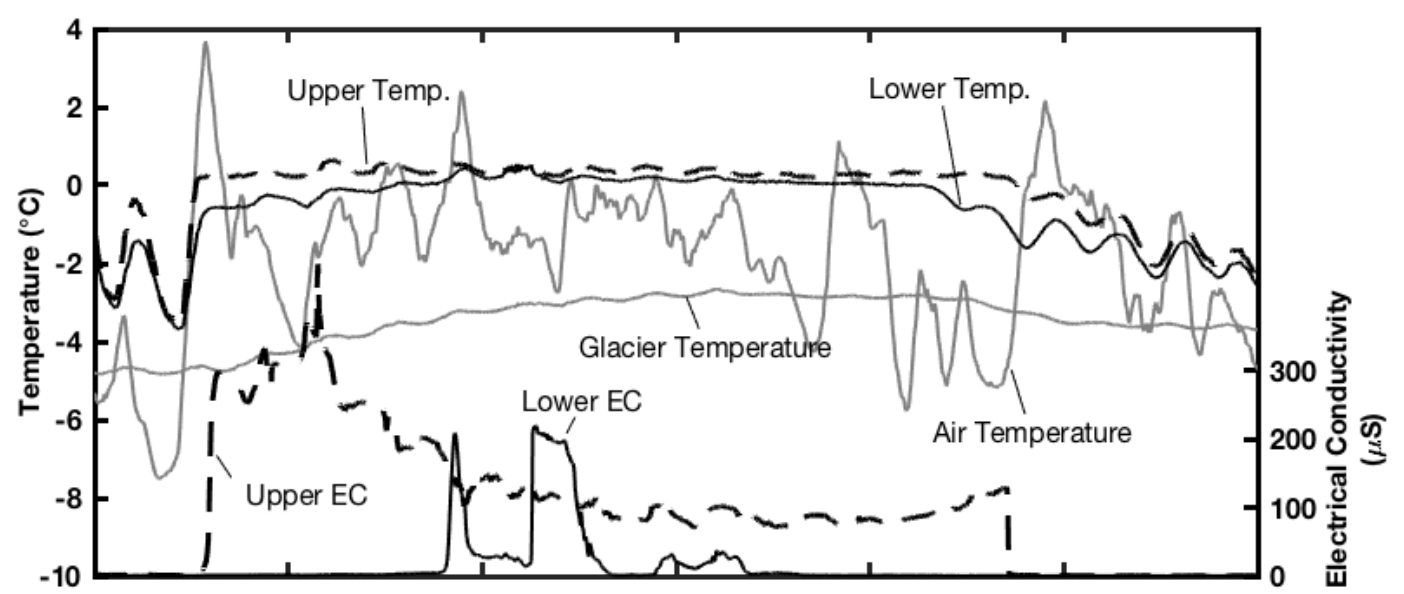

b

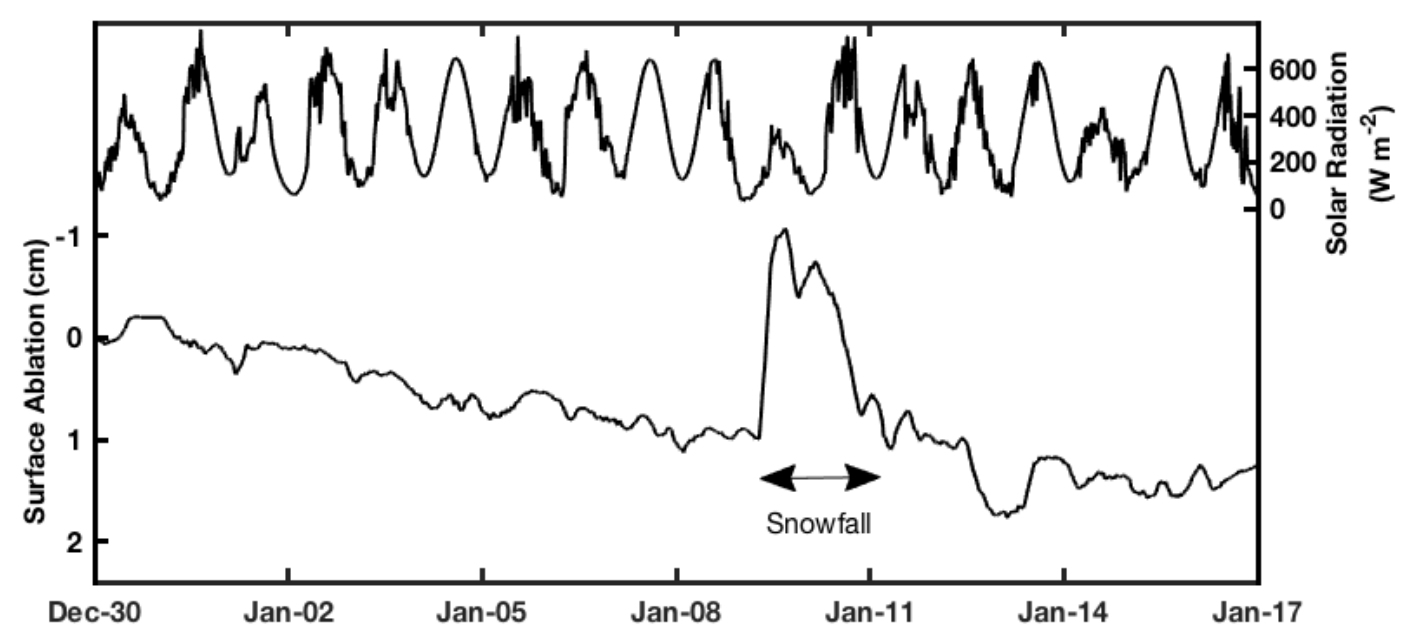

Figure 3.2 Results from a natural cryoconite hole (17-NE01) monitored on Canada

Glacier during the 2017-18 austral summer. Prior to melting, the upper probes were 22 $\mathrm{cm}$ beneath the surface $(1 \mathrm{~cm}$ beneath the cryoconite) and the lower probes were $27 \mathrm{~cm}$ beneath the surface. a) Temperature, electrical conductivity, air temperature and ice temperature $\sim 90 \mathrm{~cm}$ beneath the surface. b) Distance from the sonic ranger to the ice surface, as an indicator of surface ablation and snow, and incoming solar radiation.

The sediment of the artificial holes immediately began melting into the ice surface, like the previous season, despite air and ice temperatures below freezing. The sediments initially descended several centimeters $\left(\sim 1 \mathrm{~cm} \mathrm{day}^{-1}\right)$ for the first few days and slowed as they went deeper. In some of the holes, the sediment deepened up to $4 \mathrm{~cm}$ but ice did not form above, suggesting the meltwater drained into the subsurface. Meltwater at the upper probes was first detected December $31^{\text {st }}$ (Figure 3.3). Initial EC ranged between 50 to 
$2150 \mu \mathrm{S}$ across all the holes but all were less than $200 \mu \mathrm{S}$ after several days. Later in the season, temperatures measured by the upper probes regularly warmed well above the melting point, despite sub-freezing air temperatures, which is likely a result of it not being submerged in meltwater, as discussed below. Elevated EC persisted through midJanuary until falling sharply as the meltwater refroze. In some of the artificial holes, temperatures around the shallower probes fell below freezing first before the deeper probes, while in other holes the opposite was true.

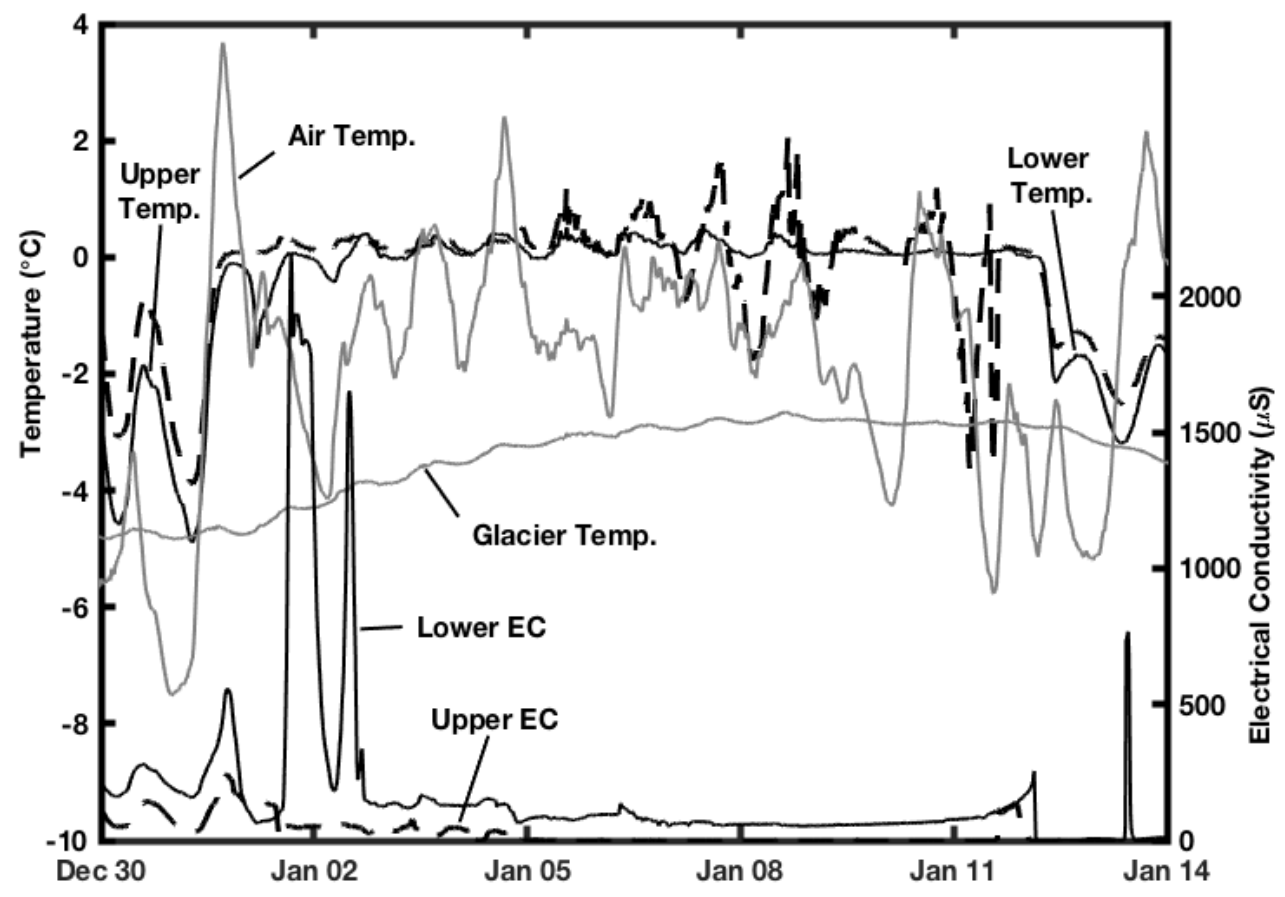

Figure 3.3 Temperature and electrical conductivity measurements in a representative artificial hole. Solid lines correspond to probes in the upper region of the ice and dashed lines correspond to probes in the lower region.

\section{Analysis}

Temperature and EC trends in the natural holes were generally similar. That the timing of melting and refreezing varied between the holes by a matter of days is likely the result of 
the variability of the optical properties of the ice across the study site and of the differences in depth to cryoconite $(1-2 \mathrm{~cm})$. Ice temperature is very responsive to diurnal variations in solar radiation and to longer-term trends in air temperature. These diurnal variations were greatest when temperatures were subfreezing and least when meltwater was present due to the heat capacity of water and phase changes of the ice walls. Snow cover reduces solar radiation transmission into the ice which causes it to cool, as occurred on December 17 $7^{\text {th }}, 2016$ (Figure A.4). In contrast, for meltwater-filled cryoconite holes the water acted as a thermal buffer that stabilized temperatures for multiple days despite decreased variations in energy flux. This is illustrated best by the stable temperatures and persistent meltwater despite a snow accumulation covering the study site on January $9^{\text {th }}, 2018$.

Initial $\mathrm{EC}$ values in most of the artificial holes were 4 to 10 times higher than what they were several days later (Figure 3.3, A.7). A similar behavior is observed in the natural holes but with smaller peak values (Figure 3.2). The higher initial EC values within the artificial holes may be due to increased hydrolysis from the fresh sediments (Bagshaw et al. 2007). Also, because the artificial holes were shallower than the natural holes, more solar radiation would reach the sediments, potentially causing increased photosynthetic activity, further increasing solutes (Stibal and Tranter, 2007). The steadily decreasing EC in the natural and artificial holes when cryoconite holes fully developed in January 2018 likely reflects dilution by the meltwater generated as the sediments melt the ice during hole enlargement. If the holes were hydrologically connected the influx of meltwater from the surrounding ice could further decrease the EC (Fountain et al. 2008). 
The difference in natural hole development between the 2016-17 and 2017-18 seasons is likely a due to differences in ice temperature. Average ice temperatures $\sim 1 \mathrm{~m}$ beneath the surface in 2016 were $-12.5^{\circ} \mathrm{C}$ in early-December and $-6.6^{\circ} \mathrm{C}$ in late December. When the limited melting did occur in late-January 2017 , ice temperatures were $-4.1^{\circ} \mathrm{C}$. By contrast ice temperature was $-6.7^{\circ} \mathrm{C}$ in early-December 2017 and $-4.7^{\circ} \mathrm{C}$ by lateDecember. When the holes developed, temperatures were $-2.7^{\circ} \mathrm{C}$. Differences in air temperature between seasons is small (Table 3.1). The cause of the difference in ice temperatures was the early season (November) snowfall in 2016 compared to later season (December) snowfall in 2017. Although the snow was removed from the study site within several days of each snow event, the surface around the study site remained covered. Because snow fell earlier during the 2016-17 season, less solar heating of the surrounding area resulted in cooler ice, so more heat was conducted away from the ice in the study site.

The artificial holes exhibited greater variation in the timing and magnitude of temperature and EC fluctuations compared to natural holes. This is likely caused by local variations in near-surface ice properties as meteorologic conditions are uniform over the study site. Observations when drilling into the ice suggest bulk density, a function of bubble content and porosity, vary at spatial scales of $0.1 \mathrm{~m}$ and decrease with depth. The drill easily passed through some ice, which was less dense, but had difficulty with other ice, which was denser. In some cases, the water used to fill the drill holes immediately filled the hole, while in others the water continually drained from the hole. These produce local variations in the optical and physical properties of the ice that affect hole development 
(Brandt and Warren, 1993; Liston et al. 1999). For the holes that diurnally cycled between melting and freezing, it may be that ice was porous, draining the melt into the ice below, which can be common in the shallow weathering crust of glaciers (Hoffman et al. 2014). In these cases the lack of stored meltwater precludes a thermal buffer, allowing temperature and EC to fluctuate more. Indeed, in some of the artificial holes as they initially melted in, sediment had descended $\sim 4 \mathrm{~cm}$ with no ice formed above it, suggesting the meltwater had drained. It would be expected that this also occurs as cryoconite holes establish themselves naturally on the surface, depending on the bulk density of the ice on which the cryoconite is deposited. This behavior is not observed with the measured natural holes because they have already established their equilibrium depth where they have been filled with meltwater, refrozen, then melted out again.

\subsection{Laboratory Results}

The purpose of these experiments was to recreate cryoconite holes in a laboratory setting to characterize the influence of key meteorologic variables on hole evolution. The ice blocks used in the laboratory experiments exhibit different radiation attenuation than observed in the field (Figure 3.4). Like the field results it attenuated exponentially as ice thickness increased, consistent with expectations (Brandt and Warren, 1993). Radiation attenuated through the laboratory ice blocks more slowly compared to that measured on Canada Glacier (Hoffman et al., 2008; this season) and similar data collected during the 2016-17 field season (Appendix A). Although adding mylar increased the transmission of radiation beyond what occurs in natural ice, it was applied to $1 / 4$ of the circumference of 
the ice blocks to enhance volume scattering (Figure 3.5) since the narrow diameter of the blocks potentially diminished it from what would otherwise occur on Canada Glacier.

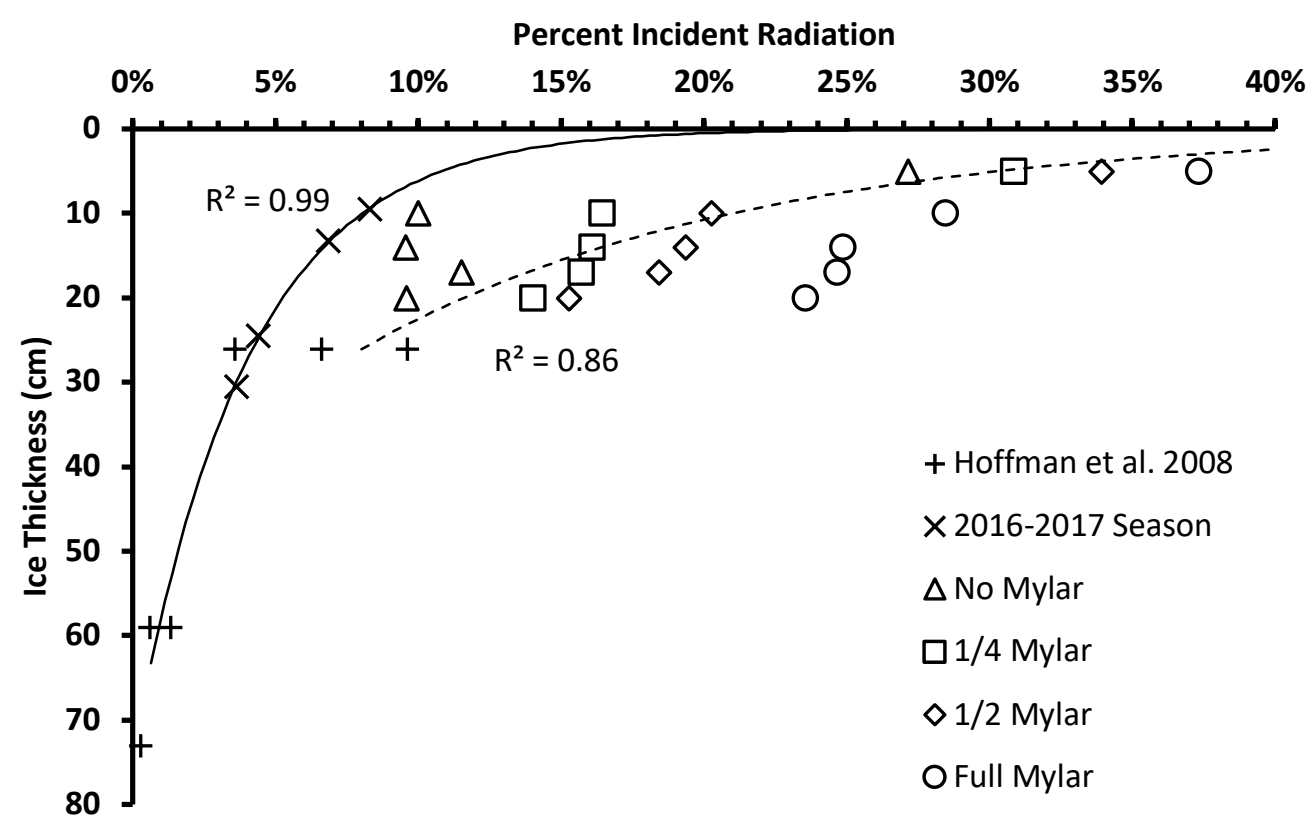

Figure 3.4 Percentage of incident radiation intensity for a given thickness of laboratory ice and field measurements from Canada Glacier. The solid line is a regression line through the 2016-2017 field data and the dashed line is for the laboratory ice with $1 / 4$ mylar applied to the outside.

Measurements of scattered radiation made $10 \mathrm{~cm}$ from the lamp-facing end of a $20 \mathrm{~cm}$ ice block show that average forward-scattered radiation was more than double backscattered radiation, as expected (Figure 3.5). The value of forward scattered radiation for ice with no mylar is unexpectedly larger than the trend displayed by the rest of the data, likely due to a spurious measurement. According to the trend in the data it should be about $15 \%$ of the open-air radiation flux. Full mylar coverage increased the scattered radiation approximately 2 to 3 times that of bare ice in any given direction. 


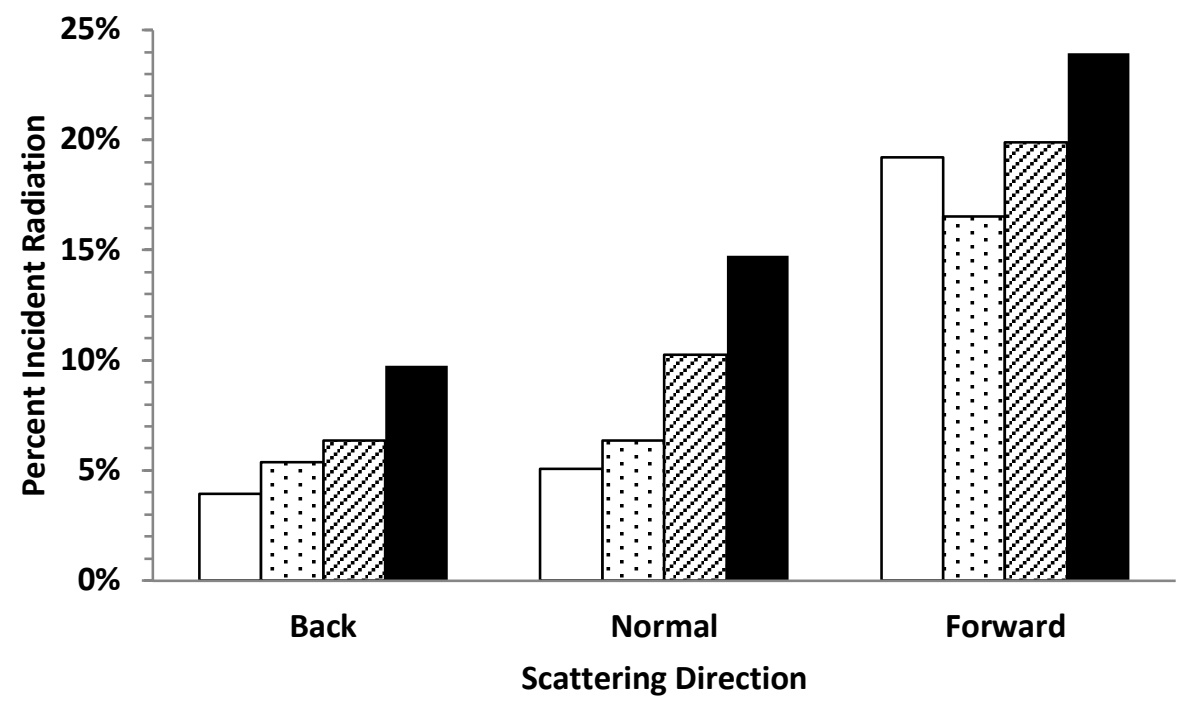

Figure 3.5 The fraction of scattered radiation relative to the open-air radiation intensity for bare ice (open bar), $1 / 4$ mylar coverage (dotted bar), $1 / 2$ mylar coverage (hashed bar), and full mylar coverage (solid bar). Scattering was measured at a point $10 \mathrm{~cm}$ along a 20 $\mathrm{cm}$ long ice block positioned $30 \mathrm{~cm}$ from the lamp.

\section{Hole development}

Once the sediment is deposited on the ice the surface temperature warms above the melting point within minutes, consistent with rapid deepening in the field (Figure 3.6). The sediment darkens as it saturates with meltwater, decreasing its albedo. Maximum sediment temperatures at the surface reached as high as $+2.6^{\circ} \mathrm{C}$ under a light intensity of $365 \mathrm{~W} \mathrm{~m}^{-2}$. As sediments descended into the ice, covered by a column of meltwater, and passed the temperature probes placed at $5 \mathrm{~cm}$ depth, maximum sediment temperatures reached $+1.5^{\circ} \mathrm{C}$. The diameter of the sediment decreased from its maximum at the surface of $10 \mathrm{~cm}$ to about $5 \mathrm{~cm}$ as it deepened, and the sediments thickened from $\sim 0.2 \mathrm{~cm}$ to about $1 \mathrm{~cm}$. Generally, the ice lid formed about the time the sediments reached their equilibrium depth. When the ambient temperature in the freezer was above $-4^{\circ} \mathrm{C}$, the ice lid formed before the sediment reached equilibrium depth (Figure 3.6). At colder 
temperatures, the formation of the ice lid halted sediment deepening but the hole would remain water-filled or refroze. Unlike field conditions the lack of air flow over the surface greatly reduces turbulent heat exchange and limited the capacity of the lid to form. Apparently $-4^{\circ} \mathrm{C}$ is on the threshold of refreezing the cryoconite hole and perhaps small differences in bubble content of the ice, lateral migration of the sediment, and thickening of sediment may decrease radiative heating sufficiently to favor refreezing.

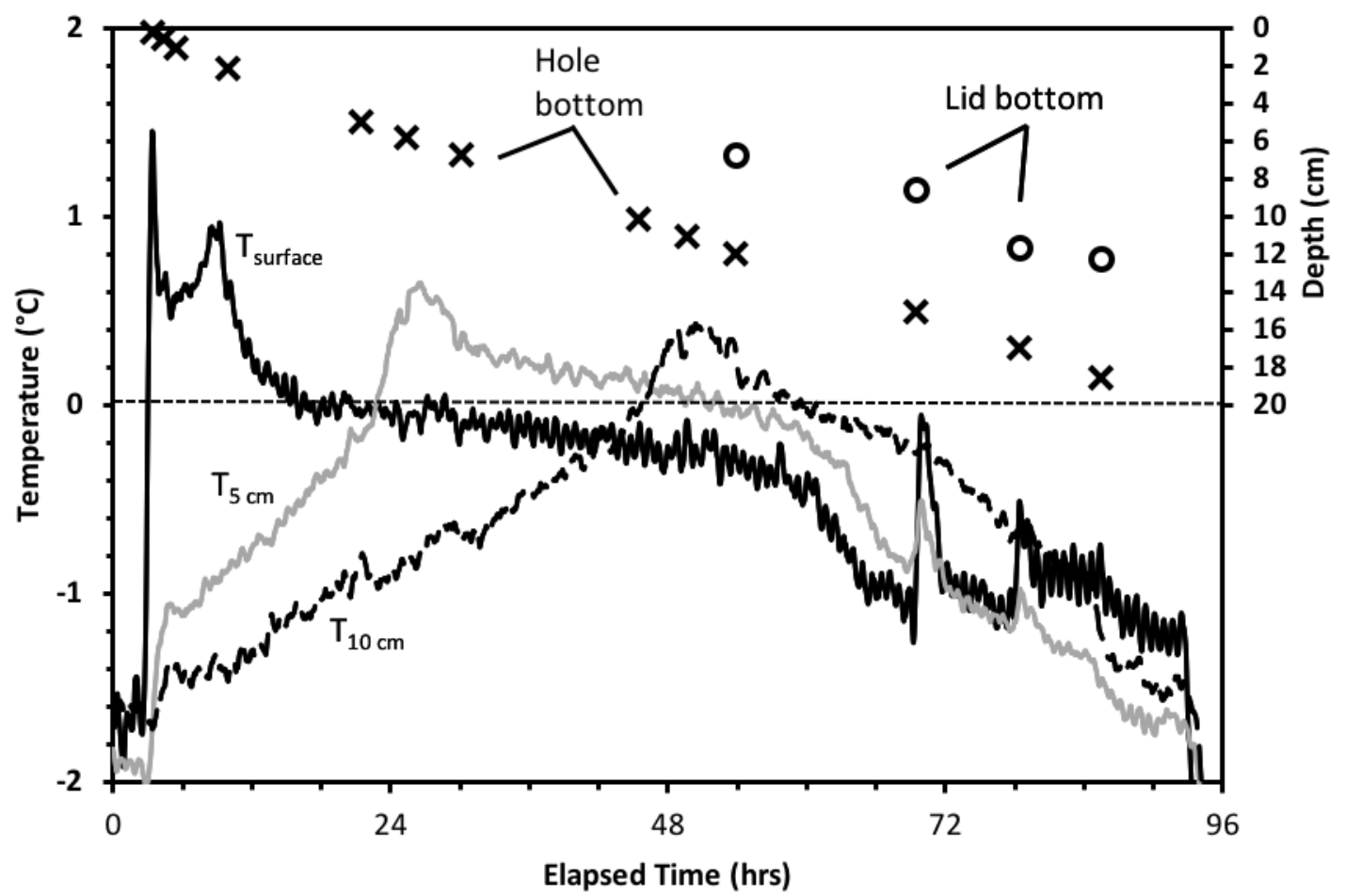

Figure 3.6 Conditions in a laboratory cryoconite hole. Air temperatures averaged $-3^{\circ} \mathrm{C}$. The sediments melted out of the side of the ice before reaching equilibrium. Temperature spikes toward the end of the experiment occurred during manual measurements. In this experiment the sediment melted out of the side of the block before they had achieved equilibrium.

As expected, equilibrium depth generally increased as incident radiation increased (Figure 3.7). In some cases the sediments did not deepen in response to the increased 
radiation (Figure 3.7; Table B.4). When this occurred an ice lid had formed and often, but not always, the entire hole froze. It is likely that the ice lid inhibited radiation transmission to the sediments so when the block was raised the radiation absorbed by the sediments was not enough to warm them sufficiently to melt the underlying ice. In other

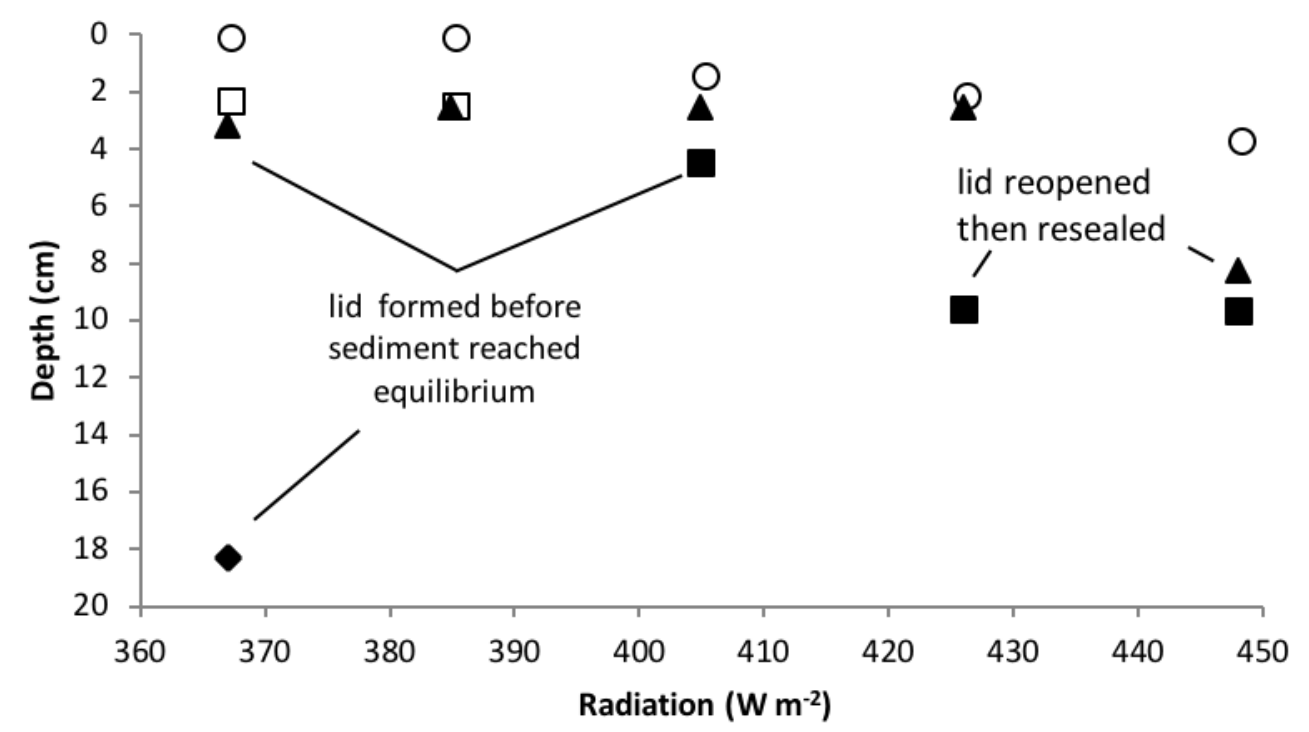

Figure 3.7 Equilibrium depth of sediment versus the incident shortwave radiation intensity at the ice surface for ambient air temperatures of $-10^{\circ} \mathrm{C}$ (circles), $-5^{\circ} \mathrm{C}$ (squares), $-4^{\circ} \mathrm{C}$ (triangles), and $-3^{\circ} \mathrm{C}$ (diamond). Mylar covered $1 / 4$ of the ice block. The results of the when the air temperatures were $-4^{\circ} \mathrm{C}$ did not align with expectation, as explained in text. Filled symbols indicate the presence of an ice lid.

cases, formation of the ice lid did not prevent the sediment from descending or the sediment had reached equilibrium and the hole meltwater did not freeze. The most consistent experimental results were achieved when the ice lid had not formed, and the sediments consistently deepened as radiation increased. This dual behavior occurred despite careful duplication of the experimental arrangement and identical air temperatures (Table B.4). 
Equilibrium depth also increased, generally, with increases in air temperature, which controlled ice temperature (Figure 3.7). When temperatures were $-10^{\circ} \mathrm{C}$ and radiation was least intense the sediment did not melt the ice. Incremental changes in equilibrium depth in response to increased radiation were greater with warmer temperatures. The pattern of equilibrium depth for ambient air temperatures of $-4{ }^{\circ} \mathrm{C}$ is odd. During this experiment the sediments deepened quickly and contracted so that it was about $5 \mathrm{~cm}$ in diameter and $2 \mathrm{~cm}$ thick. This thickness may have insulated the base of the sediment, explaining why the hole to froze from the bottom up. The base of the sediment was sufficiently insulated that it did not begin melting again until the radiation was at its maximum.

\subsection{Model Results \& Analysis}

The model adapted from Hoffman et al. (2014), was modified to predict the evolution of cryoconite holes in the MDV. Field observations from previous studies provided constraints to optimize the model. The data collected during the 2016-17 and 2017-18 field seasons were not used to optimize the model because direct measurements of hole dimensions during melting could not be collected and the extensive snow altered the timing and extent of melting, which is not adequately accounted for by the model. Rather, the model was tested against field observations measured in the austral summers of 2005-06 (Fountain et al., 2008). During those seasons snowfall was minimal and cryoconite holes developed completely. They measured cryoconite depth, hole temperature, EC, and surface ablation. 
The model was optimized by adjusting $\chi, r_{e f f}$ and $z_{0}$ so that modeled cryoconite depth and surface ablation most closely matched field observations (Table 3.2). While both models optimize ablation, the model of Hoffman et al. (2014) optimizes ice temperatures whereas I optimize subsurface melting. The model of cryoconite evolution calculated sediment depths, rates of deepening, and surface ablation similar to what has been measured in the MDV (Figure 3.8) using the parameters reported in Table 3.2, which are relatively similar to those applied by Hoffman et al. (2014). The differences in the adjustable parameters most likely result from local versus regional application. For cryoconite holes, the model considers at most a $0.5 \mathrm{~m}$ radius over one year whereas Hoffman et al. (2014) applied the model simultaneously to multiple glaciers across the MDV over 14 years. Their parameters result in different magnitudes of melting and surface ablation.

Table 3.2 Comparison of adjustable model parameters as optimized in this and previous studies. $\mathrm{C}=$ cryoconite deepening, $\mathrm{T}=$ ice temperature, $\mathrm{A}=$ ablation

\begin{tabular}{|c|c|c|c|c|}
\hline Version & $\mathrm{r}_{\mathrm{eff}}(\mathrm{mm})$ & $\mathrm{z}_{0}(\mathrm{~mm})$ & $x$ & Calibrated using \\
\hline This Study & 0.065 & 0.1 & 0.14 & C, A \\
\hline $\begin{array}{l}\text { Hoffman et al. } 2014 \\
\text { (Drainage version) }\end{array}$ & 0.015 & 0.01 & 0.24 & $\mathrm{~T}, \mathrm{~A}$ \\
\hline Hoffman et al. 2008 & 0.24 & 0.25 & 0.82 & A \\
\hline
\end{tabular}

After it was optimized, the model was ran for the 2003-04, 2005-06, 2016-17, and 201718 summers. Here, model results are compared to field measurements from the 2005-06 summer because they provided the most comprehensive data set. Modeled cryoconite evolution for the 2003-04 and 2017-18 austral summers was similar (Appendix C). The model results for the 2016-17 summer were unfavorable, for reasons discussed later. 


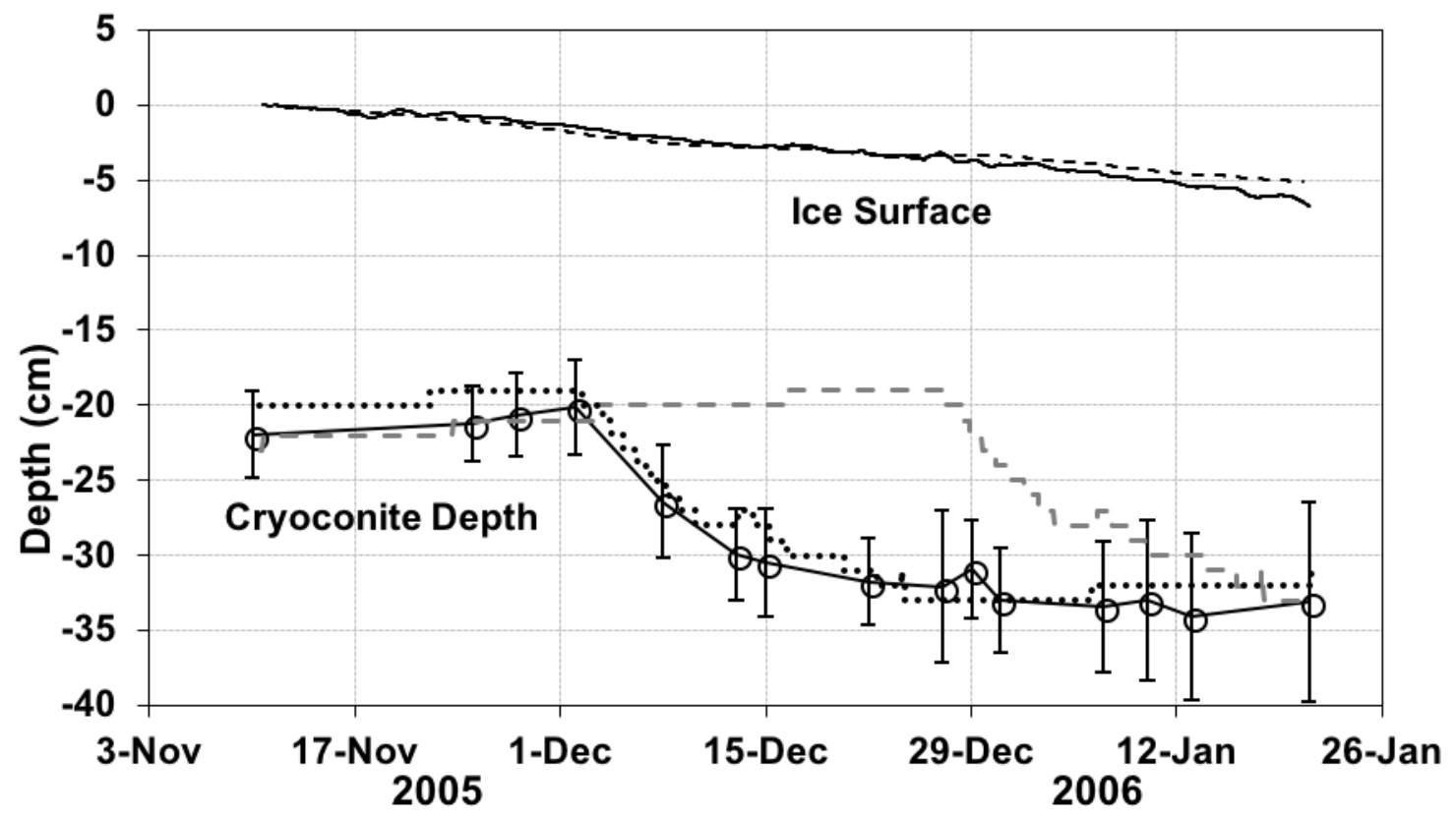

Figure 3.8. Modeled cryoconite depth and surface ablation compared to the 2005-2006 measurements (Fountain et al. 2008). Measured values are solid lines, modeled values are dashed lines. The dotted line is the modeled cryoconite depth adjusted so that melting begins at the same time as measured in the field. The stepped nature of the hole bottom occurs because the cryoconite depth is adjusted in $1 \mathrm{~cm}$ increments.

Solar energy is preferentially absorbed at the surface and by the cryoconite at depth (Figure 3.9a). Beginning November $1^{\text {st }}, 2005$, modeled ice temperatures $15 \mathrm{~cm}$ beneath the surface were $-12.6^{\circ} \mathrm{C}$ compared to measurements of $-13.5^{\circ} \mathrm{C}$ at the Canada Glacier meteorological station (McMLTER). The warmer modeled temperatures are an effect of the simulated cryoconite, discussed later. By mid-November modeled ice temperatures $15 \mathrm{~cm}$ beneath the surface fluctuated diurnally between $-3^{\circ} \mathrm{C}$ and $-7^{\circ} \mathrm{C}$, similar to field observations of $-2^{\circ} \mathrm{C}$ and $-7{ }^{\circ} \mathrm{C}$ (Fountain et al. 2008). Modeled subsurface temperatures reached the melting point in early-December (Figure 3.9b), about the same day it was measured. The water fraction in the ice around the cryoconite continued to increase, as more ice melted during the day than water froze overnight, until it completely melted in 
late-December when the sediment was $19 \mathrm{~cm}$ deep. A $\sim 3 \mathrm{~cm}$ lens meltwater formed about $8 \mathrm{~cm}$ above the cryoconite the same time as it formed immediately above the cryoconite. The two lenses of meltwater merged several hours before the sediment
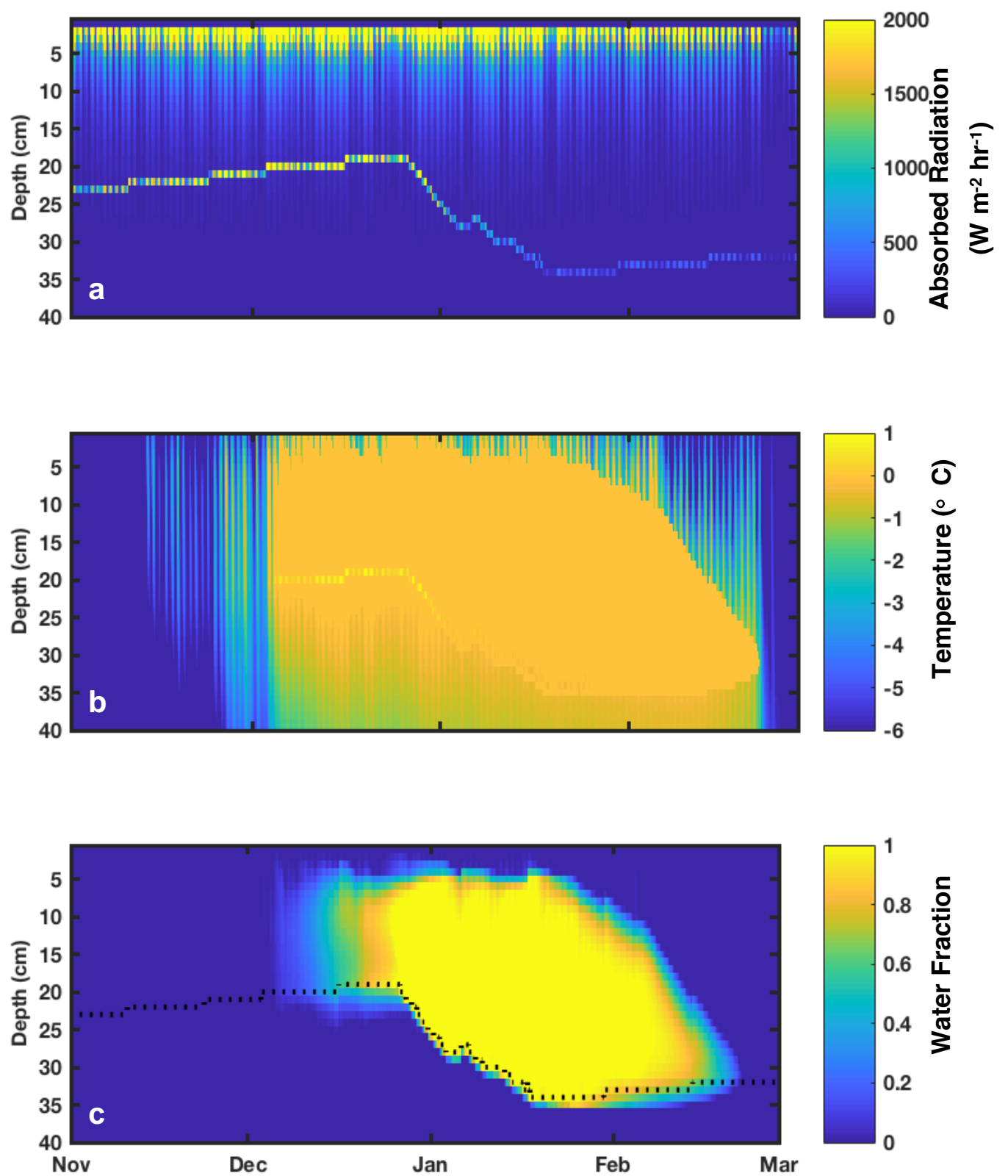

Figure 3.9. Modeled subsurface conditions over the 2005-06 austral summer.

a) Absorbed radiation b) Temperature c) Water fraction within subsurface. A water fraction of 1 represents $100 \%$ meltwater and a water fraction of 0 represents a cell of $100 \%$ ice. The dotted line represents the location of the cryoconite. 
began descending on December $27^{\text {th }}$. Notably, the model predicted the hole formed and sediment deepened 24 days after it began in the field (Figures 3.8, 3.9c). Modeled meltwater temperatures within the hole were not allowed to warm above $0^{\circ} \mathrm{C}$, consistent with field measurements. The initial modeled rate of sediment deepening was $1.5 \mathrm{~cm} \mathrm{~d}^{-1}$. A week later, at a depth of $25 \mathrm{~cm}$ the rate of sediment lowering slowed to $0.3 \mathrm{~cm} \mathrm{~d}^{-1}$ at a depth of $28 \mathrm{~cm}$. In mid-January the sediment reached an equilibrium depth of $33 \mathrm{~cm}$ when the descending rate matched the ablation rate of $\sim 0.1 \mathrm{~cm} \mathrm{~d}^{-1}$. At that time the ice lid was $7 \mathrm{~cm}$ thick and the meltwater filled hole was $26 \mathrm{~cm}$ tall (Figure 3.9c).

In mid-January the hole began freezing from the top down at a rate of $0.03 \mathrm{~cm} \mathrm{hr}^{-1}$. By late-January ablation began outpacing cryoconite deepening and the depth to cryoconite decreased. On February $6^{\text {th }}$, top down freezing accelerated to $0.1 \mathrm{~cm} \mathrm{hr}^{-1}$ and the last of the hole water $5 \mathrm{~cm}$ above the sediment froze on February $8^{\text {th }}$, although field measurements indicate this happened January $11^{\text {th }}$. The rate of freezing from the ice-lid down outpaced freezing from the bottom as the sediment continued to absorb solar energy. Finally, cryoconite was last to completely freeze (water fraction $=0$ ) on February $22^{\text {nd }}$.

The energy balance shows that the largest component of energy input is solar radiation, $Q_{s i}($ Figure 3.10). Periods of increased solar radiation correspond to hole expansion and melting. Similarly, periods of decreased solar radiation caused the rate of lowering to slow and the hole to contract, as modeled in early January 2006 (Figure 3.9c). Broadly, the hole melted and deepened as solar radiation intensity peaked on December $21^{\text {st }}$, 
through to mid-January when the average daily solar radiation was less than $300 \mathrm{~W} \mathrm{~m}^{-2}$, after which the hole ceased deepening and began to refreeze. The other components of the energy balance remained relatively constant throughout the summer. Energy losses from turbulent exchange $\left(Q_{h}\right.$ and $\left.Q_{e}\right)$ were $<-100 \mathrm{~W} \mathrm{~m}^{-2}$ most of the summer. Surface ice was typically warmer than the air. Similarly, $Q_{e}$ was negative because vapor pressure at the surface was higher and the surface is constantly sublimating. Net longwave $\left(Q_{l e}, Q_{l i}\right)$ averaged $-100 \mathrm{~W} \mathrm{~m}^{-2}$ until the subsurface water froze and outgoing longwave decreased. Heat conduction, $Q_{c}$, averaged $100 \mathrm{~W} \mathrm{~m}^{-2}$, being lowest when subsurface temperatures were cool and there was no meltwater, and highest when subsurface temperatures were warm and meltwater was abundant.

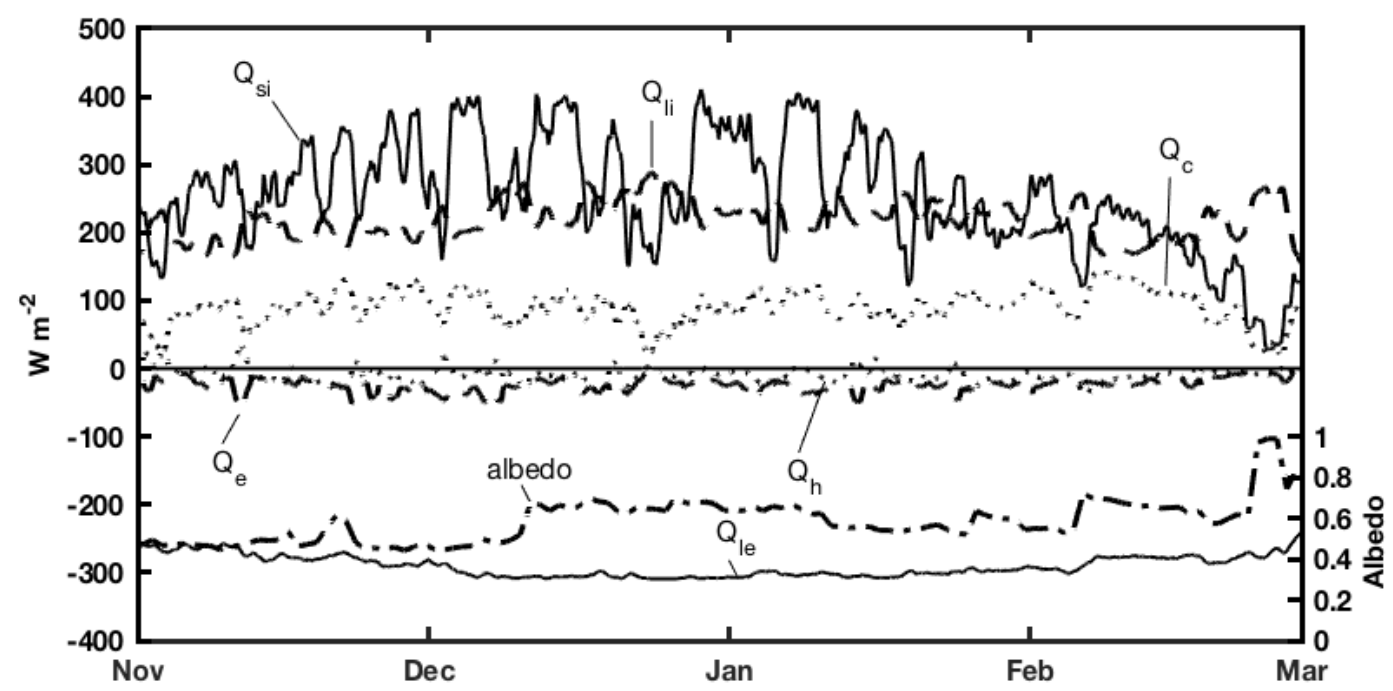

Figure 3.10. Surface energy balance over the 2005-2006 austral summer averaged daily. $\mathrm{Q}_{\text {si }}$ is solar radiation, $\mathrm{Q}_{\mathrm{li}}$ is incoming longwave radiation, $\mathrm{Q}_{\mathrm{le}}$, is emitted longwave radiation, $\mathrm{Q}_{\mathrm{h}}$ is sensible heat, $\mathrm{Q}_{\mathrm{e}}$ is latent heat, and $\mathrm{Q}_{\mathrm{c}}$ is conducted heat. The solid line that is constantly 0 is $Q_{m}$. Positive values indicate downward energy flux.

The modeled equilibrium depth of cryoconite holes on Canada Glacier ranged between $25-35 \mathrm{~cm}$, in agreement with previous studies (Fountain et al., 2004, 2008; Porazinksa 
et al. 2004). Generally, the model tended to predict melting sooner and freezing later than observed (except for early-summer 2005-06). For the 2003-04 summer, the model predicted hole melting about 3 weeks sooner (Figure C.2; Fountain et al. 2008). In the 2017-18 model run, subsurface melting began about a week sooner than observed and the meltwater refroze two weeks later than observed. For all modeled years meltwater did not refreeze until early-February, 1 to 3 weeks after observed. The one-dimensional model may overestimate the duration of meltwater presence because it does not account for lateral heat loss to the surrounding ice which is generally $1-2^{\circ} \mathrm{C}$ cooler, according to modeled temperatures that do not include cryoconite (discussed later). Finally, the model does not account for head space between the top of the water column and the ice lid, which may alter the vertical heat transfer by insulating the top of the water column from the ice above.

The pattern of development illustrated in Figures 3.8 and 3.9 highlight the two mechanisms by which cryoconite holes form. First, as the warm sediment melts the underlying ice and migrates downward, the area it previously occupied is replaced by the meltwater except near the surface where it refreezes (Fountain et al., 2008). Secondly, for cryoconite already frozen in the ice melting expands upward and downward enlarging the hole both ways. The majority of refreezing occurs from top down. Continually absorbing solar radiation, the cryoconite freezes last. 
2016 - 2017 Model Results

Unlike the 2005-06 season, extensive snow cover was present in both the 2016-17 and 2017-18 seasons and the ice was swept to perform the experiments. Albedo input for the 2016-17 and 2017-18 model runs was adjusted to reflect when the snow was removed from the study site. The surface albedo of the site was not measured after it was swept, so a value of 0.56 was applied, as used elsewhere (Hoffman et al., 2008). The 2017-18 model results (Figure C.4) resembled that of 2005-06 although the delay between modeled melt onset and measured was only a week. The 2016-17 model results did not match field observations.

In early-December 2016 , modeled sediment temperatures were $-1^{\circ} \mathrm{C}$, about $7^{\circ} \mathrm{C}$ warmer than field measurements. The model predicted that the hole began melting out in lateDecember, about three weeks before EC measurements indicate melting. The model predicted temperatures remained at the melting point through early-February and the cryoconite hole was melted the entire time, in contrast to the daily cycle of melting and refreezing described above.

The model likely predicted full cryoconite hole development in contrast to observations because of limitations in how the model accounts for snow. Snow fell on Canada Glacier in mid-November but was swept from the study site three days afterward which was reflected in the model input. Therefore, the input albedo reflected a snow-free environment the majority of summer and the modeled cryoconite hole developed completely. In reality, snow was not removed from the ice surrounding the site and ice temperatures were cool because solar heating was limited. Because the snow covered the 
glacier sooner in 2016-17, less solar heating occurred and measured ice temperatures were cooler than in 2017-18, as discussed in Section 3.1, so complete development of the cryoconite holes did not occur. Given these issues the model would not be expected to perform well under these conditions.

To examine the effect of the cryoconite on the temperature of the subsurface ice the model was reran for the 2005-06 summer without cryoconite and its results subtracted from model output with the cryoconite. The presence of cryoconite enhanced melt in the subsurface compared to the cryoconite-free model. The cryoconite absorbed as much as 25 times more radiation than the ice (Figure 3.11a). Radiation absorption in the ice was unchanged because the optical properties remain unaltered. The cryoconite was warmer than the ice for almost the entire summer (Figure 3.11b). In November, temperatures of the cryoconite were $1-3^{\circ} \mathrm{C}$ warmer than ice without cryoconite. Melting began almost 15 days sooner in the cryoconite model than in the cryoconite-free model When melting does occur in both, there is no difference in modeled temperatures between the regions where both predicted melt. In the cryoconite model, the hole is $26 \mathrm{~cm}$ at its maximum with a $7 \mathrm{~cm}$ ice lid. By comparison, in the cryoconite-free model, the maximum extent of subsurface melting is $\sim 19 \mathrm{~cm}$ beneath the surface, but it is only partial melt with a water fraction no greater than 0.3 . Melting extended more than $14 \mathrm{~cm}$ deeper in the cryoconite model than predicted by the cryoconite-free model. With the cryoconite, the presence of meltwater extended further into the summer and kept the ice above and below the hole warmer. That the difference between subsurface temperatures increased later in the summer reflects that temperatures in the ice model cooled sooner once water froze. The 
presence of the meltwater in the cryoconite hole acts as a reservoir of thermal energy. In the cryoconite model, melt persisted almost 4 weeks later, although this was likely longer than what occurs naturally, for the reasons discussed previously.
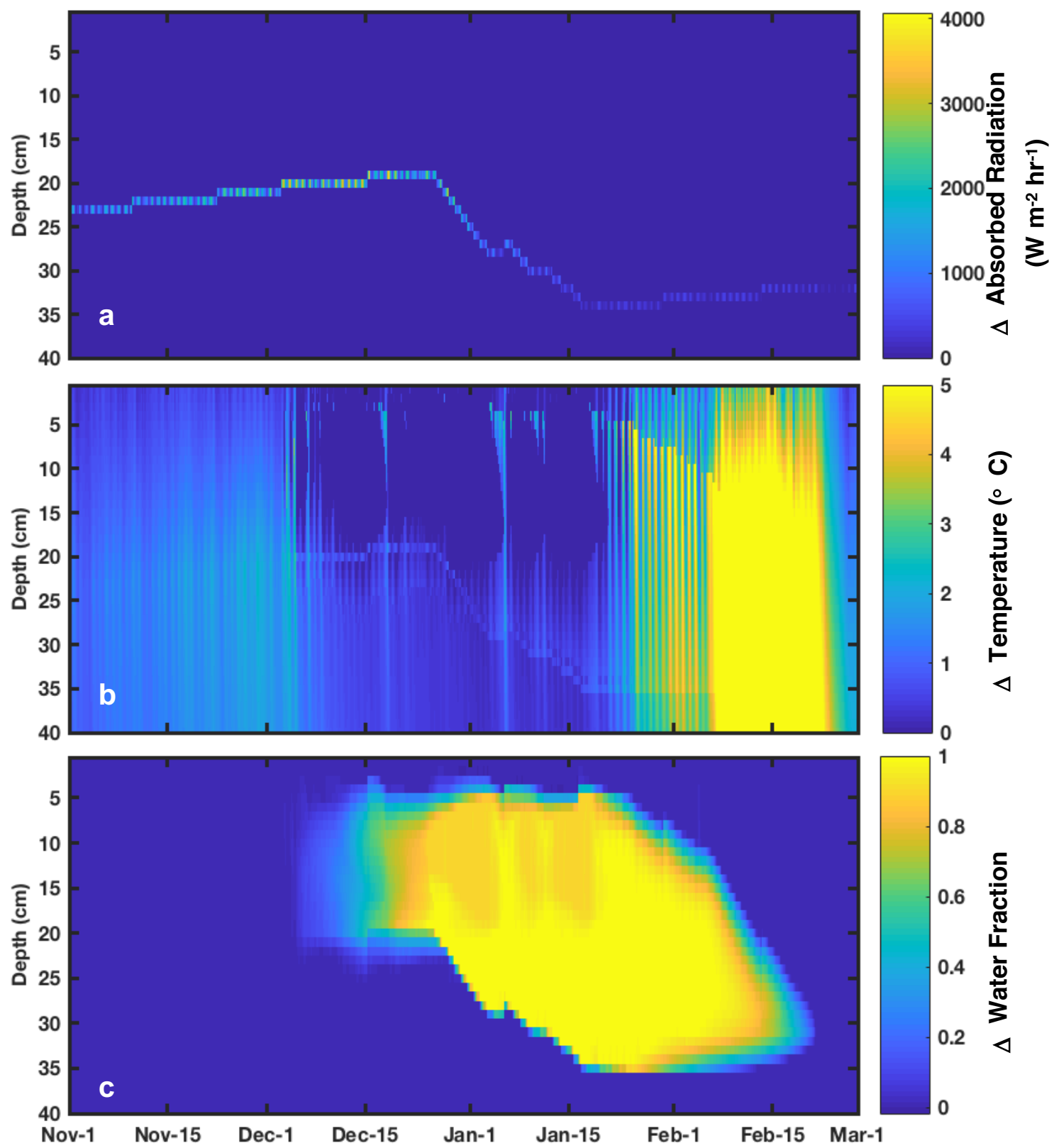

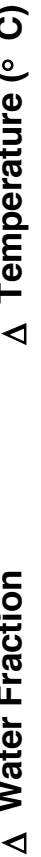

Figure 3.11 Difference in modeled subsurface conditions over the 2005-06 austral summer calculated by the cryoconite model and the cryoconite-free model for a) absorbed radiation b) temperature and c) water fraction. 


\section{Model Sensitivity}

To understand the sensitivity of the model to changes in the physical parameters of the ice and to the driving meteorologic variables, additional model runs were performed for the 2003-04 and 2005-06 summers. For these tests, one environmental parameter $\left(\chi, r_{\text {eff, }}\right.$, $\left.\mathrm{z}_{0}\right)$ or meteorologic variable $\left(T_{a i r}, u_{r}, \alpha\right)$ was altered while the others were kept at their original optimized values. Metrics for evaluation of these changes include the timing of thawing/freezing of the sediment cell, the depth of the sediment, and the height of the meltwater filled hole.

The model sensitivity for the 2005-06 summer is discussed here. Changes to $r_{\text {eff }}$ and $z_{0}$ produced the largest changes to cryoconite hole development (Table 3.3, Appendix Table C.1 for 2003-04). Decreasing reff by $0.015 \mathrm{~mm}$ (increasing scattering) delayed cryoconite deepening by several days and caused it to refreeze about one week sooner, so the overall duration was shorter by two weeks. Conversely, increasing $\mathrm{r}_{\text {eff }}$ by $0.015 \mathrm{~mm}$ caused the cryoconite to thaw about one week sooner but refreeze only one day later. The average cryoconite depth when the hole developed was $4 \mathrm{~cm}$ shallower for decreased $\mathrm{r}_{\text {eff }}$ and $2 \mathrm{~cm}$ deeper when increased. While the maximum cryoconite hole height decreased and increased alongside $\mathrm{r}_{\mathrm{eff}}$, the average hole height was $1 \mathrm{~cm}$ shorter for increased $\mathrm{r}_{\mathrm{eff}}$, possibly because the cryoconite descended deeper into the subsurface.

Changes to $\mathrm{z}_{0}$ (surface roughness), which was increased and decreased by an order of magnitude, changed the ablation rate which increased with increased $\mathrm{z}_{0}$ and vice versa. Higher roughness caused the cryoconite to be closer to the surface at the start of the austral summer, making it more prone to solar heating. Thawing and refreezing both 
occurred about a week sooner when roughness was increased, but no significant change was predicted when it was decreased. The rougher surface also caused the cryoconite to shallow more and form shorter cryoconite holes. When roughness was decreased, the cryoconite descended deeper into the surface and developed taller cryoconite holes. In this scenario, the rate of cryoconite deepening only kept pace with ablation when it was closer to the surface and absorbed more radiation. Conversely, when the surface was smoother and ablation was less, the rate of cryoconite deepening outpaced ablation so it descended deeper into the surface and taller cryoconite holes formed.

In regard to meteorologic variables, changes to $\mathrm{T}_{\text {air }}$ of $\pm 1^{\circ} \mathrm{C}$ produced notable changes in cryoconite hole development. With decreased $\mathrm{T}_{\text {air }}$ the cryoconite depth and hole height decreased, and thawed later and refroze sooner. While increased air temperatures caused the cryoconite to thaw sooner, it did not necessarily refreeze later, likely because the cryoconite is deeper in the ice by the end of summer, when solar heating would be insufficient to maintain above-freezing temperatures despite the increased heat flux. Decreased surface albedo caused the cryoconite hole to thaw sooner and freeze later and the cryoconite descended deeper into the ice with taller columns of meltwater. When albedo was increased, the window of melting was shorter and the cryoconites were shallower, with shorter cryoconite holes. This affect was expected, since albedo affects the total radiation flux into the ice. While altering the wind speed did produce some changes to hole development, they were relatively minor and are likely more reflective of the effects of ablation on cryoconite hole development. 
Table 3.3 Sensitivity analysis of 2005-2006 model run. Parameters of ptimized model run are $r_{\text {eff }}=0.065 \mathrm{~mm}, Z_{0}=0.1 \mathrm{~mm}, \chi=0.14$ with no air temperature, wind speed $\left(u_{\mathrm{r}}\right)$, or albedo $(\alpha)$ offsets applied. Thaw was the day the water fraction reached 1 , while refreeze was the day the water fraction decreased below $1 . \mathrm{z}_{\text {sed }}$ is the cryoconite depth $(\mathrm{cm}) . \mathrm{h}$ is the meltwater-filled hole height $(\mathrm{cm})$. Melt duration is in days.

\begin{tabular}{|c|c|c|c|c|c|c|}
\hline & Observed & Optimized & & $\mathrm{mm}$ ) & & \\
\hline & & & -0.015 & +0.015 & 0.01 & 1.0 \\
\hline Thaw & Dec. 12 & Dec. 26 & Dec. 30 & Dec. 18 & Dec. 26 & Dec. 14 \\
\hline Refreeze & Jan. 21 & Feb. 5 & Jan. 26 & Feb. 7 & Feb. 7 & Jan. 27 \\
\hline $\begin{array}{l}\text { Melt } \\
\text { Duration }\end{array}$ & 49 & 41 & -14 & +10 & +2 & +3 \\
\hline Min. $z_{\text {sed }}$ & 33 & 19 & -1 & 0 & +2 & -8 \\
\hline Max. $z_{\text {sed }}$ & 20 & 33 & -3 & +2 & +3 & -3 \\
\hline Avg. $z_{\text {sed }}$ & 34 & 29.8 & -4.3 & +1.0 & +3.3 & -6.2 \\
\hline Max. h & - & 27 & -1 & +2 & +3 & -4 \\
\hline Avg. $\mathrm{h}$ & - & 18.8 & +1.5 & -1.5 & +3.8 & -2.4 \\
\hline & $\mathbf{T}_{\text {air }}$ & & $u_{r}(m$ & & & \\
\hline & $-1.0 \mathrm{C}$ & $+1.0 \mathrm{C}$ & $-10 \%$ & $+10 \%$ & -0.05 & +0.05 \\
\hline Thaw & Dec. 28 & Dec. 22 & Dec. 27 & Dec. 23 & Dec. 24 & Dec. 28 \\
\hline Refreeze & Jan. 27 & Feb. 7 & Feb. 5 & Jan. 29 & Feb. 6 & Jan. 31 \\
\hline Duration & -11 & +6 & -1 & -2 & +3 & -7 \\
\hline Min. $z_{\text {sed }}$ & -1 & 0 & +1 & -1 & 0 & +1 \\
\hline Max. $z_{\text {sed }}$ & -3 & +4 & +1 & -1 & +1 & -1 \\
\hline Avg. $z_{\text {sed }}$ & -4.5 & +2.8 & +0.7 & -5.8 & +0.5 & -1.0 \\
\hline Max. h & -4 & +5 & -2 & -1 & +3 & -3 \\
\hline Avg. $\mathrm{h}$ & -1.5 & +3.2 & +1.0 & -2.6 & +1.2 & -2.1 \\
\hline
\end{tabular}




\section{Chapter 4 Discussion}

\section{Field observations}

The cryoconite holes did not fully develop during the 2016-17 and 2017-18 seasons compared to previous summer (2003-04, 05-06) because of snow accumulations. Although the snow was cleared soon after each storm, the snow surrounding the cleared site kept that ice cooler, causing lateral heat conduction from the site. A similar effect was observed in the laboratory. When an exceptionally large ice block was only partially illuminated by the lamp, sediments melted in a fraction of the depth they did compared to a narrower block of ice that was fully illuminated. The cryoconite holes developed further during the 2017-18 season than in the 2016-17 because snow fell later, so solar heating warmed the ice more before the snow fell later in the season.

Observations and measurements of cryoconite holes in 2017-18 were generally similar to those reported previously (Fountain et al., 2004, 2008). In early November, the temperatures around the sediment followed the diurnal pattern of solar radiation, warming as the solar zenith and air temperature continued to increase. In earlyDecember as the holes began to thaw, temperatures rose to $0^{\circ} \mathrm{C}$ around noon, later freezing around midnight. These patterns indicated limited daily melting that refroze in the evening. Once the hole formed, water temperatures remained at $0^{\circ} \mathrm{C}$ for over two weeks. At the start of this period, EC rose to $10^{2}-10^{3} \mu \mathrm{S}$, as solute rich ice was first to melt and photosynthesis among the microbial community may have been active (Tranter et al., 2005; Bagshaw et al., 2007). As melting progressed EC gradually declined to $10^{1}$ 
$\mu \mathrm{S}$ due to dilution from hole enlargement and perhaps meltwater entering from hydrologic connections with the surrounding ice (Fountain et al. 2008). Toward the end of summer solar radiation and air temperatures decreased. As the holes froze, EC gradually rose to $10^{2}-10^{3} \mu \mathrm{S}$ probably through freeze-concentration of solutes before dropping to zero precipitously as the last of the meltwater froze.

Due to the snow, the period of prolonged melting during the 2017-18 summer started December $31^{\text {st }}$, nearly 30 days after melt initiation in the 2005-06 summer, because the snow that fell mid-December slowed solar heating of the ice even after the surface was swept. In both seasons, subsurface melt started on clear, sunny days when the solar radiation reached as high as $\sim 600 \mathrm{~W} \mathrm{~m}^{-2}$ at noon and air temperatures rose above freezing, though no surface melt occurred. Once the hole melted in 2017-18, it remained melted even when air temperatures were as low as $-5^{\circ} \mathrm{C}$ for several days. However, snow cover over the ice and air temperatures below about $-2^{\circ} \mathrm{C}$ both appeared to cause some freezing in the hole, indicated by increased EC. The holes in both seasons refroze in midJanuary as incoming radiation decreased and air temperatures cooled.

The sediment depth at the start of the 2017-18 summers was about $3-4 \mathrm{~cm}(13 \%)$ less than reported in previous seasons due to differences in snow cover (Fountain et al. 2008; Porazinska et al. 2004). Depth measurements at the start of the 2017-18 summer confirm that the limited melting did occur in 2016-17 was sufficient for the sediments to melt the underlying ice and deepen $\sim 9 \mathrm{~cm}$. The holes developed in a typical manner by early January 2018 despite the delay and the sediments deepened to at least $26 \mathrm{~cm}$ in the 
middle of the prolonged melt period, potentially deepening further to the average depths reported for snow-free conditions.

\section{Laboratory and Field Comparison}

Cryoconite holes were successfully created in the laboratory. The equilibrium depth of the sediment increased with increased radiation intensity and warmer air (ice) temperatures. The general pattern of cryoconite development observed in the laboratory is consistent with field observations in the MDV. No melting occurred when ice temperatures were $-10^{\circ} \mathrm{C}$ and radiation intensity was $385 \mathrm{~W} \mathrm{~m}^{-2}$, roughly equivalent to early-summer conditions in the MDV. Only when the ice was sufficiently warm or the radiation was sufficiently intense $\left(405 \mathrm{~W} \mathrm{~m}^{-2}\right)$ did the sediments melt the ice and the holes formed. Changes to the equilibrium depth of the cryoconite and the hole dimensions in response to incremental increases in radiation were greatest when ice temperatures were closer to the melting point, as expected. The warmest temperatures in the experiments, $-3^{\circ} \mathrm{C}$, were near the average summer air temperature in the MDV and produced cryoconite closest (at least $18 \mathrm{~cm}$ deep) to what is seen on Canada Glacier. This agrees with cryoconite hole development in the MDV, which only occurs during the middle of summer, when incoming radiation is high and the shallow subsurface is closest to the melting point.

The formation of the ice lid itself appeared to inhibit melting in several of the experiments, although the lid is typical of cryoconite holes in the MDV. Moreover, in the field the relatively low solar angles compared to the zenith angle of the laboratory 
experiments requires radiation to penetrate more ice than the thin ice lid in the laboratory. Perhaps a positive feedback loop may be created in the laboratory, whereby the thickening ice lid increases the rate of radiation attenuation, decreasing solar heating of the sediment, and further thickening the ice lid. The sediments would be expected to deepen further than what was measured because when the ice block was closest to the lamp, more radiation $\left(+30 \mathrm{~W} \mathrm{~m}^{-2}\right)$ reached the sediments from directly above, despite the intensity of the lamp being less than peak solar radiation in the MDV. However, cryoconite holes in the MDV are subjected to volume scattering otherwise absent in the laboratory, amplifying the total radiation flux to the cryoconite from the surrounding ice and from below compared to the laboratory conditions and increasing melt.

Equilibrium sediment depths in the laboratory were typically at least $10 \mathrm{~cm}$ less than those observed on Canada Glacier. In these experiments there is essentially no sensible or latent heat losses nor is there any surface lowering. The shallow equilibrium depths in the laboratory likely result from lower radiation intensity. The greatest incident radiation intensity was $\sim 30 \%$ less than maximum daily solar radiation on Canada Glacier in midsummer. Based on the laboratory experiments, a $\sim 30 \%$ increase of incident radiation should increase the equilibrium depth to about $26 \mathrm{~cm}$ for ambient temperatures of $-5^{\circ} \mathrm{C}$, closer to field measurements. Jepsen et al. (2010) performed similar experiments but with a light source $+30 \%\left(140 \mathrm{~W} \mathrm{~m}^{-2}\right)$ more intense than the most intense radiation applied here, although they did not report whether an ice lid developed in their experiments. At temperatures of $-5^{\circ} \mathrm{C}$, their sediment melted completely through the ice 
blocks, ranging in height from 16 to $49 \mathrm{~cm}$, over periods of 20 to 110 hours, well past equilibrium depths reported on Canada Glacier.

Unlike field conditions where cryoconite holes cover $\sim 4 \%$ of the ice surface in the laboratory the sediment covered $35 \%$ of the surface. The shadowing caused by the sediments with the vertical orientation of the lamp perhaps significantly limited backscattered radiation which likely caused the base of the sediment to be cooler than what it would be in the field. Indeed, on Canada Glacier, temperatures $5 \mathrm{~cm}$ beneath the sediment were about $-0.5^{\circ} \mathrm{C}$ (Figure 3.2 ), whereas in the laboratory at the same position they were -1.5 to $-2{ }^{\circ} \mathrm{C}$ (Figure 3.6).

\section{Model performance}

This differences between the optimized parameters used in the cryoconite model compared to other models of subsurface melting in the MDV (Hoffman et al. 2014) may be one of scale. The parameters used in the cryoconite model reflect the small area (a few $\mathrm{m}^{2}$ ) around a single cryoconite hole over one year whereas the values of other models were optimized to characterize melting over the entire surface (which includes the mostly cryoconite-free ice) of multiple glaciers over several years. The model replicated cryoconite deepening rates and equilibrium depths exceptionally well, with initial deepening rates of $1.5 \mathrm{~cm} \mathrm{~d}^{-1}$ which slowed to $0.1 \mathrm{~cm}^{-1}$ as the cryoconite reached equilibrium $33 \mathrm{~cm}$ beneath the surface, similar to 2005-06 field observations. Although modeled temperatures reached the melting point on the same day it was measured in the field, the modeled cryoconite did not deepen until more than three weeks after it was 
measured. However, for the other 2003-04 and 2017-18 years, the model tended to predict holes melted sooner and refroze later than what occurred in the field. This discrepancy may be due to the inability of the one-dimensional vertical model to account for laterally conducted heat losses to the cooler surrounding ice. The optimal effective grain radius, $r_{\text {eff, }}$ used to model the 2005-06 cryoconite measurements here is an order of magnitude larger than that previously determined for Canada Glacier (Hoffman et al. 2014). A sensitivity analysis shows that cryoconite evolution is strongly influenced by $r_{\text {eff, }}$ which controls radiation transmission through the ice to the cryoconite. Increased $r_{\text {eff }}$ increased the duration of melting and caused the cryoconite to melt deeper into the surface and form taller meltwater-filled holes. Similarly, decreased albedo enhanced melting because it also enhanced the total flux of radiation to the cryoconite.

Changes to surface roughness affects the rate of heat transfer between the atmosphere and the surface, with the primary effect of altering the rate of surface ablation and, in turn, the rate that the cryoconite rose toward the surface. This is particularly significant in winter when the cryoconite hole is frozen. Increased winter ablation thins the ice above the cryoconite making it more shallow and subject to greater solar intensity in the spring, so it melts sooner than if it were deeper. However, the melt rate outpaces surface ablation only in the upper part of the ice column where solar radiation absorption is greater, so the equilibrium depth is shallower. In low ablation environments the rate of cryoconite melt deepening outpaces the ablation rate, resulting in deeper cryoconite with larger holes. 
The model of cryoconite hole development presented here agrees generally with the equilibrium model of Wharton et al. (1985) that the rate of melting decreases with depth as available energy decreases. However, the models differ as mine includes a detailed surface energy balance with a spectrally dependent radiative transmission term whereas theirs is a parameterized model. Wharton et al. (1985) did not quantify the fraction of energy actually convected down to the hole bottom and attempts to apply their model were unsatisfactory.

Equilibrium depths of cryoconite on glaciers in the MDV are more than a meter shallower than cryoconite holes in lake ice in the MDV, which are $\sim 2.2 \mathrm{~m}$ (Jepsen et al., 2010). The summer temperature of lake ice surrounding the sediment is at or near the melting point, so losses to lateral thermal conduction are relatively small. Conversely, the glacier ice is $1-4^{\circ} \mathrm{C}$ cooler (Figures $3.1,3.2,3.11$ ) than the cryoconite hole. While the model of Jepsen et al. (2010) is designed to quantify the net energy flux to the sediment within the ice, it does not account for a full energy balance at the surface, causing large errors in their modeled ablation. However their model accounts for energy loss due to lateral thermal conduction, of which there is little. They also used a broadband absorption coefficient smaller than the spectrally dependent absorption coefficients applied in the cryoconite model (Liston et al., 1999), which increased radiation transmission deeper in the ice surface. In their model, increased ablation rates had the effect of decreasing the average sediment depth, as was observed in the cryoconite model described here. Although lateral heat losses were insignificant in the lake ice model, the 
cryoconite model may be improved by accounting for energy losses due to lateral thermal conduction, since shallow glacier ice is cooler than lake ice (Figure 3.2).

Similar to cryoconite holes that form on lake ice, holes on the Ross Ice Shelf adjacent to the MDV are deeper, extending $1.0-1.5 \mathrm{~m}$ beneath the surface, and reach up to $15 \mathrm{~m}$ in diameter with ice lids as thin as $7 \mathrm{~cm}$ (Paige 1968). The hole evolution follows the same seasonal pattern of melting as occurs on glaciers in the MDV and can also be restricted by increased surface albedo. The albedo of the ice is lower due to a mix of darker "blueice" and high sediment concentration. Similar to the lake ice, temperatures in this ice are warmer which enhances melt to produce larger holes (Ishikawa and Kobayashi, 1985). 


\section{Chapter 5 Conclusions}

Field observations, laboratory experiments, and numerical modeling were used to characterize cryoconite hole evolution on a polar glacier in the MDV. At the peak of summer, cryoconite holes in the MDV are loci of meltwater generation. Without cryoconite ice melt is incomplete and only fractional melt occurs. Temperatures are warmest around the cryoconite, which can be as high as $+2.6^{\circ} \mathrm{C}$ at the surface. When fully developed, temperatures within the hole are consistently at the melting point surrounded by cooler ice. EC was up to 2 orders of magnitude higher when the hole initially melted compared to later in the summer suggesting increased microbial activity or subsurface hydrologic connections, in agreement with previous measurements. The extent of hole melting changes from year to year, depending largely on snowfall events and to a lesser degree air temperature, at least for the conditions observed.

Laboratory experiments support previous studies that hole melting and equilibrium depth increases as radiation intensity increases. Laboratory results show that at temperatures of $-10^{\circ} \mathrm{C}$ at least $405 \mathrm{~W} \mathrm{~m}^{-2}$ is needed to warm the cryoconite sufficiently to melt

surrounding ice. When the ambient temperature of the ice was closer to the melting point deepening of the sediment in response to increased radiation was greatest. When the ice temperature is close to the melting point, minor changes in local weather can produce disproportionately large volumes of meltwater. The formation of the ice lid caused great variability in the laboratory results, likely related to radiation attenuation through the ice lid and the vertical orientation of the lamp. The deeper cryoconite and larger holes in the MDV compared to those created in the laboratory highlighted environmental differences 
including scale (sediment patch vs. ice block diameter), radiation intensity, the incident angle of radiation entering the ice, and the importance of volume scattering in warming the cryoconite from above and below.

The model is the first to predict cryoconite hole development on glaciers and provide a realistic replication of field observations. Numerical modeling reaffirms that transmission of solar radiation into the subsurface and its absorption by the sediment is fundamental in warming it to the melting point. The absorption of downwelling and upwelling radiation was essential to amplify total energy flux to the cryoconite and warm temperatures above the melting point. Cryoconite holes descend deeper in the subsurface when more radiation is transmitted further into the ice. The warmed cryoconite enlarges the hole as it melts both the ice above and the underlying ice as it descends. Refreezing occurs from the top down, with the cryoconite last to freeze as it continually absorbs solar radiation. Surface snow and decreased solar radiation drastically reduce solar heating and can prevent cryoconite hole melting or cause them to contract if already developed. Surface ablation controls how much the cryoconite shallows over the winter and the radiation absorption come spring. The balance between the surface ablation and cryoconite induced melting at depth controls the equilibrium depth and hole height. Increased air temperatures enhance hole melting by increasing thermal energy conduction from the surface down to the sediment. The accuracy of the model would likely be improved by accounting for the conduction of heat from the relatively warm cryoconite hole to the cooler ice surrounding it. Based on these relationships, regional changes in ice properties and local climate would be expected to alter cryoconite hole development 
geographically. Since cryoconite are loci of warming compared to cryoconite-free ice, conditions which exaggerate this, such as increased radiation flux into the subsurface or warmer air temperatures, may lead to increased melting in the cryoconite-free ice as heat is conducted from warm cryoconite to cooler ice. 


\section{References}

Anesio, A.M, Laybourn-Parry, J., 2012. Glaciers and ice sheets as a biome. Trends in Ecology \& Evolution, 27(4) 219-225.

Bagshaw, E., Tranter, M., Fountain, A., Welch, K., Basagic, H., and Lyons, B. 2007. The biogeochemical evolution of cryoconite holes on glaciers in Taylor Valley, Antarctica. Journal of Geophysical Research. 113, G04S35, doi:10.1029/2007JG000442.

Brandt, R.E., Warren, S.G., 1993. Solar-heating rates and temperature profiles in Antarctic snow and ice. Journal of Glaciology, 39(131), 99-110.

Brutsaert, W. 1982. Evaporation Into the Atmosphere: Theory, History, and Applications, Kluwer Academic Publishers, Dordrecht, Netherlands. 299.

Coakley, J.A., 2003. Reflectance and albedo, surface. Encyclopedia of the Atmosphere. 1914-1923

Cook, J.M., Hodson, A.J., Irvine-Flynn, T.D.L., 2016. Supraglacial weathering crust dynamics inferred from cryoconite hole hydrology. Hydrological Processes 30, 433-446.

Das, B., 2008, Advanced Soil Mechanics. Taylor \& Francis, London \& New York.

Doran, P.T., McKay, C.P., Clow, G.D., Dana, G.L., Fountain, A.G., Nylen, T., Lyons, W.B., 2002. Valley floor climate observations from the McMurdo dry valleys, Antarctica, 1986-2000. Journal of Geophysical Research 107(D24), 4772.

Fountain, A.G., Lyons, B.W., Burkins, M.B., Dana, G.L., Doran, P.T., Lewis, K.J., McKnight, D.M., Moorhead, D.L., Parsons, A.N., Priscu, J.C., Wall, D.H., Wharton, R.A., Virginia, R.A., (1999). Physical Controls on the Taylor Valley Ecosystem, Antarctica. Bioscience 49(12), 961-971.

Fountain, A.G., Tranter, M., Nylen, T.H., Lewis, K.J., Mueller, D.R., 2004. Evolution of cryoconite holes and their contribution to meltwater runoff from glaciers in the McMurdo Dry Valleys, Antarctica. Journal of Glaciology 50(168), 35-45.

Fountain, A.G., Nylen, T.H., MacClune, K.J., Dana, G.L. 2006. Glacier mass balances (1993-2001) Taylor Valley, McMurdo Dry Valleys, Antarctica. Journal of Glaciology, 52(178), 451-462.

Fountain, A.G., Nylen, T.H., Tranter, M., Bagshaw, E., 2008. Temporal variations in physical and chemical features of cryoconite holes on Canada Glacier, McMurdo Dry Valleys, Antarctica. Journal of Geophysical Research 113, G01S92.

Fountain, A.G., Nylen, T.H., Monaghan, A., Basagic, J., Bromwich, D. (2010). Snow in the McMurdo Dry Valleys. International Journal of Climatology 30(5), 633-642. 
Fountain, A.G., Basagic, H.J., Niebuhr, S., 2016. Glaciers in equilibrium, McMurdo Dry Valleys, Antarctica. Journal of Glaciology, 62(235), 976-989.

Gribbon, P.W.F., (1979). Cryoconite holes on Serminkavsak, West Greenland. Journal of Glaciology, 22(86), 177-181.

Hoffman, M.J., Fountain, A.G., Liston, G.E., 2008. Surface energy balance and melt thresholds over 11 years at Taylor Glacier, Antarctica. Journal of Geophysical Research 113, F04014.

Hoffman, M.J., Fountain, A.G., Liston, G.E., 2014. Near-surface internal melting: A substantial mass loss on Antarctic Dry Valley glaciers. Journal of Glaciology, 60(220), 361-374.

Ishikawa, N., Kobayashi, S., 1985. On the internal melting phenomenon (puddle formation) in fast seas ice, East Antarctica. Annals of Glaciology, 6, 138-141.

Jepsen, S.M., Adams, E.E., Priscu, J.C., 2010. Sediment melt-migration dynamics in perennial Antarctic lake ice. Arctic, Antarctic, and Alpine Research, 42(1), 57-66.

Leslie, A. (1879). The Arctic Voyages of A.E. Nordenskjöld, MacMillian, London, 440.

Lewis, K.J., Fountain, A.G, Dana, G.L., 1998. Surface energy balance and meltwater production for a Dry Valley Glacier, Taylor Valley, Antarctica. Annals of Glaciology 27, 603-609.

Liston, G.E., Winther, J.G., Bruland, O., Elveiioy, H., Sand, K., (1999). Below-surface ice melt on the coastal Antarctic ice sheet. Journal of Glaciology 45(150), 273-285.

MacDonell, S., Fitzsimons, S., 2008. The formation and hydrological significance of cryoconite holes. Progress in Physical Geography 32(6), 595-610.

McIntyre, N.F., 1984. Cryoconite hole thermodynamics. Canadian Journal of Earth Sciences 21, 152-156.

Paige, R.A., 1968. Sub-surface melt pools in the McMurdo Ice Shelf, Antarctica. Journal of Glaciology, 7(51), 511-516.

Podgorny, I.A., Grenfell, T.C., 1996. Absorption of solar energy in a cryoconite hole. Geophysical Research Letters, 23(18), 2465-2468.

Porazinska,D.L., Fountain, A.G. Nylen, T.H.,Tranter, M. Virginia, R. A., and Wall, D. H., 2004. The biodiversity and biogeochemistry of cryoconite holes from McMurdo Dry Valley glaciers, Antarctica. Arctic, Antarctic, and Alpine Research, 36(1), 84-91. 
Takeuchi, N., Kohshima, S., Yoshimura, Y., Seki, K., Fujita, K., 2000. Characteristics of cryoconite holes on a Himalayan glacier, Yala Glacier, Central Nepal. Bulletin of Glaciological Research 17, 51-59.

Stibal, M., Tranter, M., 2007. Laboratory investigation of inorganic carbon uptake by cryoconite debris from Werenskioldbreen, Svalbard. Journal of Geophysical Research, 112, G04S33.

Tranter, M., Fountain, A.G., Lyons, W.B., Nylen, T.H., Welch, K.A., 2005. The chemical composition of runoff from Canada Glacier, Antarctica: implications for glacier hydrology during a cool summer. Annals of Glaciology, 40, 15-19.

Vincent, W., Howard-Williams, C., 2000. Life on snowball Earth. Science 287(5462), $2421 b$.

Wetzel, R.G., 2001. Limnology: Lake and River Ecosystems. Academic Press, San Diego.

Wharton, R.A., McKay, C.P., Simmons, G.M., Parker, B.C., 1985. Cryoconite holes on glaciers. Bioscience 35(8), 499-503. 


\section{Appendix A. Field Measurements}

Site Maps
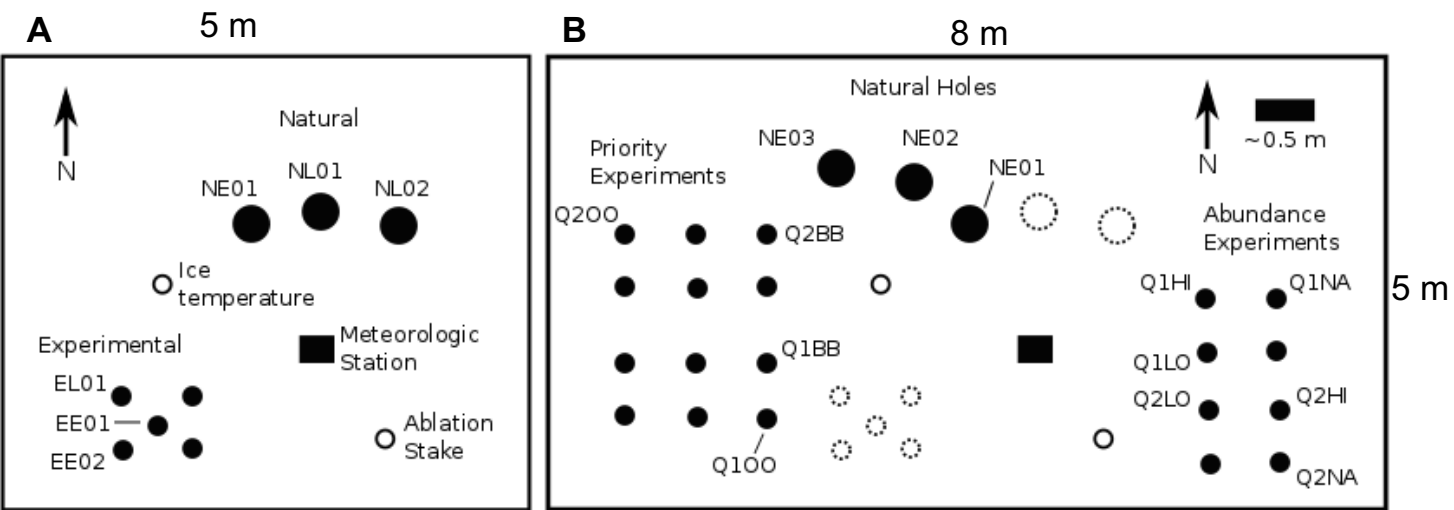

Figure A.1. A). Study site map of 2016-17 field season. B) Study site map of 2017-18 field season. Dashed circles are uninstrumented holes from the previous season.

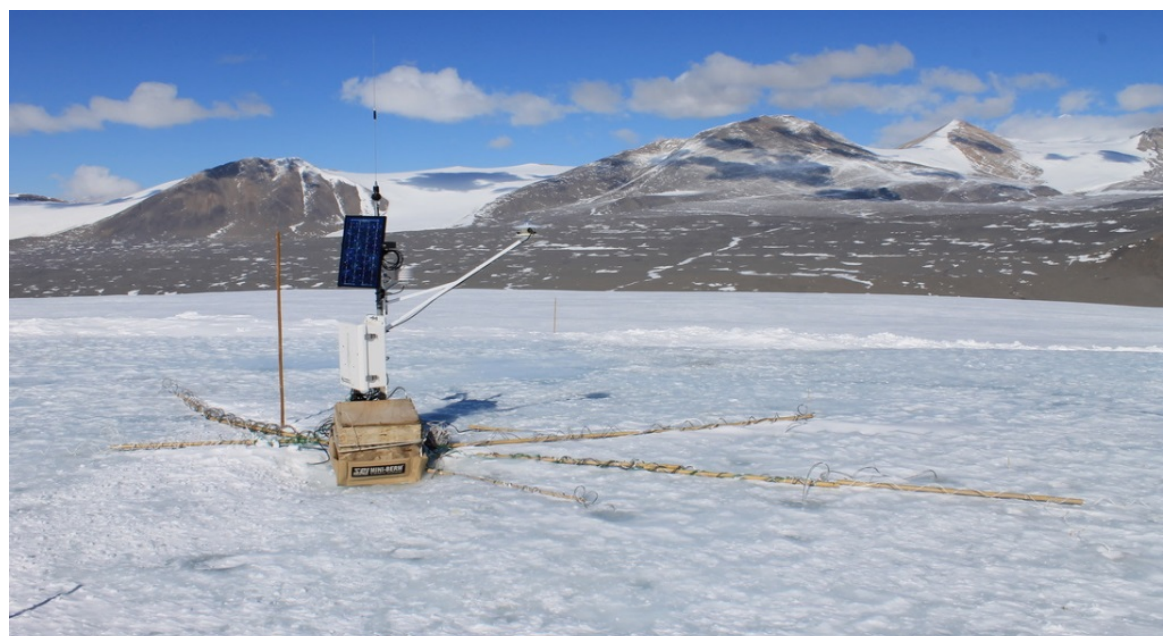

Figure A.2. Photo of study site during 2017-18 summer. The vertical bamboo stake is 1 $\mathrm{m}$ tall. The bamboo stakes on the ground are used to lead the probe wires from the met station to the cryoconite holes. 


\section{Field Arrangements}

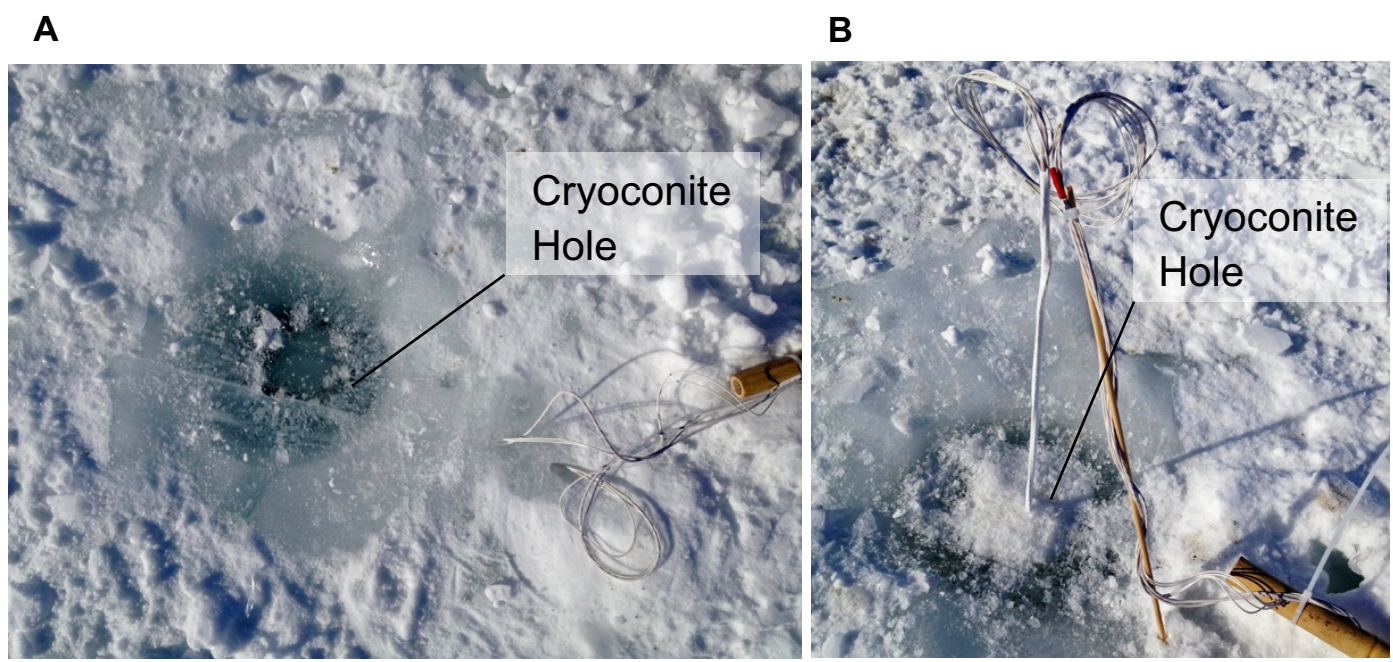

Figure A.3. A). Natural cryoconite hole instrumented during the 2016-17 austral summer using the A) Eularian arrangement (hole is $20 \mathrm{~cm}$ in diameter) and B) Lagrangian arrangement (hole is $19 \mathrm{~cm}$ in diameter).

\section{Electrical Conductivity Probe Construction \& Calibration}

To detect the presence of meltwater in the cryoconite holes and provide a coarse measurement of solute concentration, two-pronged electrical conductivity probes were created in the laboratory at PSU. Stainless steel $(0.4 \mathrm{~mm}$ diameter $)$ wire was used as the electrodes, ranging $2-3 \mathrm{~mm}$ in length. The electrodes were housed in white heat-shrink tubing (4.0 mm diameter) and secured within using epoxy. Stainless steel wires $(0.4 \mathrm{~mm}$ diameter, $5 \mathrm{~m}$ long) with white Teflon insulation lead from the electrodes to the datalogger.

To calibrate the EC probes, the cell constant of each probe was calculated individually as the product of the conductivity of a standard solution at $0^{\circ} \mathrm{C}$ (the temperature of water within the cryoconite holes) and a single-ended voltage measurement (made via an AC Half Bridge) within that solution. For the 2016-17 season, EC probes were calibrated 
against a $1000 \mu \mathrm{S} \mathrm{NaCl}$ solution. Given the limited resources in the field, the solution was created by incrementally adding the solute to $500 \mathrm{ml}$ of distilled water until the conductivity measured $1000 \mu \mathrm{S}$, as measured by a CS547-L conductivity probe $( \pm 5 \%$, Campbell Scientific, Inc.) of known cell constant. For the 2017-18 season, probes were calibrated against a 0.01 molal $\mathrm{KCl}$ solution $(1408 \mu \mathrm{S})$ created in the laboratory. The PRT temperature probes were calibrated according to manufacturer instructions accompanying the 4WPB100 PRT bridge terminal (Campbell Scientific, Inc.).

\section{Measuring solar radiation attenuation on Canada Glacier}

Radiation attenuation beneath the ice surface was measured on Canada Glacier in December 2016. Bore holes were drilled horizontally $1 \mathrm{~m}$ into a vertical cliff face on the western margin of Canada Glacier using a SIPRE corer. The center of the holes were positioned $9.5,13,24.5$, and $30.5 \mathrm{~cm}$ beneath the ice surface. Downward radiation flux at depth was measured by a PSP pyranometer $\left( \pm 0.8 \mathrm{~W} \mathrm{~m}^{-2}\right.$, Eppley Laboratory, Inc.) inserted approximately level into the borehole. Light was prevented from entering into the hole by sealing the entrance with a black cloth. A second pyranometer was positioned at the surface to measure incident radiation at the surface. Downward flux was measured for at least 48 hours at each depth. Radiation attenuation was calculated as the average ratio of downward to incident flux. 
Field Results 2016-17

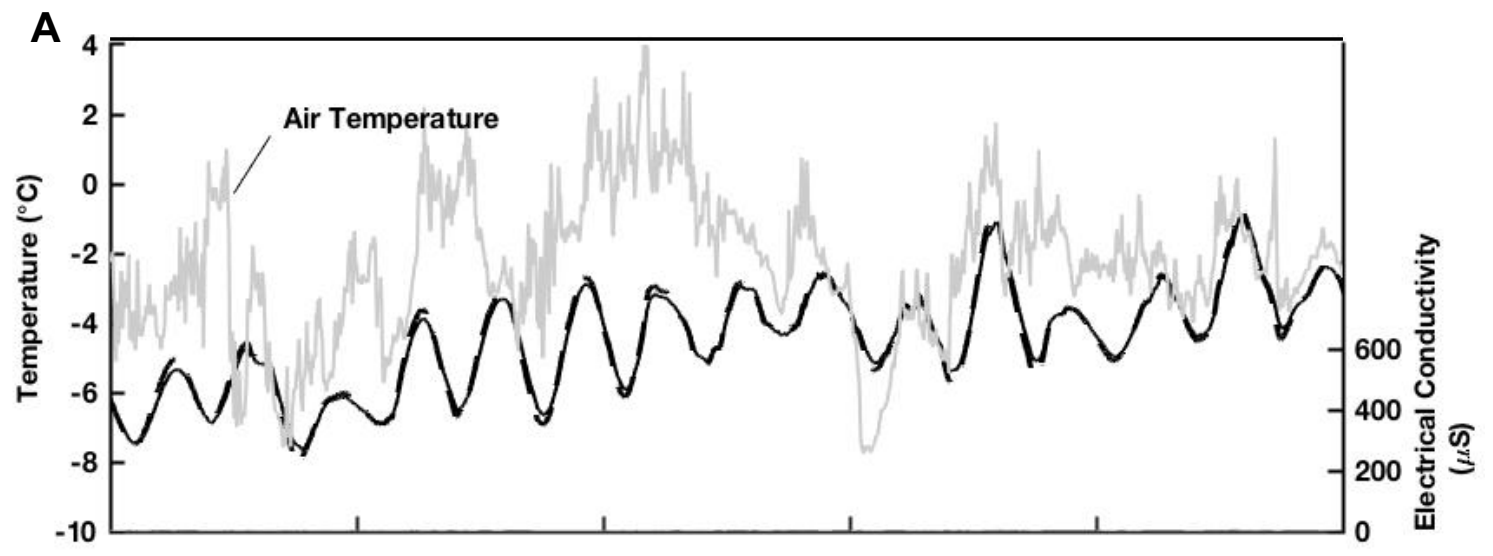

B

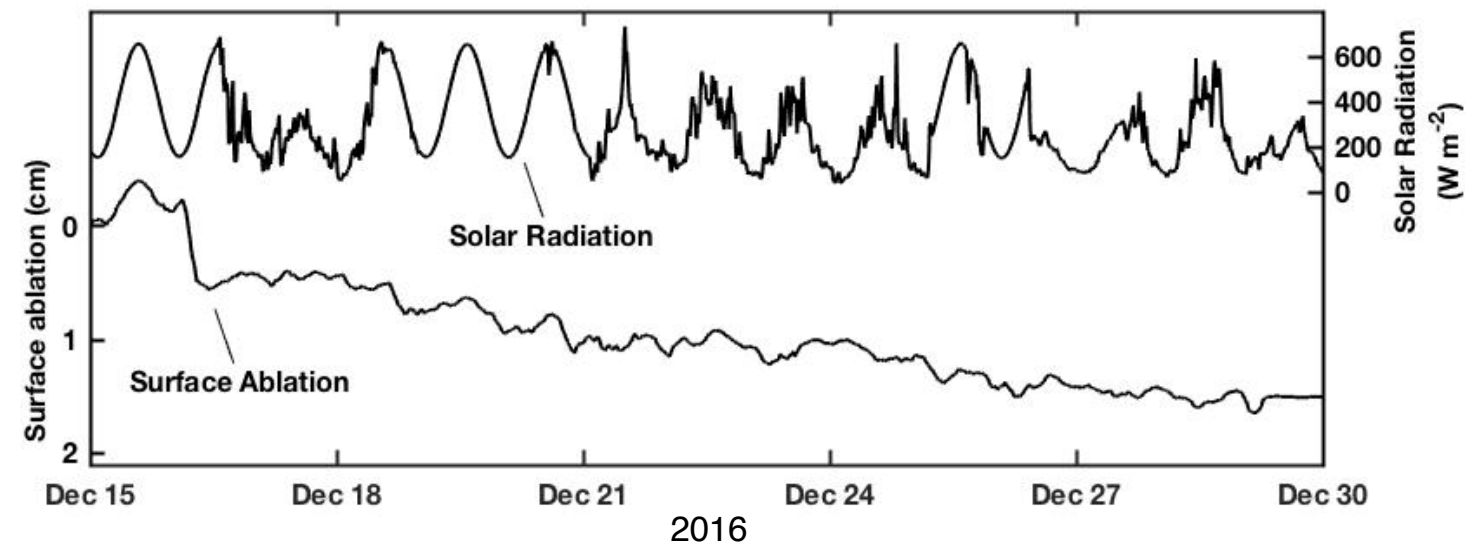

Figure A.4. A) Natural hole conditions during early-summer during the 2016-17 season. The solid line is the sediment temperature and the dashed line is the ice $5 \mathrm{~cm}$ above. No melt occurred during this time so EC is zero. The gray line is air temperature. B) Solar radiation and surface ablation. 


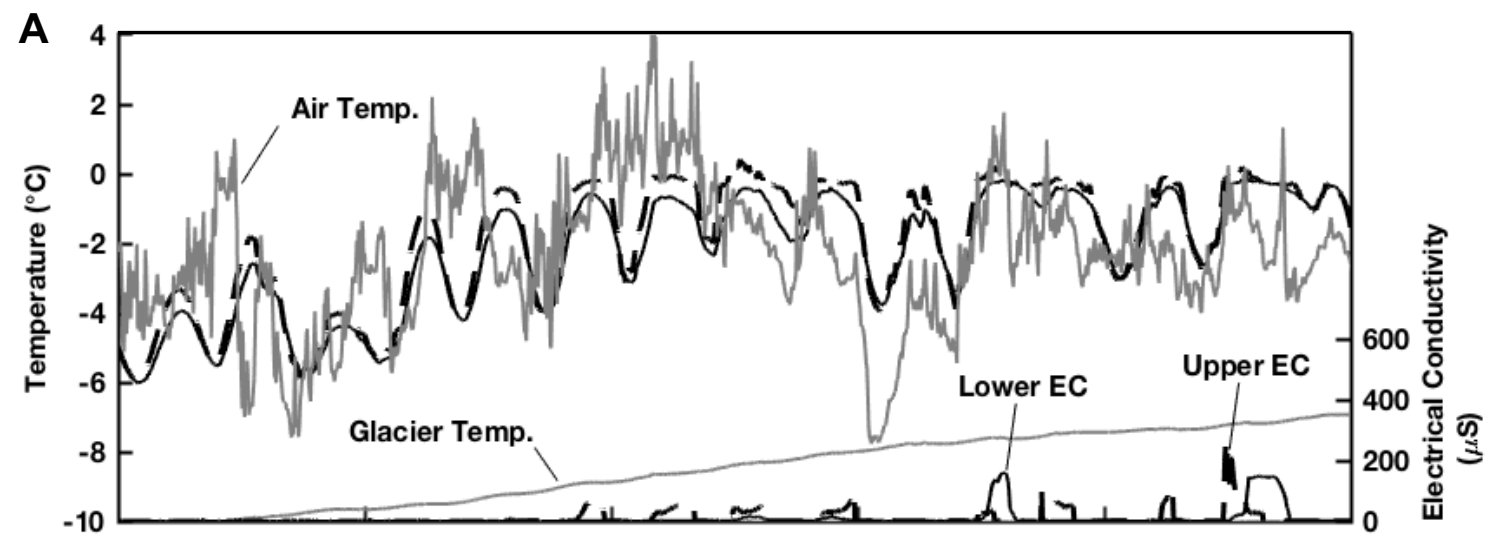

B

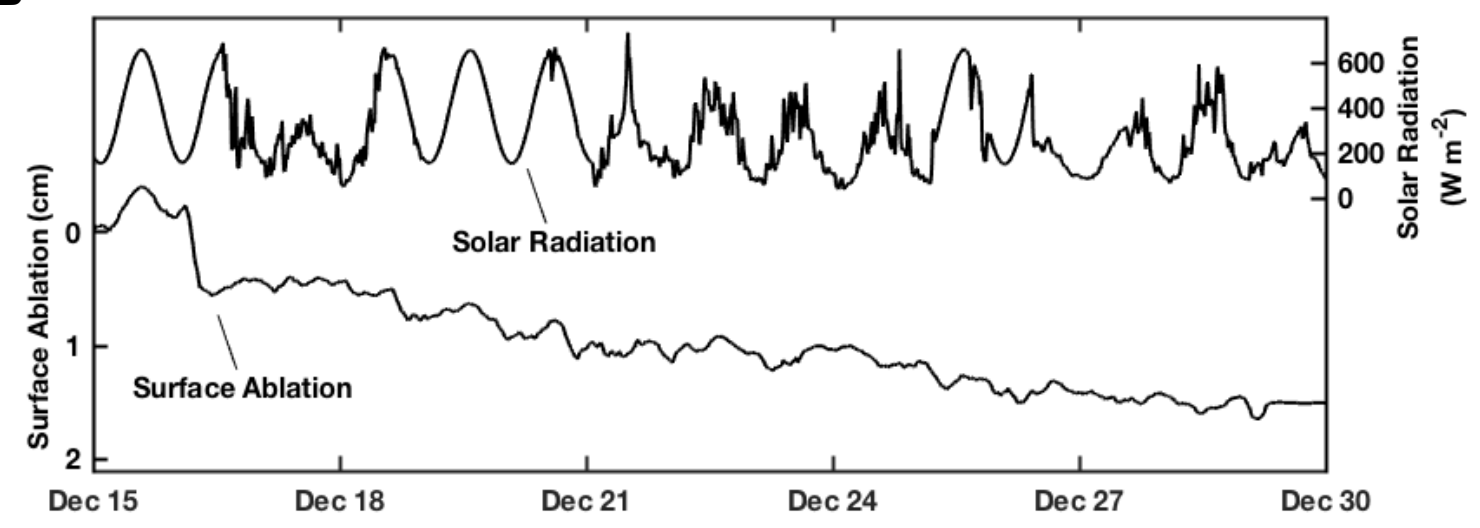

Figure A.5. A) Artificial hole (16-EL01) conditions during early-summer during the 2016-17 season. On December $15^{\text {th }}$ the sediment was $\sim 4 \mathrm{~cm}$ beneath the surface. The solid black line is temperature and EC $10 \mathrm{~cm}$ beneath surface and the dashed line is the temperature and EC $5 \mathrm{~cm}$ beneath the surface. B) Solar radiation and surface ablation. 

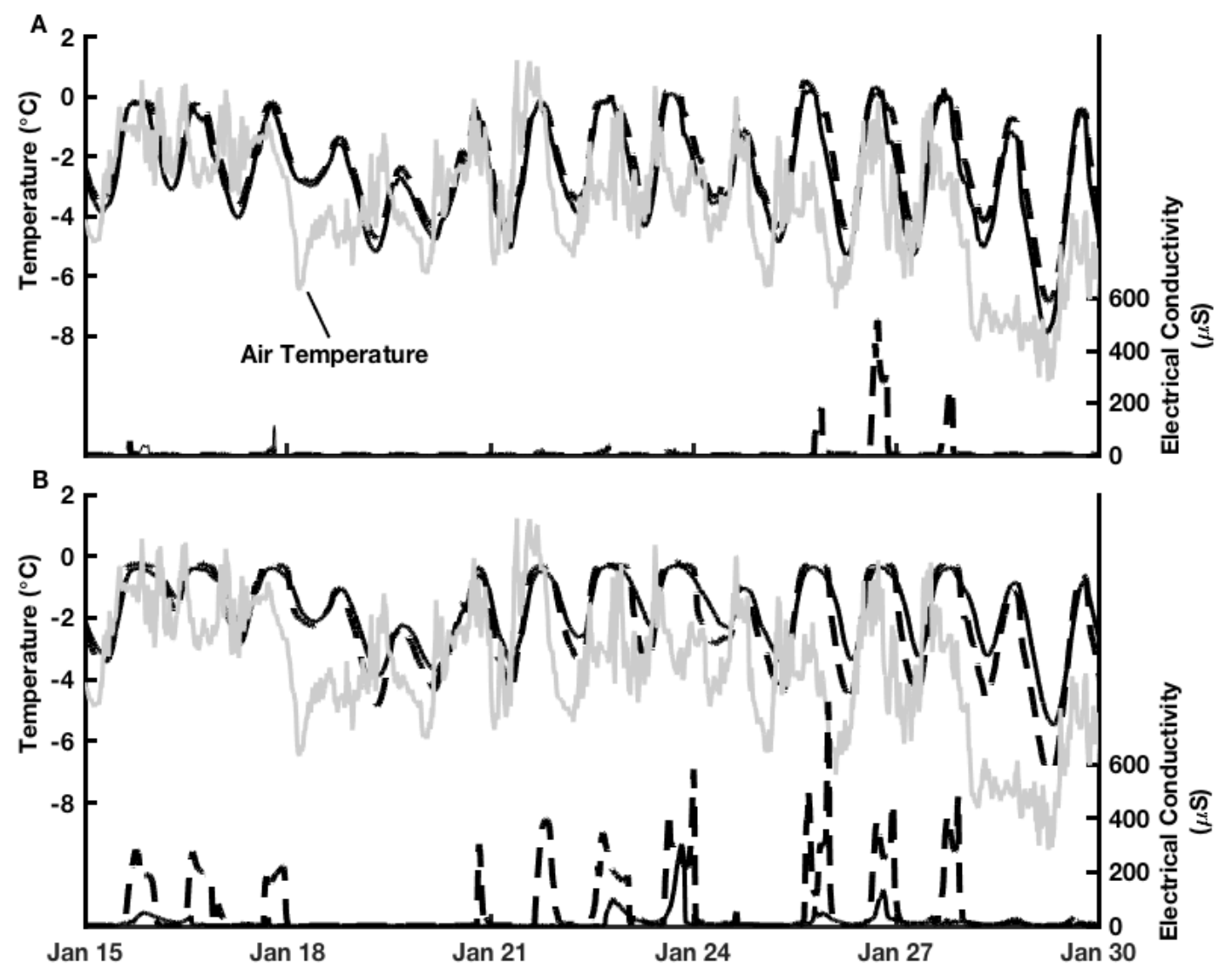

Figure A.6. A) Natural cryoconite hole 16-NL02 (Lagrangian) monitored during the latesummer 2016-17. The black lines are temperature and electrical conductivity of sediment (dashed) and in the region $5 \mathrm{~cm}$ above (solid). B) Natural hole 16-NE01 (Eularian). The black lines are temperature and electrical conductivity $5 \mathrm{~cm}$ below the sediment (dashed) and the sediment itself (solid). The Lagrangian sensors did not descend with the sediment as anticipated. 

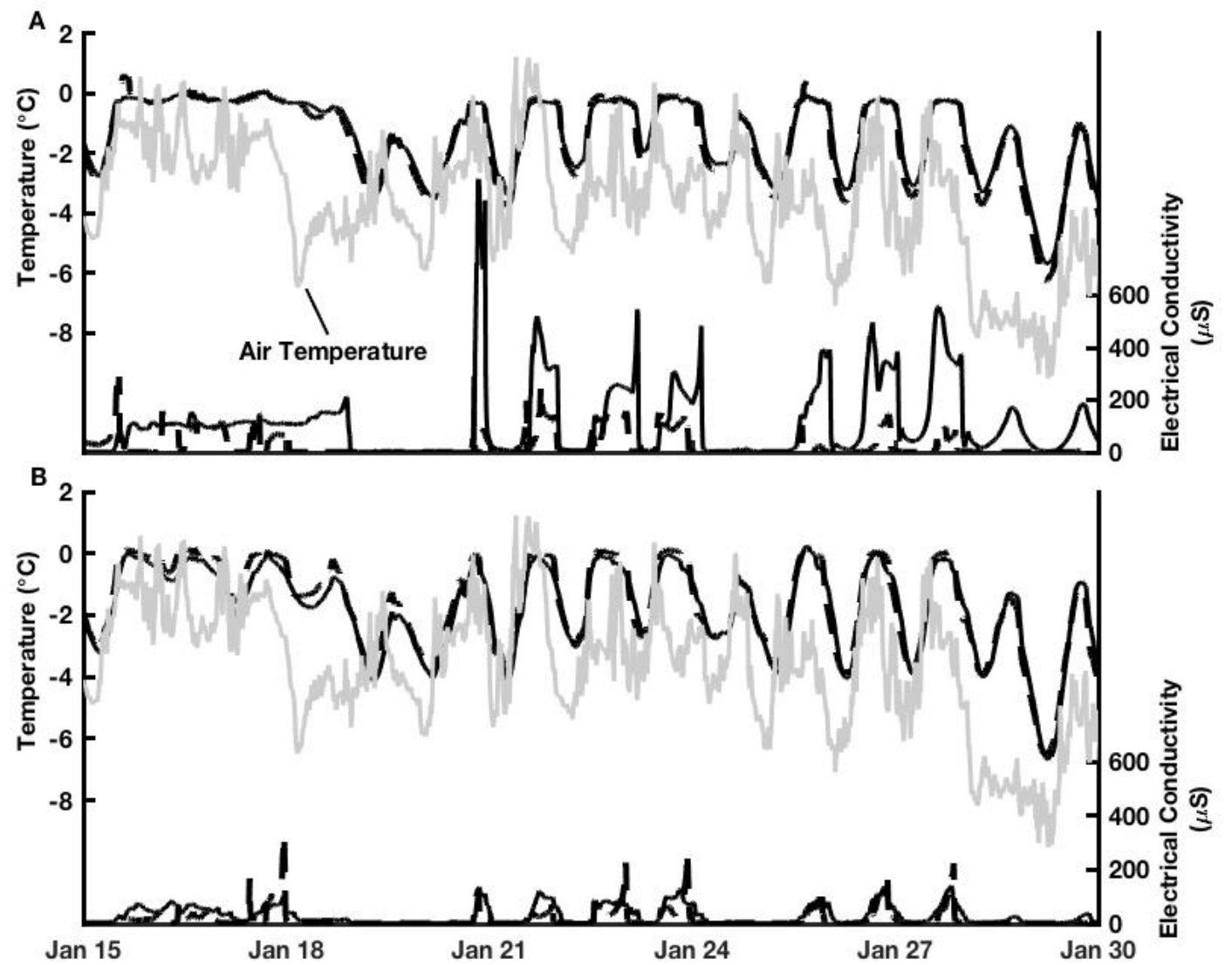

Figure A.7. Artificial holes A) 16-EL01 (Lagrangian) and B) 16-EE01 (Eularian) monitored during the 2016-17 austral summer. The black lines are temperature and electrical conductivity $5 \mathrm{~cm}$ below the sediment (dashed) and 10 below the sediment (solid). 16-EE02 is not shown because the upper probes were pulled from their position by high winds. 
Field Results 2017-18
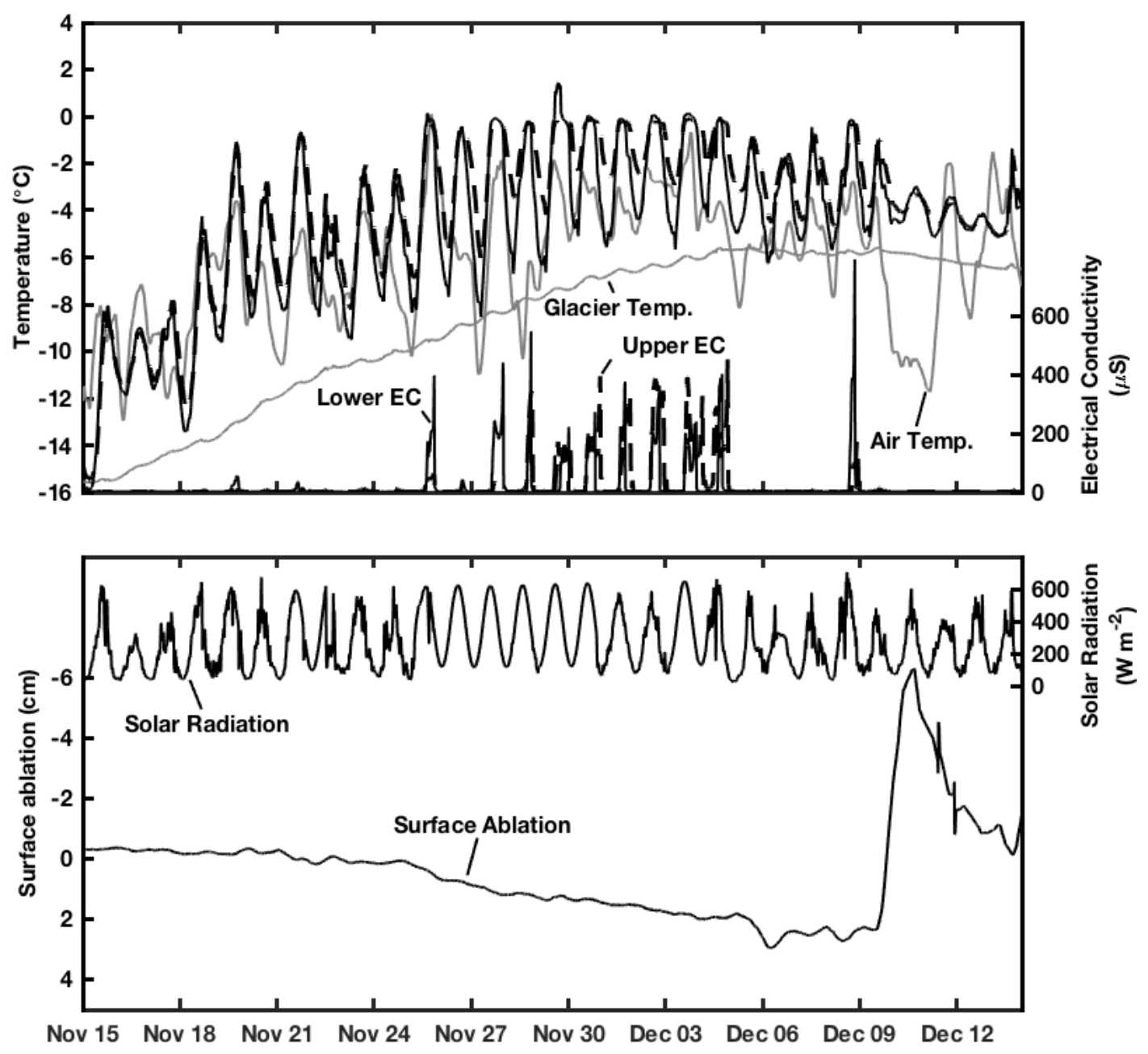

Figure A.8. Early season summer conditions (2017-18) in a natural cryoconite hole (16NL01) monitored on Canada Glacier. On November $15^{\text {th }}$ the sediment was $\sim 21 \mathrm{~cm}$ beneath the surface and temperature and electrical conductivity probes were $\sim 11 \mathrm{~cm}$ (solid) and $\sim 6 \mathrm{~cm}$ beneath the surface (dashed). The gray lines are air temperature and the ice temperature $1 \mathrm{~m}$ beneath the surface. b) Air temperature and solar radiation measured at the site. The site was cleared of snow on December $15^{\text {th }}, 2017$. 

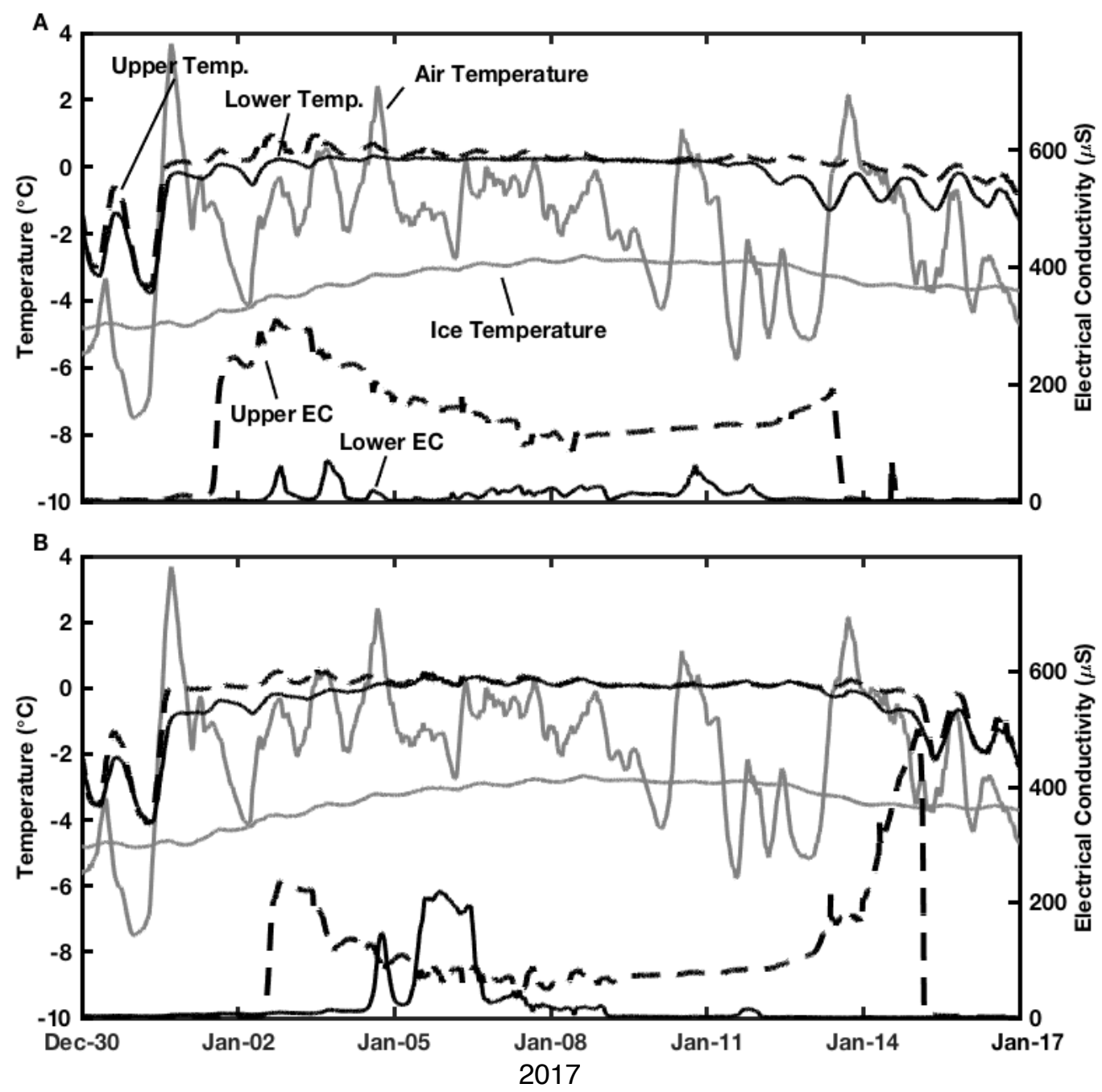

Figure A.9. Natural holes A) 17-NE02 and B) 17-NE03 monitored during the 2017-18 austral summer. The black lines are temperature and electrical conductivity $5 \mathrm{~cm}$ below the sediment (dashed) and $10 \mathrm{~cm}$ below the sediment (solid). 


\section{Appendix B. Laboratory Experiments}

\section{Probe Treatments}

Experiments were performed to determine which material, applied to the temperature probes, best minimized radiative heating. The temperature probes were 0.020 in. diameter copper-constantan thermocouples (Omega Engineering Inc.). One probe was wrapped in white Teflon tape, one in .001" mylar, and two, were untreated controls with the bare, brown Teflon sheath and probe tips exposed. Ambient air temperature outside the beam of the lamp was measured using a 107 probe (Campbell Scientific, Inc.). All measurements were recorded with a CR10x data logger. First, at room temperature outside of the chest freezer, the probes were placed $50 \mathrm{~cm}$ in front of the LED lamp (340 $\mathrm{W} \mathrm{m}^{-2}$ ) used in the experiments and the temperatures were recorded. A fan was then used to circulate the air around the probes to keep the air around the probes from heating. For another test, the probes were inserted $5 \mathrm{~cm}$ beneath the surface and $5 \mathrm{~cm}$ from the side of an ice block, which was positioned $30 \mathrm{~cm}$ away from the LED lamp (400 $\mathrm{W} \mathrm{m}^{-2}$ ). Individual probes were shaded from the lamp at various points in the experiments to determine if the effects were different between treatments.

For the tests both in the air and ice, temperature measurements from both Teflon and mylar treated thermocouples were more than $1^{\circ} \mathrm{C}$ cooler than the untreated thermocouples (Table B.1). Temperature measurements from the Teflon-treated thermocouples were $0.1-0.6^{\circ} \mathrm{C}$ cooler than those from the mylar thermocouples. When both probes in the ice were shaded, the difference between the measurements was 
$<0.1^{\circ} \mathrm{C}$. However, when exposed to the light, the temperature of the mylar-treated probe was consistently $0.4^{\circ} \mathrm{C}$ warmer than the Teflon-treated probe in open-air and in the ice. In the ice, with the mylar probe shaded, the temperature was still $0.2^{\circ} \mathrm{C}$ warmer than the unshaded Teflon probe, indicating scattered radiation was still warming the probe more than the Teflon probe. Given these results, Teflon was determined as the most effective material to minimize solar heating of the temperature probes.

Table B.1 Offset of temperature measurements $\left({ }^{\circ} \mathrm{C}\right)$ by treated probes relative to the ambient air temperature of probes covered in various materials.

\begin{tabular}{lllll}
\hline \hline & $\begin{array}{l}\text { Ambient } \\
\text { Temperature }\end{array}$ & Teflon & Mylar & Untreated \\
Lamp off, fan off & 23.2 & 22.5 & 22.5 & 22.6 \\
Lamp on, fan off & 23.1 & 23.5 & 24.1 & 26.2 \\
Lamp on, fan on & 23.6 & 23.4 & 23.5 & 24.4 \\
Lamp on, Ice & -3.4 & -3.6 & -3.2 & -2.3 \\
\hline
\end{tabular}

Optical properties of sediment and ice

Reflectance and radiance were measured with a FieldSpec Pro spectrometer (Analytical Spectral Devices, Inc.) fitted with an 8 degree field-of-view optical adapter. A Spectralon reference panel was used to make relative albedo and spectral intensity measurements per the manufacture's instructions. The spectral profile of the LED lamp shows a bimodal distribution with peaks in the blue and yellow portions of the spectrum (Figure B.1) 


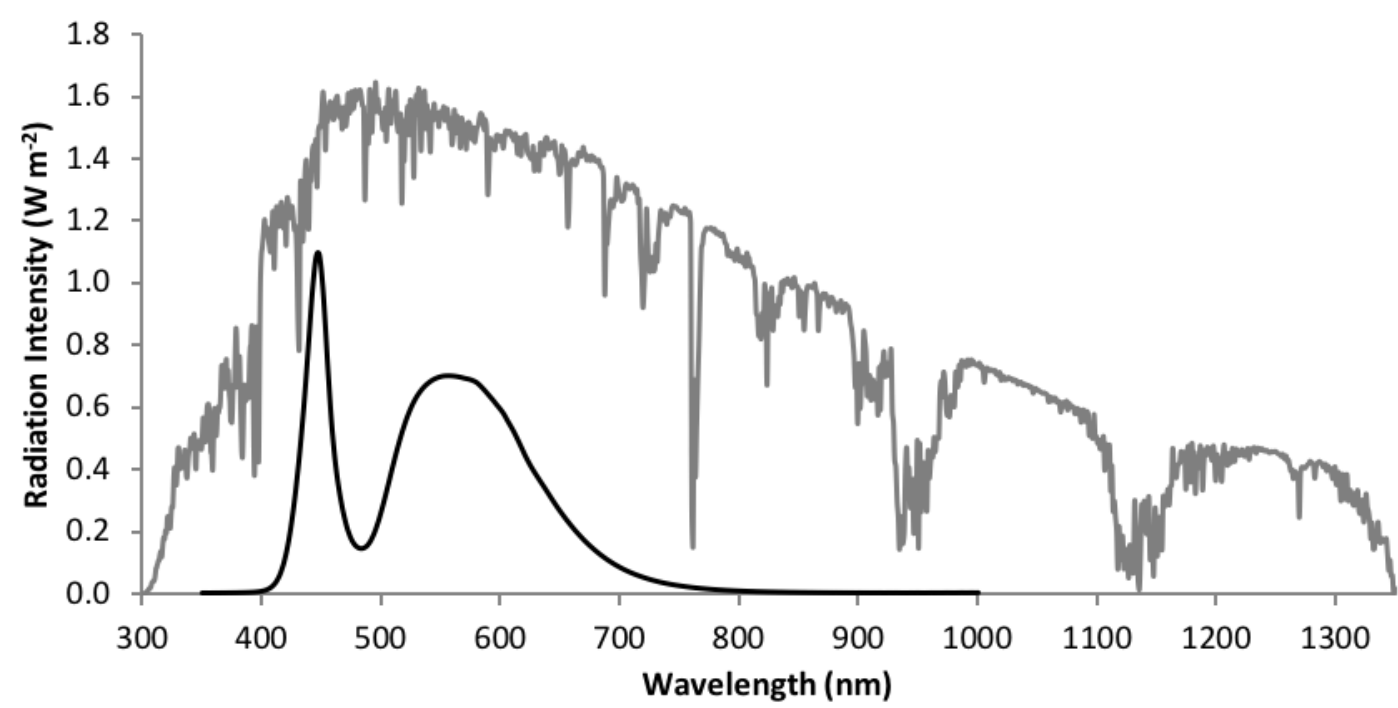

Figure B.1. Spectral profile of 150 Watt LED lamp (Larson Electronics LLC) at $30 \mathrm{~cm}$ (black) and the standard solar spectrum (gray) based on ASTM G-173-03 SMARTS (Simple Model of the Atmospheric Radiative Transfer of Sunshine) from International standard ISO 9845-1, 1992.

The attenuation of radiation with distance from the lamp was measured using a series of intensity measurements with reference panel at positions $30 \mathrm{~cm}, 40 \mathrm{~cm}, 60 \mathrm{~cm}$, and $70 \mathrm{~cm}$ away from lamp. The net intensity was calculated by integrating each intensity curve from $350 \mu \mathrm{m}$ to $1000 \mu \mathrm{m}$. These data were plotted and an exponential regression curve fitted (Figure B.2).

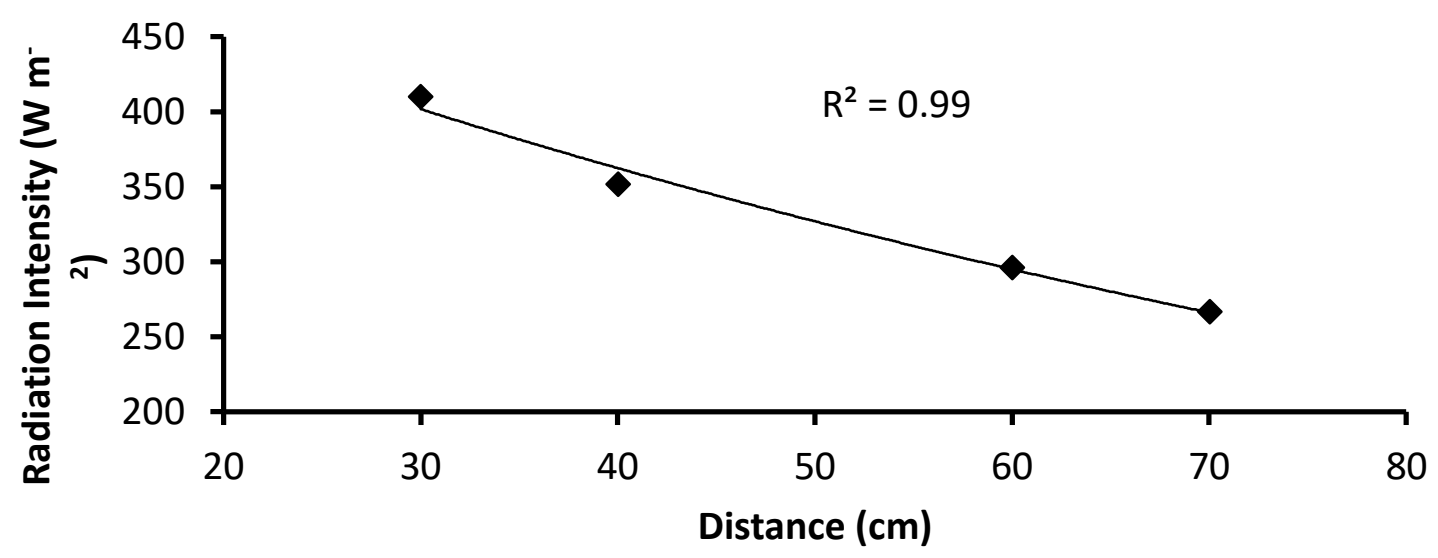

Figure B.2. Radiation intensity from LEDP5W lamp (Larson Electronics) vs. distance from lamp. 
To quantify the net shortwave radiation flux within the cryoconite hole, two sets of experiments were conducted. The first measured the albedo of the surface of the ice block and wetted sediments. The second measured the attenuation of transmitted radiation related to ice thickness and radiation scattering.

Albedo of the wetted sediments was measured by spreading the sediments $1 \mathrm{~cm}$ thick over a $40 \mathrm{~cm}$ x $40 \mathrm{~cm}$ surface. The reference panel was placed $30 \mathrm{~cm}$ away from lamp and the reflected intensity measured with the spectrometer sensor oriented $\sim 45^{\circ}$ from vertical. Then the intensity of light reflected by the sediments were measured. The ratio of the sediment reflectance to the reference panel was the albedo. Repeated albedo measurements of the saturated sediments were made from multiple positions around the sediment. The average albedo of the wetted sediments was $0.18 \pm 0.02$.

The albedo of the ice block was measured in the same manner, $30 \mathrm{~cm}$ from the lamp. Repeated measurements for different ice thickness and proportion of mylar coverage around the outside of the block, both of which affects internal scattering, yielded an albedo of $0.5 \pm 0.02$.

It immediately became apparent that the scattering in the ice block was much less than in the field. In the field, the cryoconite is in a semi-infinite plane of ice with scattered radiation striking it from all directions. By comparison the narrow ice block in the laboratory predominantly received radiation from above with limited light received from normal scattering or back scattering . To characterize the scattering in the ice I measured the transmitted light at the end of the block and the forward, back, and normal scattering 
along the side of the block. The ice blocks were laid horizontally with one end $30 \mathrm{~cm}$ away from the lamp while the ice block was incrementally shortened at the other end over the course of the experiment (Figure B.3). A baffle was placed at the lamp-end of the ice block and the walls of the freezer were lined with black fleece to minimize reflection off the sides of the freezer and ensure the radiation measured at the end of the block was directly from the lamp. To measure light transmission through the block as it became increasingly shortened, intensity measurements were made at the end of the ice block with the reference panel placed $60 \mathrm{~cm}$ and $70 \mathrm{~cm}$ from the lamp, where the light had passed through the block. Measurements taken at the end of the ice block were more consistent than those taken a distance from the ice because the optics of the ice block scattered the radiation in an erratic pattern. Intensity measurements were made on two ice blocks incrementally shortened to thicknesses of $20,17,14,10$, and $5 \mathrm{~cm}$. The percentage of transmitted radiation in the ice was calculated by dividing the intensity measured at the end of the ice by the expected "open-air" intensity for the distance of the ice block from the lamp.

Table B.2. Percentage of incident radiation for a given thickness of laboratory ice. The front of the block was kept $30 \mathrm{~cm}$ from the lamp, with incident radiation intensity ( $405 \mathrm{~W}$ $\mathrm{m}^{-2}$ ). The original intensity refers to the expected intensity if the ice were absent.

\begin{tabular}{|c|c|c|c|c|c|}
\hline $\begin{array}{l}\text { Block } \\
\text { Thickness (cm) }\end{array}$ & $\frac{\text { Orig. Intensity }}{\left(\mathrm{W} \mathrm{m}^{-2}\right)}$ & $\underline{\text { Bare Ice }}$ & $\underline{1 / 4 \text { coverage }}$ & $\underline{1 / 2 \text { coverage }}$ & Full coverage \\
\hline 5 & 385 & $27.2 \%$ & $30.8 \%$ & $33.9 \%$ & $37.3 \%$ \\
\hline 10 & 367 & $10.0 \%$ & $16.4 \%$ & $20.2 \%$ & $28.5 \%$ \\
\hline 14 & 352 & $9.6 \%$ & $16.1 \%$ & $19.3 \%$ & $24.9 \%$ \\
\hline 17 & 342 & $11.5 \%$ & $15.7 \%$ & $18.4 \%$ & $24.7 \%$ \\
\hline 20 & 332 & $9.6 \%$ & $14.0 \%$ & $15.3 \%$ & $23.6 \%$ \\
\hline
\end{tabular}

The intensity of scattered radiation was measured, including backscatter, normal-scatter, and forward-scatter. Measurements were taken in $5 \mathrm{~cm}$ increments from the lamp-facing 
end of the block with the sensor oriented 45 degrees from normal for back- and forwardscatter. Results from these experiments are reported in Table B.4 and Section 3.2.

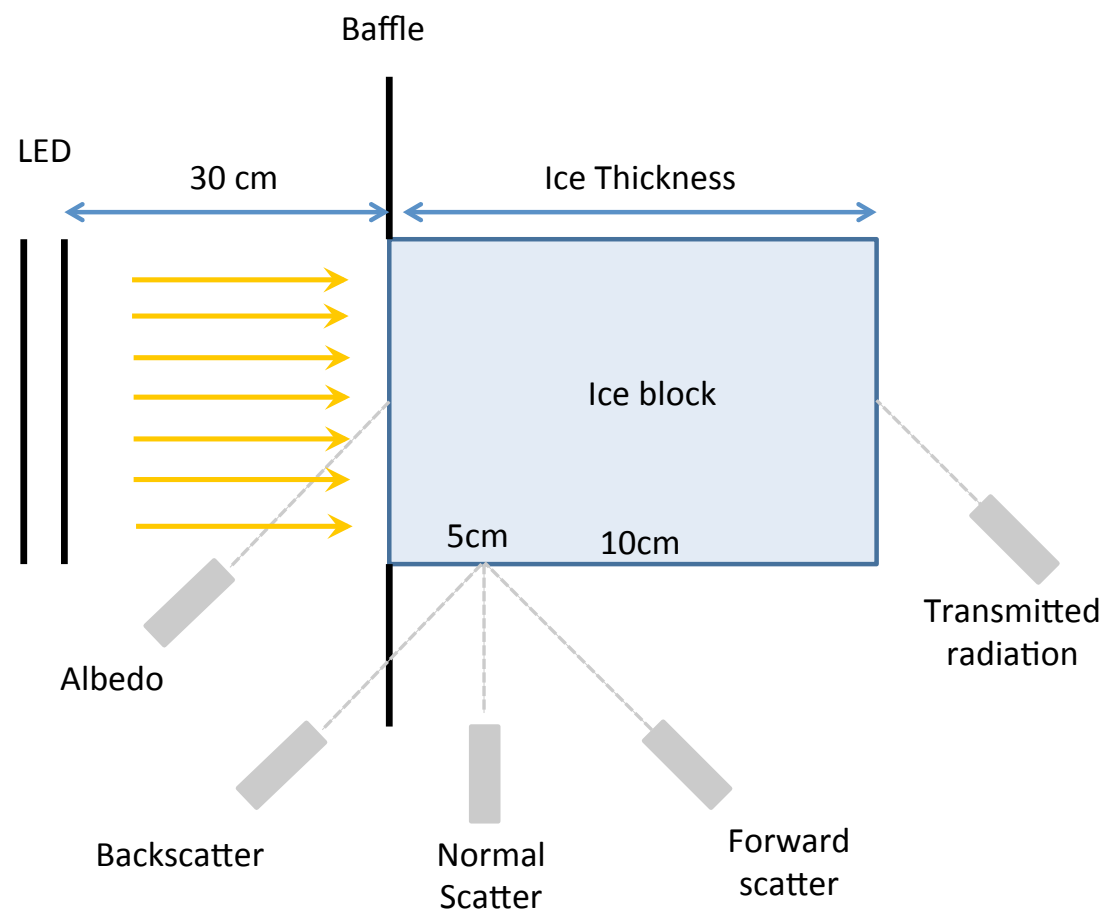

Figure B.3. Experimental arrangement to determine optical properties of laboratory ice highlighting the location of albedo, scattering and transmitted radiation on the ice block.

Table B.3. Horizontal scattering as a percentage of the open-air radiation flux at $40 \mathrm{~cm}$ (Lamp intensity at $40 \mathrm{~cm}=370 \mathrm{~W} \mathrm{~m}^{-2}$ ). The measurements were made $10 \mathrm{~cm}$ from the lamp-facing end of a $20 \mathrm{~cm}$ ice block. *This value would be $15 \%$ if plotted according to the trend of the other data.

\begin{tabular}{lcccc}
\hline & Backscatter & & Normal Scatter & Forward Scatter \\
\cline { 2 - 3 } No Mylar & $4.0 \%$ & & $5.1 \%$ & \\
1/4 Mylar & $5.4 \%$ & $6.4 \%$ & $19.2 \% *$ \\
1/2 Mylar & $6.4 \%$ & $10.3 \%$ & $16.5 \%$ \\
Full Mylar & $9.8 \%$ & $14.8 \%$ & $19.9 \%$ \\
\hline
\end{tabular}

The experiments were conducted at the laboratory at Portland State University as described in Section 3.2 (Figures B.3, B.4). Temperature probes at the surface and at 
depth record conditions within the block as the sediments descend from above, and the conditions within the hole after the sediments has passed.

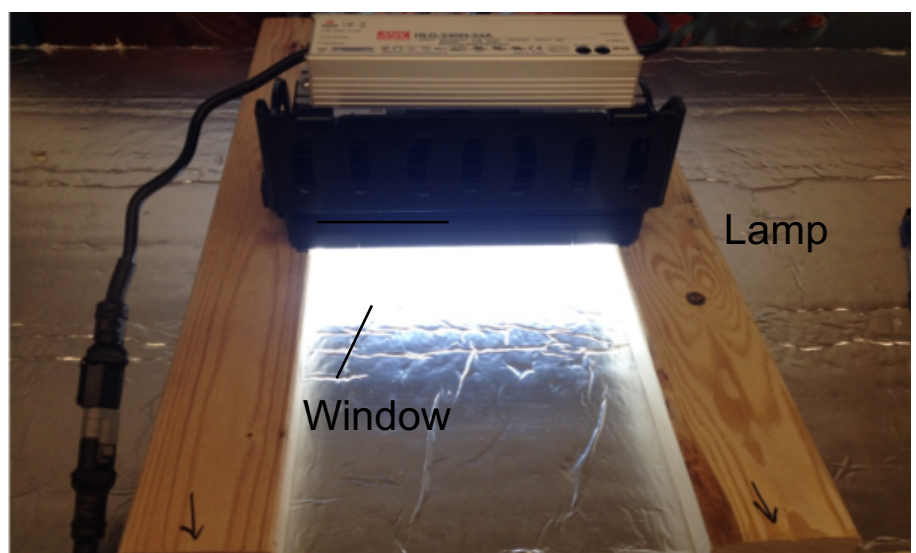

Figure B.4 LED lamp positioned above the window cut into the freezer lid.

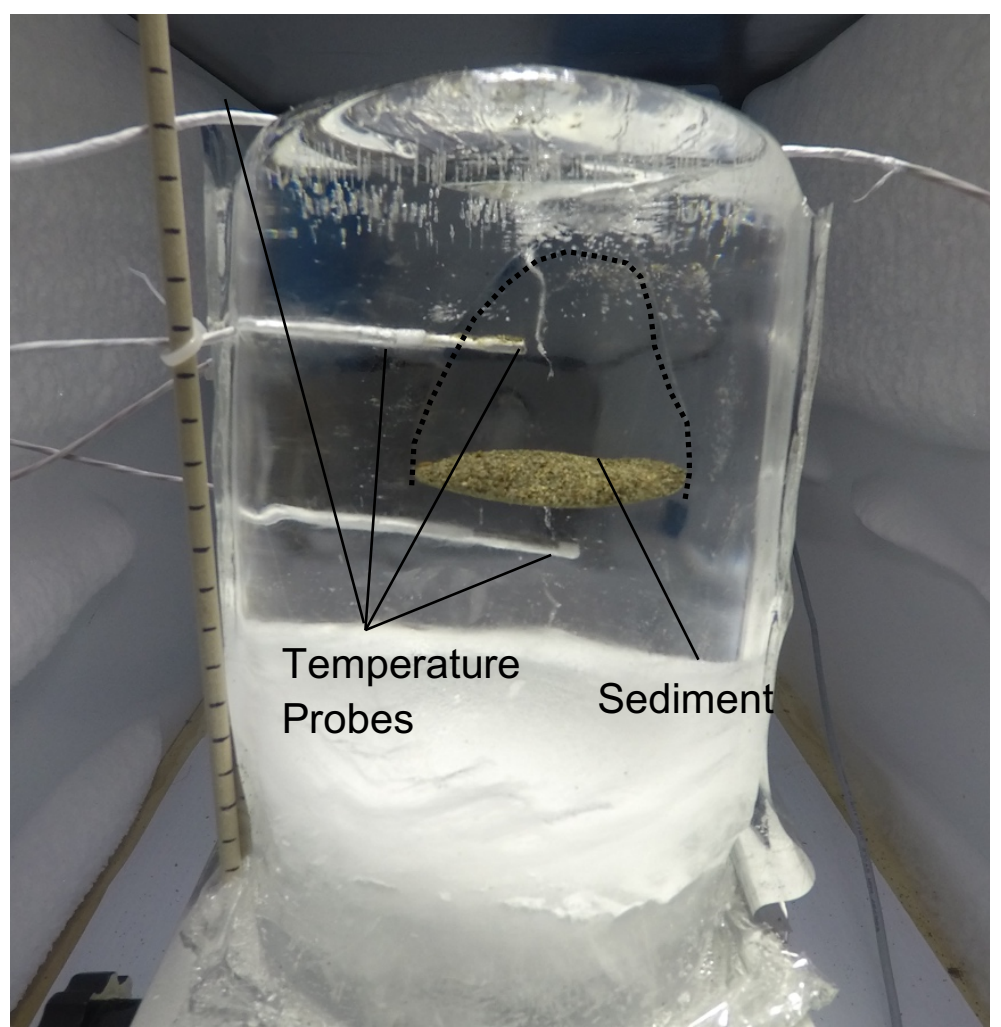

Figure B.5 Profile view of ice block during experiment 13 (Table B.2). The dashed line is the wall of the cryoconite hole. A temperature probe, not visible in the picture, is also positioned at the surface of the block. The block was $25 \mathrm{~cm}$ from the lamp and the cryoconite had not reached equilibrium. The bubble content of this block was less than normal. 
Table B.4. Laboratory Experiment Comments. Experiments 01 through 04 are not detailed because they were conducted with larger ice blocks with varying porosity and insufficient light coverage.

\section{Ambient Freezer}

Experiment Temperature $\left({ }^{\circ} \mathrm{C}\right)$

05

06

07

09

10

11
$-10$
Notes

The sediment did not begin melting until the distance of the lamp was $30 \mathrm{~cm}$. An ice lid did not develop over the hole, likely because the sediment did not melt far into the surface.

The experiment was suspended after the sediment had reached the equilibrium depth when the lamp-ice distance was $30 \mathrm{~cm}$ and the hole froze. The lamp was turned back on and the hole melted, without the sediment moving downward. Each time the radiation was increased after this, the sediment melted further into the ice block and the lid thickened, and the hole remained melted, at varying sizes.

The sediment continuously melted while the lamp-ice distance was $40 \mathrm{~cm}$. The lid began forming when the sediment was $\sim 6 \mathrm{~cm}$ beneath the surface but did not seal until the sediment was $\sim 16 \mathrm{~cm}$ beneath the surface. The sediment melted out of the side of the block before it had reached equilibrium depth.

When the lamp-ice distance was reduced to 35 $\mathrm{cm}$, the sediments began freezing from the bottom up, with the hole freezing later. The sediments were $\sim 2 \mathrm{~cm}$ thick, which was more than normal. The lower sediments were likely insulated from the relatively warmer sediments. Before the experiments began, the false-floor had been installed as part of the wind experiments and was kept in place for the remaining experiments described here.

The experiment started with the lamp-ice distance equal to $30 \mathrm{~cm}$.

The film of sediment on the surface was removed after the hole formed. The hole completely froze shortly after the ice lid had developed when lamp-ice distance equaled $40 \mathrm{~cm}$. The hole did not melt after decreasing the distance to $35 \mathrm{~cm}$. 
After decreasing the distance to $30 \mathrm{~cm}$, the hole had melted out but the experiment ended prematurely because the block split down the center when drilling into the hole.

The film of sediment on the surface was removed after the hole formed. The lid sealed when the sediment was $\sim 8 \mathrm{~cm}$ beneath the surface. The sediment did not intersect T02 as it descended. The experiment ended prematurely because the sediment melted out of the side. The sediment appeared to preferentially melt toward the mylar.

The block from the experiment 10 was reused. The sediment was frozen $\sim 4 \mathrm{~cm}$ beneath the ice surface. The sediment did not begin melting until the lamp-ice distance was $25 \mathrm{~cm}$. A small pool of meltwater formed on the surface of the block. The lid was not completed sealed and the hole was connected to the surface pool via a $\sim 1 \mathrm{~cm}$ diameter hole in the lid. The experiment ended prematurely when the hole intersected a fracture in the block and the meltwater drained.

\section{Turbulent Heat Exchange Experiment}

In an attempt to include the effects of turbulent heat exchange on cryoconite hole development, a duct fan was used to generate winds of $\sim 2.3 \mathrm{~m} \mathrm{~s}^{-1}$ over a $10 \mathrm{~cm}$ horizontal space immediately above the surface of the ice block while the ambient temperature was set at $-5^{\circ} \mathrm{C}$. When the incident radiation was $367 \mathrm{~W} \mathrm{~m}^{-2}$ (ice block $40 \mathrm{~cm}$ away from lamp) no melting occurred. However, when the incident radiation increased to $386 \mathrm{~W} \mathrm{~m}^{-}$

${ }^{2}$ by raising the block $5 \mathrm{~cm}$ toward the lamp, the sediment melted $4.2 \mathrm{~cm}$ into the ice block which was $1.4 \mathrm{~cm}$ deeper than the equilibrium depth measured without the wind. Most of the meltwater evaporated as it was produced, so there was no water to scatter the radiation or absorb the heat from the sediment. A similar effect was observed in some of 
the artificial holes on Canada Glacier as they initially melted into the subsurface and a hollow cavity formed above the sediments. Although it is unclear if this was due to evaporation or drainage of the meltwater into porous ice below. Additionally, once the sediments melted in they were sheltered from the wind which would have reduced turbulent heat flux. Given the initial absence of melting that occurred when the sediments were at the surface, this simple augmentation demonstrated that turbulent heat exchange suppresses melt in the lab. However, the addition of the fan was excluded from the experiments because the evaporation of the meltwater prevented the formation of the ice lid. 


\section{Appendix C. Model Results}

2003 - 04 Model Results

The model uses ice parameters identical to those applied in the 2005-06 iteration and results were similar to field measurements reported by Fountain et al. (2008). In midwinter, the cryoconite sediment was $25 \mathrm{~cm}$ beneath the surface and the ice ablated $<0.1$

$\mathrm{cm} \mathrm{month}^{-1}$ (Figure C.1). By early November ablation increased to $2-3 \mathrm{~cm} \mathrm{month}^{-1}$, thinning the ice over the sediment, which had yet to melt the ice and the sediment shallowed relative to the surface. At the same time, as the sun azimuth increased so did incoming solar radiation and the proportion of radiation absorbed by cryoconite relative to the surrounding ice, absorbing as much as $\sim 25$ times more energy than the surrounding ice (Figure C.2a). By mid-November, the ice temperature began rapidly warming until the sediment and the ice above reached the melting point in early-December (Figure C.2b). Simultaneously, the water fraction, which is the fraction of the subsurface cell composed of meltwater, immediately rose above zero as ice began to melt (Figure C.2c). The ice-water fraction around the sediment cell fluctuated diurnally but continued to rise. Daily sediment temperatures reached as high as $1.7^{\circ} \mathrm{C}$. 


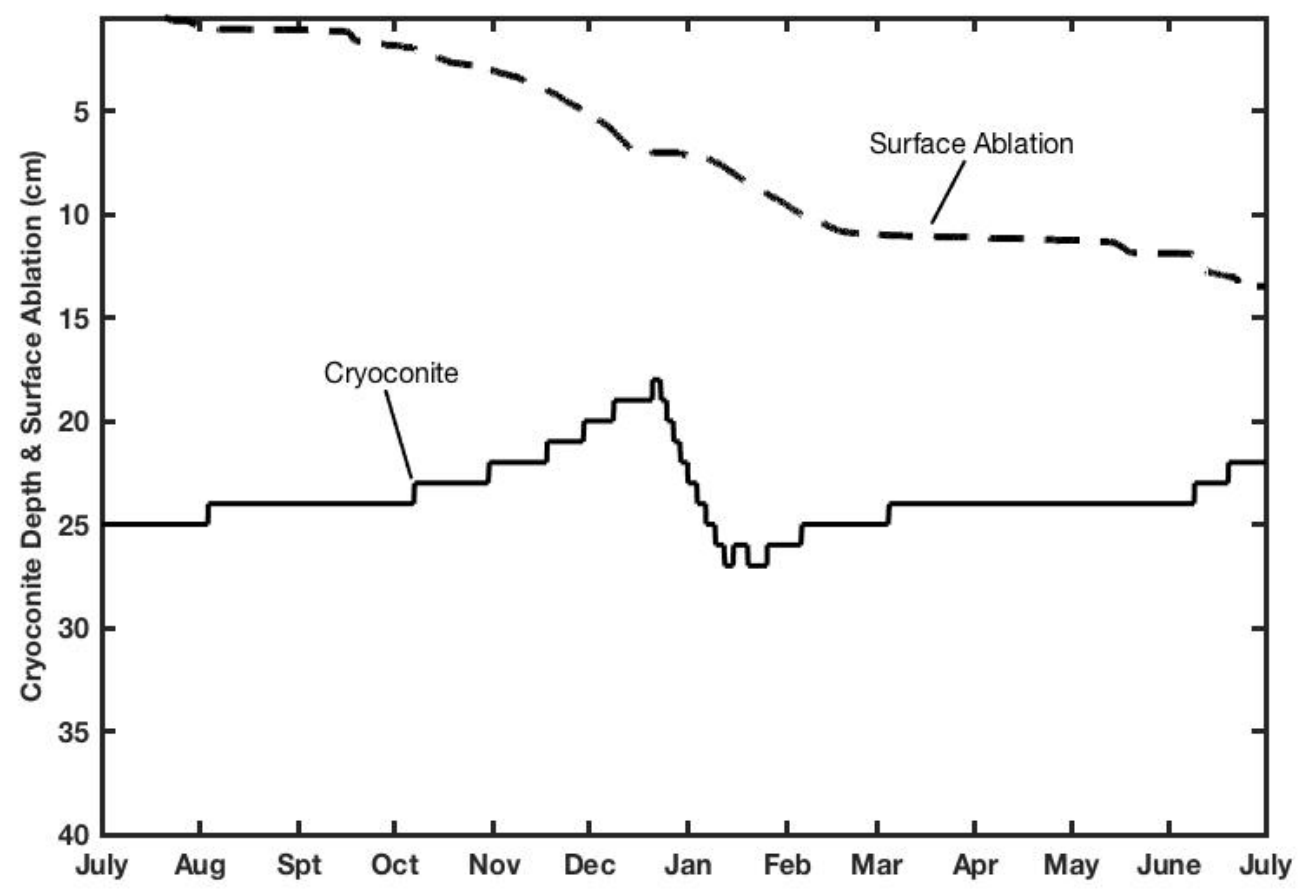

Figure C.1. Modeled sediment depth (solid line) and surface ablation (dashed line) from winter 2003 through winter 2004. The stepped nature of the cryoconite plot occurs because the cryoconite depth is adjusted in $1 \mathrm{~cm}$ increments.

In mid-December, the water fraction of the sediment reached 1; the sediment was $18 \mathrm{~cm}$ beneath the surface. Several days after the sediment thawed, the sediment began migrating downward, and as the cells above maintained a water fraction of 1 . During the first several days, the sediment layer descended at a rate of $1.0 \mathrm{~cm} \mathrm{~d}^{-1}$. The cryoconite temperatures ranged between 0.3 to $1.8^{\circ} \mathrm{C}$. At a depth of $23 \mathrm{~cm}$ in late-December the rate slowed to $0.3 \mathrm{~cm} \mathrm{~d}^{-1}$, and sediment temperatures varied between 0.0 to $0.8^{\circ} \mathrm{C}$. In midJanuary, the cryoconite sediment was $31 \mathrm{~cm}$ deep and maintained this depth through early-February reaching its the equilibrium depth. The descending rate matched the ablation rate of $0.1 \mathrm{~cm} \mathrm{~d}^{-1}$. The hole was largest when it reached the equilibrium depth, being $20 \mathrm{~cm}$ tall with a $10 \mathrm{~cm}$ thick ice lid. 

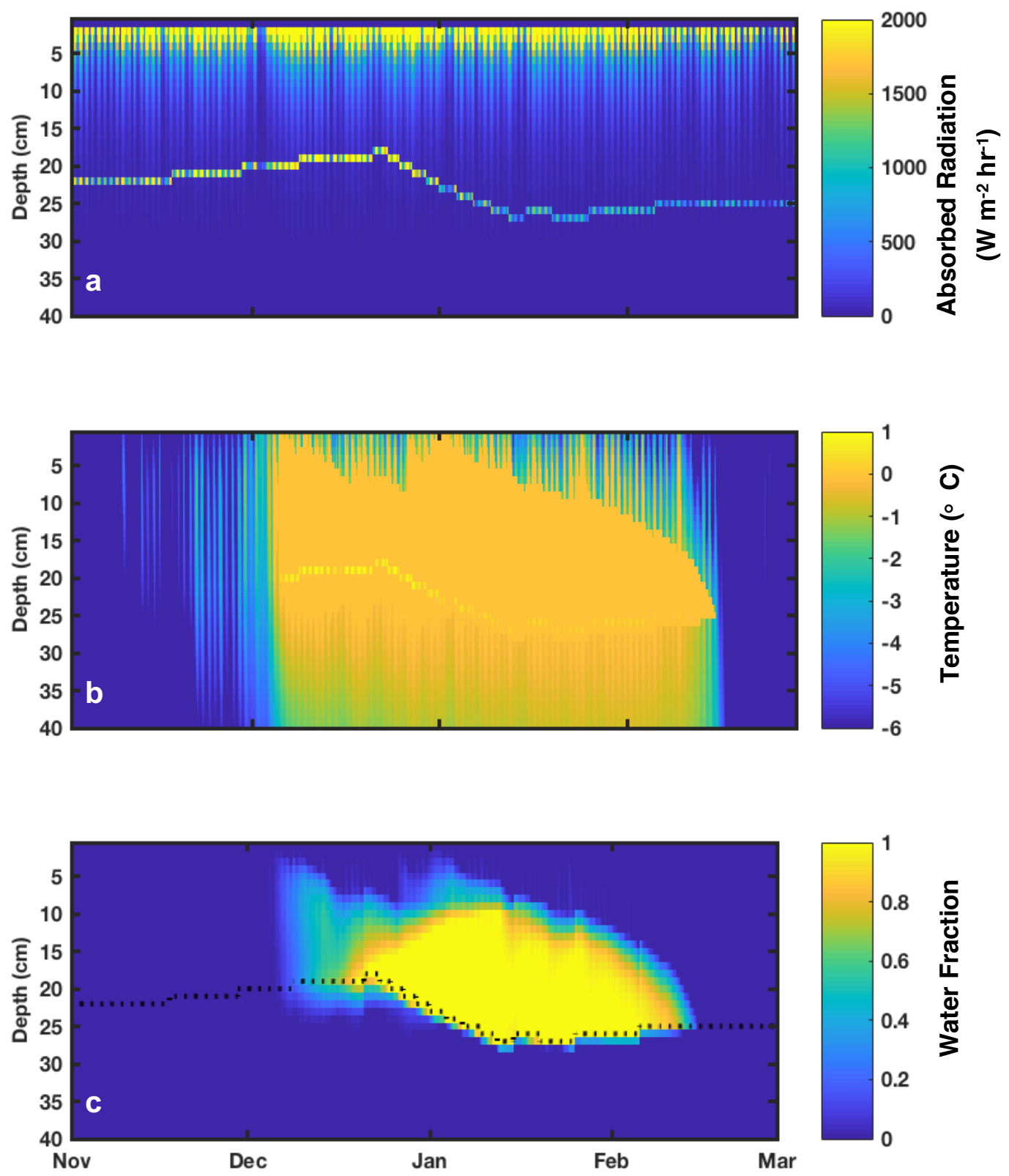

Figure C.2 Modeled subsurface conditions over the 2003-04 austral summer.

a) Absorbed radiation b) Temperature c) Water fraction within subsurface. A water fraction of 1 represents $100 \%$ meltwater and a water fraction of 0 represents a cell of $100 \%$ ice. The dotted line represents the location of the cryoconite.

When the hole reached equilibrium it began freezing from the top down. While at equilibrium, the height of the cryoconite hole averaged $11 \mathrm{~cm}$ with a $19 \mathrm{~cm}$ ice lid and modeled cryoconite temperatures were $0^{\circ} \mathrm{C}$. By early-February, surface ablation began to 
outpace sediment deepening and its depth below the surface decreased. Continued cooling air temperatures and decreasing solar radiation decreased the energy to the sediment. By the end of the second week of February, the hole water started to freeze, with complete freezing by mid-February. From early-April to July, the end of the model run, the surface ablated $2.6 \mathrm{~cm}$ raising the sediment to a depth of $27 \mathrm{~cm}$. Modeled surface ablation from July 2003 through June 2004 was $13.5 \mathrm{~cm}$, which compares well with LTER measurements of $12.7 \mathrm{~cm}$. The average temperature of the sediment through the austral winter was about $-30^{\circ} \mathrm{C}$.

The model predicted the hole melted a week sooner than in 2005-06. Although it melted sooner, the cryoconite hole was $\sim 6$ centimeters shorter on average. The sediments reached an equilibrium depth of $25 \mathrm{~cm}, 8 \mathrm{~cm}$ shallower than predicted in 2005-06. Periods of subdued incident solar radiation aligned with decreased subsurface temperatures and cryoconite hole contraction while increased radiation caused hole enlargement. Despite a similar pattern of incoming solar radiation (Figure C.3) hole development was diminished during 2003-04, likely because albedo was generally higher, beginning in mid-December through February. 


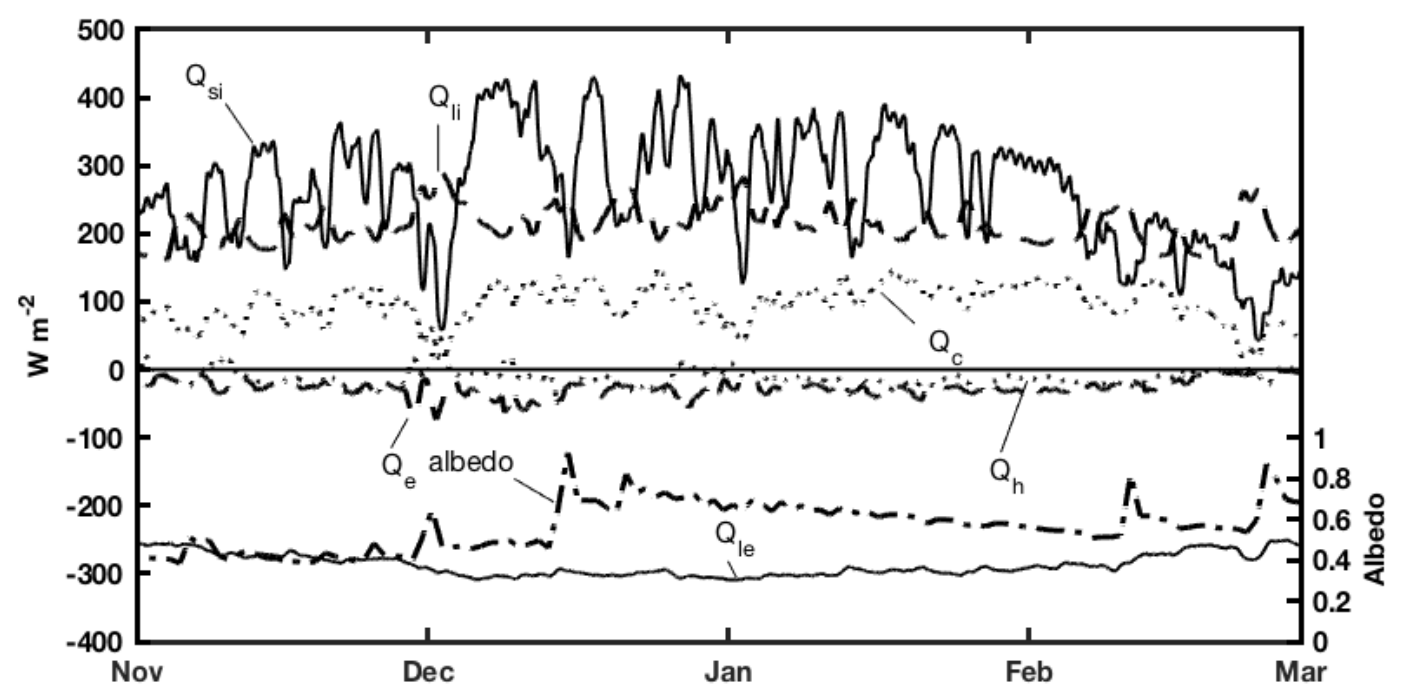

Figure C.3 Surface energy balance over the 2003-04 austral summer. Positive values indicate downward energy flux. The positive dotted line is $Q_{c}$ and the negative dotted line, adjacent to $Q_{e}$, is $Q_{h}$. The solid line that is constantly 0 is $Q_{m}$, indicating no surface melt. 
Table C.1 Sensitivity analysis of 2003-06 model run. Parameters of original model run are $r_{\text {eff }}=0.065 \mathrm{~mm}, Z_{0}=0.1 \mathrm{~mm}, \chi=0.14$ with no air temperature, wind speed $\left(\mathrm{u}_{\mathrm{r}}\right)$, or albedo $(\alpha)$ offsets applied. $Z_{\text {sed }}$ is the cryoconite depth $(\mathrm{cm}) . \mathrm{h}$ is the meltwater-filled hole height $(\mathrm{cm})$. Melt duration is in days.

\begin{tabular}{|c|c|c|c|c|c|c|}
\hline & \multirow[t]{2}{*}{ Observed } & \multirow[t]{2}{*}{ Original* } & \multicolumn{2}{|c|}{$r_{\text {eff }}(\mathrm{mm})$} & \multicolumn{2}{|c|}{$\mathrm{Z}_{0}(\mathrm{~mm})$} \\
\hline & & & -0.015 & +0.015 & .01 & 1.0 \\
\hline Thaw & & Dec. 23 & Jan. 4 & Dec. 17 & Dec. 27 & Dec. 12 \\
\hline Refreeze & & Feb. 5 & Feb. 3 & Feb. 6 & Feb. 5 & Jan. 27 \\
\hline $\begin{array}{l}\text { Melt } \\
\text { Duration }\end{array}$ & & 45 & -18 & +6 & -6 & +1 \\
\hline Min. $z_{\text {sed }}$ & & 15 & -4 & +3 & +6 & -12 \\
\hline Max. $z_{\text {sed }}$ & & 29 & -2 & +2 & -3 & -2 \\
\hline Avg. $z_{\text {sed }}$ & & 24.1 & -3.5 & +2.8 & +5.2 & -3.1 \\
\hline Max. h & - & 19 & -1 & +3 & +4 & -4 \\
\hline \multirow[t]{3}{*}{ Avg. $\mathrm{h}$} & - & 12.6 & -0.3 & -0.4 & 0 & -3.2 \\
\hline & \multicolumn{2}{|c|}{$\mathrm{T}_{\text {air }}\left({ }^{\circ} \mathrm{C}\right)$} & \multicolumn{2}{|c|}{$u_{r}\left(m s^{-1}\right)$} & \multicolumn{2}{|c|}{$\alpha$} \\
\hline & $-1.0 C$ & $+1.0 \mathrm{C}$ & $-10 \%$ & $+10 \%$ & -0.05 & +0.05 \\
\hline Thaw & Dec. 27 & Dec. 19 & Dec. 26 & Dec. 19 & Dec. 22 & Dec. 23 \\
\hline Refreeze & Feb. 2 & Feb. 3 & Feb. 6 & Feb. 5 & Feb. 6 & Feb. 5 \\
\hline Duration & -8 & +1 & -3 & +3 & +1 & -2 \\
\hline Min. $z_{\text {sed }}$ & -2 & +3 & +1 & -2 & 0 & 0 \\
\hline Max. $z_{\text {sed }}$ & -2 & +2 & 0 & 0 & 0 & -1 \\
\hline Avg. $z_{\text {sed }}$ & -1.6 & +2.4 & +0.6 & -0.6 & +0.4 & -0.1 \\
\hline Max. h & -3 & +5 & +1 & 0 & +2 & -2 \\
\hline Avg. $\mathrm{h}$ & -2.6 & +0.4 & +0.3 & -1.2 & +0.7 & -2.2 \\
\hline
\end{tabular}



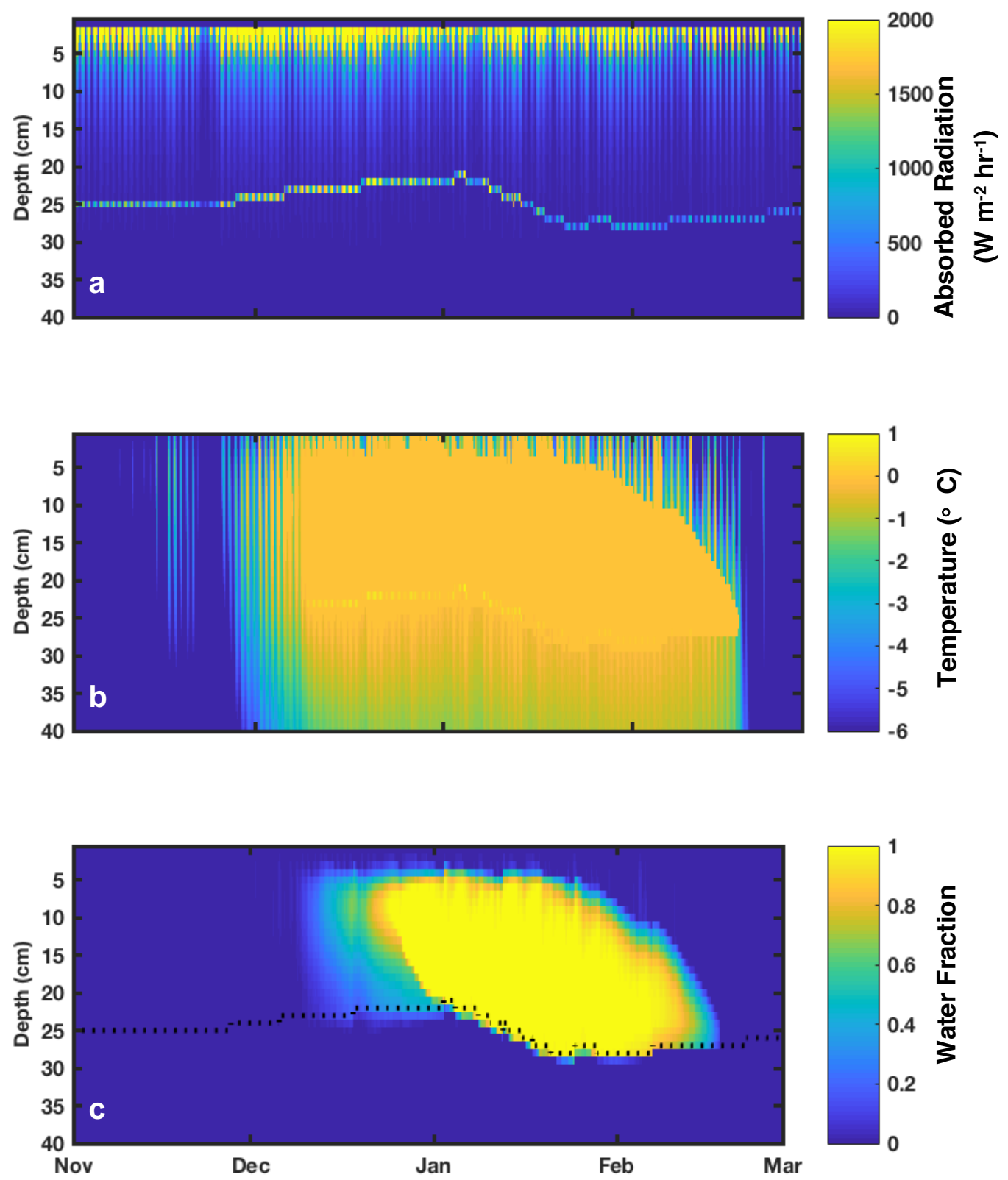

Figure C.4. Modeled subsurface conditions over the 2016-17 austral summer. a) Absorbed radiation b) Temperature c) Water fraction within subsurface. A water fraction of 1 represents $100 \%$ meltwater and a water fraction of 0 represents a cell of $100 \%$ ice. The dotted line represents the location of the cryoconite. 
2017 - 18 Model Results

Over the 2017-18 model run, surface albedo of snow was unadjusted until midDecember, when the site was swept. Modeled subsurface temperatures reached the melting point shortly after the snow was removed and the albedo decreased surface albedo in mid-December (Appendix Figure C.2b). Again, the cryoconite hole began melting out $12 \mathrm{~cm}$ above the sediment in early January, expanding outward until merging with the sediment several days later. From an initial depth of $20 \mathrm{~cm}$ beneath the surface, the sediment then began migrating down. This is generally in agreement with field observations that first show elevated EC in the region $\sim 21 \mathrm{~cm}$ beneath the surface. At its maximum, the hole was $18 \mathrm{~cm}$ tall. The modeled hole reached an equilibrium depth of $26 \mathrm{~cm}$ briefly in mid-January, when it began to refreeze from the top down. Elevated EC measurements $\sim 27 \mathrm{~cm}$ beneath the ice surface confirm sediments descended down to this depth. Shortly after reaching equilibrium depth, the hole began freezing from the top down and surface ablation outpaced sediment melting, thinning the layer of ice above. The last of the remaining meltwater froze within the sediment in mid-March. The hole evolved similarly to that predicted in the other modeled years except that melt initiated in several weeks later in early-January, likely because of the increased albedo in midDecember, due to snow. 

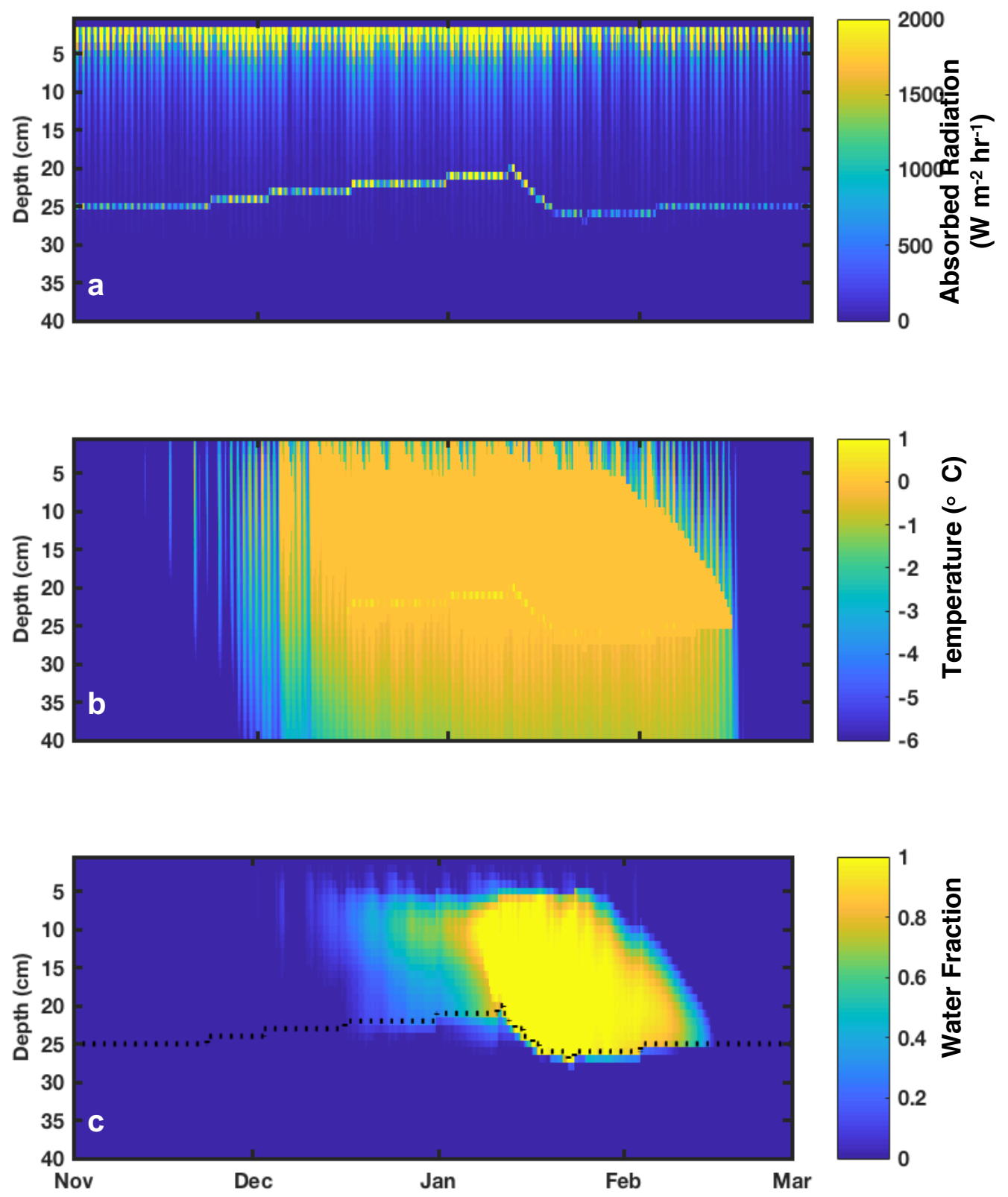

Figure C.5. Modeled subsurface conditions over the 2017-18 austral summer. a) Absorbed radiation b) Temperature c) Water fraction within subsurface. A water fraction of 1 represents $100 \%$ meltwater and a water fraction of 0 represents a cell of $100 \%$ ice. The dotted line represents the location of the cryoconite. 